\title{
ANÁLISE DAS CARACTERÍSTICAS FRACTAIS DO MOVIMENTO VERTICAL DA ÁGUA NO SOLO, EM CONDIÇÕES DE CAMPO
}

\section{EDIVÂNIA DOS SANTOS}

Engenheira Agrônoma

Orientador: Prof. Dr. IVAN AMARAL GUERRINI

Tese apresentada à Escola Superior de Agricultura "Luiz de Queiroz", Universidade de São Paulo, para obtenção do título de Doutor em Agronomia, Área de concentração: Irrigação e Drenagem

\section{PIRACICABA}

Estado de São Paulo

Outubro - 2000 
Dados Internacionais de Catalogaçāo na Publicaçāo (CIP)

DIVISĀO DE BIBLIOTECA E DOCUMENTAÇĀO - Campus "Luiz de Oueiroz"/USP

\author{
Santos, Edivânia dos \\ Análise das caracteristicas fractais do movimento vertical da água no solo, em \\ condições de campo / Edivânia dos Santos. - - Piracicaba, 2000. \\ 86 p. : il. \\ Tese (doutorado) - - Escola Superior de Agricultura Luiz de Queiroz, 2000. \\ Bibliografia. \\ 1. Ȧgua do solo 2. Geometria fractal 3. Infiltração I. Título
}

CDD 631.432

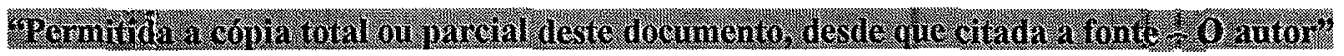




\section{AGRADECIMENTOS}

À Escola Superior de Agricultura "Luiz de Queiroz" - ESALQ/USP - através do Departamento de Engenharia Rural, pela oportunidade de realizar o curso de pósgraduação.

À Coordenação de Aperfeiçoamento de Pessoal de Nível Superior - CAPES, pela concessão da bolsa de estudos.

Ao Prof. Dr. Ivan Amaral Guerrini, pela orientação, apoio e amizade durante todos esses anos.

Ao Prof. Marcos Vinícius Follegati, pela co-orientação, apoio e amizade durante todo esse período.

Ao Prof. Dr. Osny Bacchi, pela colaboração, apoio e fornecimento dos dados utilizados nesse estudo.

A minha família e aos meus amigos de todos os momentos, que sempre me apoiaram e que tem uma participação indireta nesse trabalho.

Um agradecimento às amigas Caroline, Tamara, Virgínia, Cássia e Marcela que estiveram sempre ao meu lado.

Aos colegas de pós-graduação pelos bons momentos de convivência e amizade. 


\section{SUMÁRIO}

Página

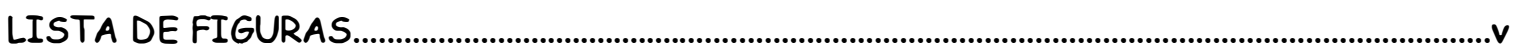

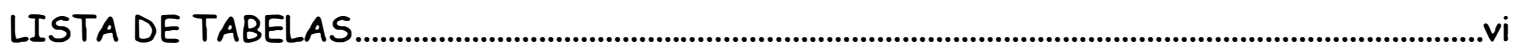

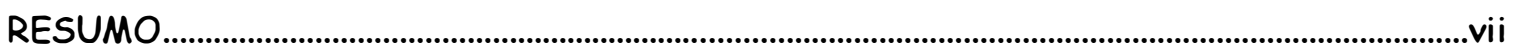

SUMMARY

1 INTRODUÇÃO

2 A TEORIA DO CAOS E FRACTAIS

2.1 Caos e Ordem - A dualidade que rege o universo desde o seu primórdio............................13

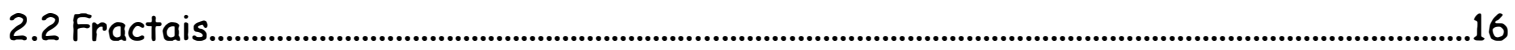

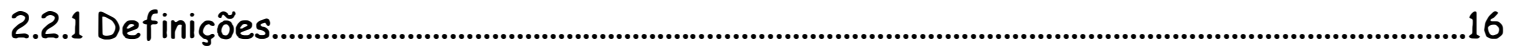

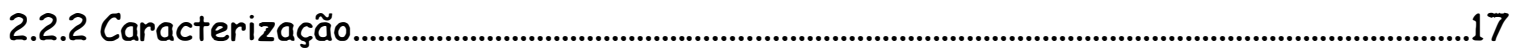

2.2.3 Dimensão fractal e figuras fractais clássicas...............................................................19

2.2.4 0 processo de difusão como um fenômeno fractal..............................................................25

2.2.5 O uso da Teoria do Caos e Fractais na ciência do solo.........................................................28

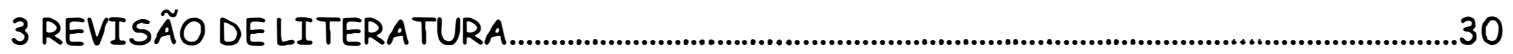

3.1 Aplicação de Caos e Fractais do movimento da água no solo...................................................30

3.2 Estudo de erros experimentais.......................................................................................................40

3.2.1 Erros sistemáticos, acidentais e grosseiros de uma medida experimental......................41

3.2.2 Precisão, exatidão e algarismos significativos.......................................................................43

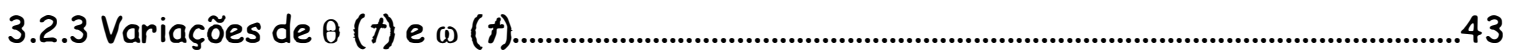

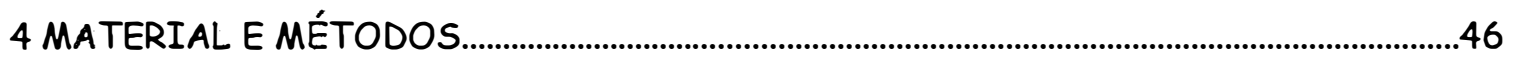

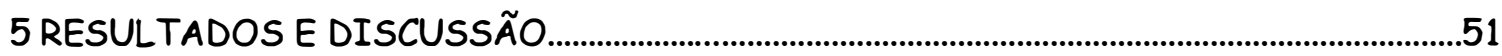

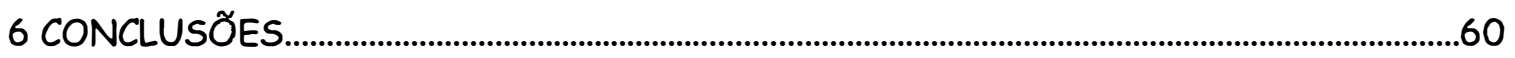

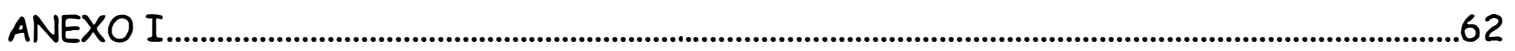

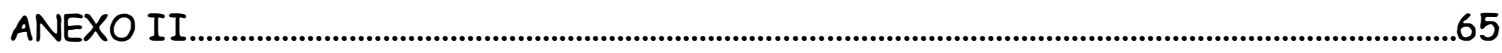

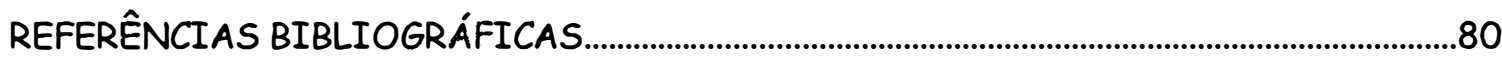




\section{LISTA DE FIGURAS}

Página

1 Conjunto de MANDELBROT, figura fractal clássica.

2 Esponja de MENGER, figura fractal clássica, utilizada como modelo

em solos. .21

3 Processo de geração da curva de Koch. .23

4 Curvas de Koch geradas a partir de uma reta (dimensão 1) e um quadrado

(dimensão).

5 Processo de geração do Triângulo de Sierpinsky. .25

6 Valores do expoente (n) em função da umidade normalizada para infiltração vertical (Caso 01, 02, 03, 04, 05 e 06). .57

7 Valores do expoente (n) em função de $\omega$ para experimentos em colunas horizontais ( nível, horiz. 02, horiz. 03, Russel e Salkum) e infiltração vertical (Caso 01 e Caso 04). 


\section{LISTA DE TABELAS}

Página

1 Dados de umidade $(\theta)$ em função do tempo $(t)$, para cada profundidade, obtidos pelo método da tensiometria, para profundidade de 15 a $75 \mathrm{~cm}$

2 Dados de umidade $(\theta)$ em função do tempo ( $t)$, para cada profundidade, obtidos pelo método da tensiometria, para profundidade de 90 a $135 \mathrm{~cm}$

3 Valores do tempo $(t)$ em cada posição (conjunto $x, t$ ) para cada umidade normalizada

4 Valores do expoente $(n)$ do ajuste $\times$ vs. $t$, para cada umidade normalizada:

Caso 01 e Caso 02 53

5 Valores do expoente $(n)$ do ajuste $x$ vs. $t$, para cada umidade normalizada:

Caso 03 e Caso 04.

6 Valores do expoente $(n)$ do ajuste $x$ vs. $t$, para cada umidade normalizada:

Caso 05. .54

7 Valores do expoente $(n)$ do ajuste $x$ vs. $t$, para alguns valores de umidade normalizada $(\omega)$ com a incorporação do erro no tempo, com todos os pontos experimentais (Caso 6 ). . .55 


\title{
ANÁLISE DAS CARACTERÍSTICAS FRACTAIS DO MOVIMENTO VERTICAL DA ÁGUA NO SOLO, EM CONDIÇÕES DE CAMPO
}

\author{
Autora: EDIVÂNIA DOS SANTOS \\ Orientador: PROF. DR. IVAN AMARAL GUERRINI
}

\section{RESUMO}

A Geometria Fractal ou Teoria dos Fractais é uma ciência que está inteiramente relacionada com a Teoria do Caos Determinístico. Fractal é um termo inventado por Benoit Mandelbrot (1983), para descrever formas irregulares na natureza. Os fractais têm como características a dimensão fracionária, autosimilaridade em escala, complexidade infinita e processo de realimentação iterativo. Na Ciência do Solo, muitos estudos têm sido realizados sob a ótica dos fractais, para propriedades fisicas (textura, estrutura, porosidade, agregação), movimento da água no solo, curvas de retenção, entre outros. Na pesquisa, o objetivo final, na maioria das vezes, é determinar um modelo matemático que venha a representar o fenômeno estudado. Tem-se observado que as leis naturais são predominantemente não-lineares e podem ser regidas por uma equação do "tipo potência". O movimento Browniano, um processo de difusão, é um fenômeno fractal bastante conhecido e estudado que representa o caminhamento de uma partícula dentro de um gás, dependente da temperatura. À semelhança do Movimento Browniano, os processos de difusão, como por exemplo, o movimento da água no solo, podem ser estudados sob a ótica da Teoria do Caos e Fractais. O objetivo do presente trabalho foi estudar o movimento da água no solo durante um processo de infiltração, em condições de campo, sob a ótica da Teoria do Caos e Fractais. Com os dados obtidos por Bacchi (1988) foi estudado o movimento vertical da água no solo, utilizando a equação de ajuste $x=\lambda \times \mathrm{t}^{\mathrm{n}}$. A infiltração vertical da água no solo foi medida através da técnica da tensiometria, sendo que os ajustes dos dados de umidade em função do tempo, foram feitos por um modelo matemático bipotência proposto por Guerrini \& Swartzendruber (1998). O valor do expoente $n$ da equação $x=\lambda \times \mathrm{t}^{\mathrm{n}}$ diminuiu com o aumento da 
umidade. Comparando-se os movimentos horizontais da água no solo (molhamento) descritos na literatura e o movimento vertical (secamento), observa-se que pode haver um ponto final comum (atrator) para os valores do expoente $n$ com a umidade normalizada próxima de 0,5 a 0,6 , e também, pode-se concluir que o fenômeno fractal de infiltração da água no solo não está totalmente compreendido. Serão necessárias outras pesquisas mais específicas para um maior entendimento desse fenômeno, até onde e quando o mesmo pode ser caracterizado como fractal, quais as relações das dimensões fractais da dinâmica com as dimensões fractais da estrutura do meio, etc.

Palavras-chave: Água do solo, geometria fractal, infiltração 


\title{
ANALYSIS OF FRACTAL CHARACTERISTIC OF THE SOIL WATER VERTICAL MOVEMENT IN FIELDS CONDITIONS
}

\author{
Autora: EDIVÂNIA DOS SANTOS \\ Orientador: PROF. DR. IVAN AMARAL GUERRINI
}

\section{SUMMARY}

Fractal geometry or fractal theory is a science that is entirely related with Theory of Chaos. Fractal is a term created by Mandelbrot (1983) to describe irregular forms in nature. The fractal has as characteristics, self-affine scaling, infinity complexiy and interative feed-back process. Many studies in the soil science have been realized under the optics fractal theory, as physical properties (texture, structure, porosity, aggregation), soil-water movement, retention curve among others. In research, the final objective, most of the time, is to find a matematical models which can be applied to this phenomenon. It has been observed that the natural laws are mainly no-linear and that they can be regulated by a power-law function. The brownian motion diffusion process, is a well know fractal phenomenon that represents the movement of a particle within a gas, dependent on temperature. In simularity to the brownian diffusion process movement, soil-water movement can be studied under optics of the Chaos and Fractal Theory. The objetive of this study was studied the soil water movement during infiltration process, in fields conditions, under optic Fractals and Chaos theory. With data obtained by Bacchi (1988), the vertical flow of water in soil was studied using the adjustment equation $x=\lambda \times \mathrm{t}^{\mathrm{n}}$. The vertical soil-water flow was measured by the tensiometer tecnic while moisture adjustments in function of time were made by a bypower model proposed by Guerrini \& Swartzendruber (1998). The value of the exponent $n$ of the equation $x=\lambda \times \mathrm{t}^{\mathrm{n}}$ decreased with the increase of moisture. Comparing horizontal soil-water flow (wetting) described in literature and vertical soil-water movement (drying), it is observed that there can be a common final point (atractor) for the values of the exponent $\boldsymbol{n}$ with moisture normalized near 0.5 to 0.6 . It can be concluded that the fractal phenomenon of 
soil-water infiltration is not totally understood. More specific researches will be necessary for a better comprehention of the phenomenon, as to where and when it can be characterized as fractal, what is the relationship of dinamic fractal dimension with fractal dimension of the environalmental struture.

Key words: soil water, fractal geometry, infiltration 


\section{INTRODUÇÃO}

A quantidade de água a ser utilizada e o momento correto de irrigar são fatores de influência decisiva na estabilidade da produção agrícola, qualidade e conservação dos recursos hídricos. Por isso, muitos pesquisadores têm buscado novas tecnologias e o uso eficiente dos recursos disponíveis, através de métodos cada vez mais precisos de medição do teor de água no solo, bem como ampliar os conhecimentos do fenômeno que rege o movimento da água no solo.

O estudo do movimento da água no solo, um processo de difusão, sempre apresentou-se como um desafio para pesquisadores, considerando uma abordagem convencional e determinística, pois, muitos processos fisicos no solo são dificeis de serem quantificados pela matemática convencional. No entanto, surgiu no meio científico nas últimas décadas a Teoria do Caos e Fractais que permite analisar, sob uma ótica diferente da convencional, o processo de infiltração da água no solo.

Muitos fenômenos naturais têm revelado, em inúmeros estudos recentes, seu caráter fractal (Mandelbrot,1983; Peitgen et al.,1992; Barnsley,1993; Birdi,1993) e o movimento da água no solo, como um processo de difusão, também tem apresentado características fractais (Feder,1988; Guerrini \& Swartzendruber, 1994 e 1998; Santos, 1997; Santos \& Guerrini, 1998).

São conhecidos vários métodos de determinação do teor de água no solo, tais como o método direto - gravimétrico - que é considerado como método padrão e os métodos indiretos como, a tensiometria, a sonda de neutrons, a atenuação da radiação gama, entre outros.

Os tensiômetros são bastante utilizados para fins práticos e, dependendo do critério de quem os utiliza, podem vir a ser pouco precisos, uma vez que é necessário 
conhecer as curvas de retenção ou curvas características de cada solo estudado e os mesmos possuem uma faixa de uso limite de tensão de água no solo (Villagra, 1988). O método gravimétrico necessita de um grande número de amostras para ser representativo e além de ser bastante trabalhoso e destrutivo, demanda muito tempo. O método da atenuação da radiação gama e a sonda de neutrons permitem trabalhar com amostras indeformadas e com rapidez na obtenção dos resultados mas exigem pessoal qualificado para empregar material radioativo. Além disso, há um problema sério de calibração desses métodos para se evitar erros sistemáticos que possam inviabilizar as medidas, o que nem sempre é considerado pelo pesquisador menos crítico ou menos informado. Semelhantes problemas ocorrem com o método da reflectometria no domínio do tempo (TDR).

O objetivo do presente trabalho, baseado em alguns resultados iniciais já obtidos e citados na literatura (Guerrini et al., 1997; Santos, 1997; Santos \& Guerrini, 1998), é a análise do movimento vertical da água no solo durante um processo de infiltração, baseando-se em dados de campo, sob a ótica da Teoria do Caos e Fractais. 


\section{A TEORIA DO CAOS E FRACTAIS}

\subsection{Caos e ordem - A dualidade que rege o universo desde o seu primórdio.}

O estudo dos fractais está ligado à chamada Teoria do Caos que busca padrões organizados de comportamento dentro de um sistema aparentemente aleatório. $\mathrm{Na}$ mitologia grega, Caos era o estado não-organizado ou o Nada de onde todas as coisas surgiam, mas não era apenas o mero vácuo e sim o estado de escuridão e nebulosidade infinita.

De acordo com Isaac Newton, quando se conhece o estado do sistema fisico (posições e velocidade) num dado instante - instante inicial - podemos deduzir seu estado em qualquer outro instante. Este é o princípio da mecânica newtoniana ou mecânica clássica.

Por outro lado, como o acaso e as probabilidades desempenham na prática um papel importante em nossa compreensão da natureza, podemos ser tentados a rejeitar o determinismo (Ruelle,1993).

Hoje em dia, com o desenvolvimento da matemática e ciência, a Teoria do Caos surgiu para compreender as flutuações erráticas e irregulares da natureza. Sistemas de comportamento caótico são encontrados em muitos campos da ciência e engenharia e são objetos de estudo, pois muitas vezes revelam padrões de uma estrutura ordenada.

Uma característica de um sistema caótico é que ele sempre mostra uma "dependência hipersensível das condições iniciais" (conhecido como Efeito Borboleta), o que quer dizer que uma pequena mudança no estado do sistema no tempo zero (na verdade, qualquer tempo pode ser considerado como tempo zero) produz uma mudança 
ulterior que cresce exponencialmente com o tempo. Portanto, uma pequena causa pode ter um grande efeito num Sistema Dinâmico Complexo Adaptativo (SDCA), fazendo com que a previsão de um evento futuro torne-se muito dificil. Compreendendo melhor o comportamento caótico/ordenado do SDCA, muitas vezes é possível entender como o sistema se comportará como um todo (em termos de padrões) ao longo do tempo.

"O Caos não tem estátua nem figura e não pode ser imaginado; é um espaço que só pode ser conhecido pelas coisas que nele existem, e ele contém o universo infinito." (Frances A. Yates)

Uma das questões que se coloca é a seguinte: como pode um fenômeno caótico ser bem determinado ou levar a um resultado razoavelmente previsível?

Pela $2^{\mathrm{a}}$ Lei da Termodinâmica, todo sistema possui uma função de estado extensiva chamada Entropia (proporcional à desordem do sistema), a qual tem uma tendência para um aumento natural, o que é conhecido como o Princípio do Aumento da Desordem (P.A.D.), o que se contrapõe ao Princípio do Aumento da Ordem (P.A.O.) que é uma tendência também natural à organização dos sistemas (Peitgen, 1992; Guerrini, 2000). Um dos cientistas que primeiramente discutiu esses princípios foi David Ruelle, fisico-matemático Belga. O impulso no sentido de uma ordem maior, ao qual muita atenção tem sido dada nas últimas décadas, principalmente pelo ganhador de Prêmio Nobel de Bioquímica, Illia Prigogine, pode ser um dos princípios fundamentais da natureza denominado Sintropia, que seria o Princípio do Anti-Caos, sendo que este e o da Entropia (P.A.O. e P.A.D.) coexistem simultaneamente nos seres vivos (Marilyn Ferguson e Albert Szent-Gyorgyi, citados por GUERRINI, 2000).

De certa forma, essa nova abordagem permite entender o enigma de como as coisas vivas têm-se evoluído emum universo em decadência.

É importante introduzir neste ponto, a partir da Teoria do Caos e Fractais, o conceito de "atrator" que é entendido como um conjunto invariante ou dinâmico (atrator estranho) para o qual as trajetórias (órbitas) convergem depois de um tempo suficientemente longo. $\mathrm{O}$ atrator descreve a situação do regime depois do 
desaparecimento dos fenômenos transitórios. Os atratores aparecem também em sistemas dinâmicos dissipativos reais (geralmente um SDCA) e nesses casos, segundo Mandelbrot (1983), eles não são curvas ou superficies lisas, mas objetos com dimensões não inteiras: fractais. Um exemplo clássico é a previsão do tempo que apresenta um atrator estranho (dinâmico) chamado de Atrator de Lorenz, altamente sujeito a Efeitos Borboleta.

Com a introdução do conceito de "atrator caótico" ou "estranho" e noção de "dependência sensível das condições iniciais" (Efeitos Borboleta), estabeleceram-se bases para uma teoria matemática dos processos caóticos.

O estudo quantitativo do Caos num sistema necessita de uma compreensão quantitativa da dinâmica desse sistema. Esta compreensão, não raro, é baseada num bom conhecimento das equações de evolução temporal do sistema, que podem ser integradas com precisão no computador. Estas equações nem sempre são conhecidas completamente mas podem ser obtidas experimentalmente através de séries temporais longas e precisas (Ruelle, 1993).

$\mathrm{Na}$ década de 70, os cientistas começaram a abrir caminho em meio a desordem. Assim surgiu a Teoria do Caos, que hoje é utilizada em vários campos de pesquisa, como ecologia, medicina, economia e fisica. Essa nova ciência ultrapassou o "círculo" dos primeiros estudiosos e mexeu até mesmo com divulgação científica e a imaginação popular. Um exemplo disso é o filme de Spielberg, "Parque dos Dinossauros", que utiliza a Teoria do Caos e Fractais para explicar porque os seres vivos poderiam fugir ao controle de seus criadores, ou seja, explicar a razão de sistemas aparentemente simples, "seguros" e previsíveis poderem, de repente, apresentar um comportamento caótico e imprevisível (sensibilidade às condições iniciais). Podemos facilmente encontrar outros exemplos: na natureza, um rio calmo pode apresentar pontos de redemoinho de um instante para outro; em nosso dia-a-dia, a fumaça do cigarro que se eleva em linha reta, de repente pode aumentar sua velocidade e formar círculos e movimentos turbulentos; no corpo humano, o aparelho digestivo que apresenta ondulações dentro de ondulações, como os alvéolos pulmonares, o sistema urinário e o sistema circulatório que são considerados fractais. 
A Teoria do Caos mostra que um movimento aparentemente desordenado de uma partícula possuí na verdade um padrão bastante definido ("ordem na desordem"). Na maior parte dos casos, atratores com dimensão fractal estão associados a sistemas dinâmicos caóticos, ou seja, SDCA.

A correspondência entre fractal e caos não é acidental, mas um sinal de uma profunda relação: a geometria fractal é a geometria do caos (Hofstadler,1984).

\subsection{Fractais}

\subsubsection{Definições}

Deu-se o nome de Geometria Fractal para uma nova geometria que contempla os fragmentos e as formas irregulares da natureza. $\mathrm{O}$ primeiro a utilizar o termo fractal foi Benoit Mandelbrot (1983), cujo termo é derivado do latim fractus (quebrado). Segundo Mandelbrot, "um conjunto é dito fractal se a dimensão Hausdorff-Besicovich deste conjunto for estritamente maior que a sua dimensão topológica". Hoje, esta definição de objeto fractal já é considerada incompleta, sendo necessária uma análise mais detalhada do fenômeno e uma definição mais ampla, que será mencionada a seguir.

Os fractais podem apresentar uma infinidade de formas diferentes, não existindo uma aparência consensual. Contudo, uma definição clássica de fractais diz que são objetos que apresentam auto-semelhança (auto-similaridade) e complexidade infinita, ou seja, têm sempre cópias, fiéis ou aproximadas, de si mesmas em seu interior.

Inicialmente, desde a década de 70 , os fractais ficaram conhecidos como figuras geométricas, ou sejam, estruturas espaciais (freqüentemente muito ordenadas), enquanto que o Caos designaria um tipo de comportamento temporal, onde os pontos que representariam a evolução caótica no espaço-fase do sistema estudado é que estariam formando a estrutura fractal.

Sabe-se, por outro lado, que a Geometria Euclidiana é habitualmente descrita como fria e austera e ligada a figuras geométricas convencionais e regulares. Ela é 
incapaz de descrever a forma de uma nuvem, de uma montanha, de uma linha costeira de um país ou de uma folha de um vegetal. Foi aí que Mandelbrot, o matemático polonês, observou que a natureza exibe não apenas um grau mais elevado de ordem, mas um nível de complexidade completamente diferente. $\mathrm{O}$ número de motivos naturais é, para todos os efeitos, infinito. A existência desses motivos no universo, segundo Mandelbrot, é que nos estimula a estudar aquelas formas que a Geometria Euclidiana não explica.

A Geometria Fractal nasceu, portanto, da necessidade de descrever o pormenor irregular e quase aleatório de muitos padrões da natureza, que não podem ser descritos pela geometria tradicional, considerando-se que os todos os objetos naturais possuem características fractais (Feder,1988).

Como cita Mandelbrot (1983): "nuvens não são esferas, montanhas não são cones, continentes não são círculos, um latido não é contínuo e nem o raio viaja em linha reta".

\subsubsection{Caracterização}

A Geometria Fractal permite infinitas possibilidades de identificar formas e fenômenos da natureza, cujas dimensões podem apresentar valores fracionários, que se ajustam melhor às condições naturais. Por exemplo, o torrão de um solo é algo maior que um plano e menor que uma esfera, pois contém poros e irregularidades, fazendo com que sua dimensão fique entre dois e três.

Um outro exemplo fractal familiar é simplesmente uma árvore. A invariância de escala nela é notável: o tronco se divide em ramos principais, que irão se dividir em ramos secundários, que se dividem mais e mais sucessivamente e de forma semelhante. A justificativa para a natureza produzir um caráter fractal para a árvore poderia estar ligado a uma otimização da captação da energia luminosa e trocas com a atmosfera (Bergé et al., 1996).

Um outro exemplo prático é a tentativa de se medir o perímetro de uma linha costeira de qualquer país utilizando medidas de comprimento com várias subdivisões, 
como por exemplo, $20 \mathrm{~m}, 10 \mathrm{~m}, 5 \mathrm{~m}, 1 \mathrm{~m}, 0.5 \mathrm{~m}, 30 \mathrm{~cm}, 10 \mathrm{~cm}, 1 \mathrm{~cm}$, etc.. O perímetro da linha costeira vai aumentando progressivamente, à medida que se diminui a escala de observação (ou escala de medida), porém, o processo experimental tem um limite pois, à medida que nos aproximamos da escala molecular, a observação torna-se impraticável. Existe, então, um padrão de "recortes" em todas as escalas, tanto as pequenas como as grandes.

Se olharmos para o mundo à nossa volta, vemos uma infinita variedade de objetos com uma estrutura geométrica complexa e intrincada: uma folha de árvore, um cristal de neve, uma superficie irregular, ou mesmo uma descarga elétrica. Analisando a estrutura microscópica destes objetos, algo bastante surpreendente pode ser observado: a parte é muito semelhante ao todo. É a propriedade denominada auto-semelhança (ou autosimilaridade), ou seja, a independência de escala.

Estudando essa dimensão fracionada, descobriu-se que o grau de irregularidade permanece aproximadamente constante em diferentes escalas e que o mundo exibe repetidamente uma "irregularidade regular". Um outro exemplo é o sistema circulatório que compreende uns $96.000 \mathrm{~km}$ de canais que transportam o sangue para todas as partes do corpo. O sangue é bombeado do coração para as artérias que se bifurcam em outras menores, que por sua vez, se dividem em milhões de capilares microscópicos. O sangue usado, depois de oxigenado pelos pulmões, volta para o coração e o ciclo começa novamente.

A ciência dos fractais apresenta estruturas geométricas de grande complexidade e beleza infinita, ligadas às formas da natureza, ao desenvolvimento da vida e à própria compreensão do universo (fig. 01). São imagens de objetos reais ou abstratos que possuem o caráter de onipresença por terem as características do todo infinitamente multiplicadas dentro de cada parte, escapando assim da compreensão, em sua totalidade, pela mente humana.

É importante salientar também que a auto-semelhança está relacionada ao conceito de dimensão fracionária. Esta dimensão, diferente da dimensão topológica habitual (que é um número inteiro), serve para caracterizar um objeto fractal. 


\subsubsection{Dimensão fractal e figuras fractais clássicas}

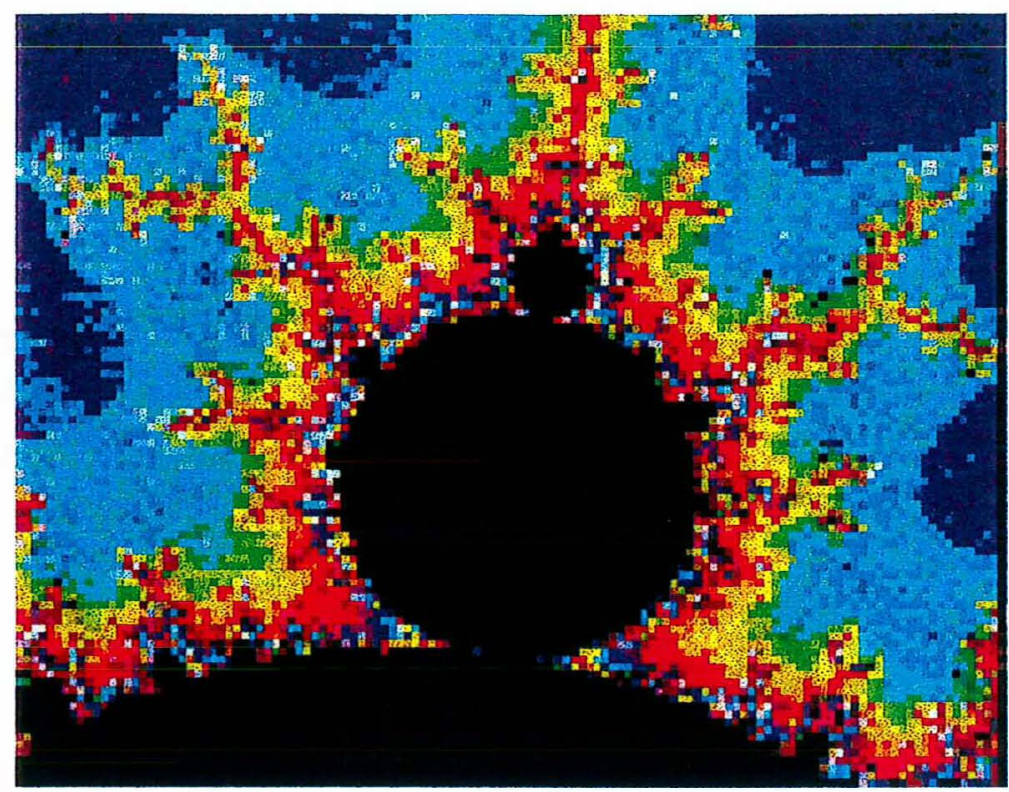

Figura 01- Conjunto de Mandelbrot, figura fractal clássica. (Extraído da Internet)

O desenvolvimento da matemática trouxe alguns exemplos singulares de figuras fractais e tem quebrado muitos dos conceitos e teorias vigentes. Muitos pesquisadores começaram a utilizar computadores para simular e modelar sistemas dinâmicos com diversas variáveis de controle, que representavam fenômenos naturais, tais como dinâmica de populações e meteorologia, exemplos de SDCA.

A noção de Fractais tem sido desenvolvida para descrever objetos naturais formados também por processos de agregação randômica, formação de clusters, ou por subdivisão randômica, semelhante à unidade, numa determinada ordem de magnitude de escala.

Calcular a dimensão fractal de um objeto é efetuar medidas sobre os objetos ou o espaço onde ele está inserido. Teoricamente, como já foi mencionado, objetos fractais são caracterizados por uma estrutura auto-similar em todas as escalas. Esta similaridade a si própria pode ser exata ou estatística, como é o caso dos objetos naturais, incluindo os solos (Mandelbrot, 1983). 
Sob a ótica dessa nova geometria, o cálculo de dimensão mais famoso é o de Hausdorff-Besicovich, citado anteriormente, cuja definição de fractais, dada por Mandelbrot (1983):

$$
\text { Nped }=\left(\frac{1}{\text { Tam }}\right)^{D}
$$

onde : Nped é o número de pedaços da figura analisada num determinado estágio (ou escala) de formação da mesma, Tam é o tamanho dos pedaços nesse estágio em relação ao tamanho do pedaço original e $D$ é a dimensão fractal da figura (objeto) analisada.

Um outro cálculo de dimensão, também bastante conhecido, é o denominado "Box Counting" (Contagem de Caixas) que consiste no recobrimento do objeto a ser estudado com pequenos cubos ou esferas de tamanho (ou raio) $\varepsilon$, considerando uniforme a distribuição dos pontos (No) ao longo de uma linha unidimensional no espaço tridimensional. Calcula-se o número mínimo de cada cubo ou esfera $N(\varepsilon)$ para cobrir o conjunto $(\mathrm{N}(\varepsilon)<\mathrm{No})$. Quando No é grande e $\varepsilon$ pequeno, o número de cubos para cobrir uma linha será:

$$
N(\varepsilon) \approx \frac{1}{\varepsilon}
$$

Da mesma maneira, se os pontos são distribuídos numa superficie em três dimensões no espaço, nota-se que o número mínimo de cubos para cobrir a área será:

$$
N(\varepsilon) \approx \frac{1}{\varepsilon^{2}}
$$

Intuitivamente pode-se definir que pela lei de escala: 


$$
N(\varepsilon) \approx \frac{1}{\varepsilon^{D}}
$$

Aplicando-se logaritmo nos dois lados da equação tem-se que a dimensão fractal é dada por:

$$
\begin{aligned}
& D_{C}=\operatorname{Lim} \frac{\log N(\varepsilon)}{\log (1 / \varepsilon)} \\
& \varepsilon \rightarrow 0
\end{aligned}
$$

Alguns fractais citados na literatura podem ser considerados clássicos, como por exemplo, a Poeira de Cantor, a Curva de Koch, o Triângulo de Sierpinsky, o Carpete de Sierpinsky, o Triângulo de Pascal e a Esponja de Menger. A Curva de Koch foi usada por Mandelbrot (1983) para ilustrar as suas idéias a respeito da dimensão de perímetro costeiro dos países europeus.

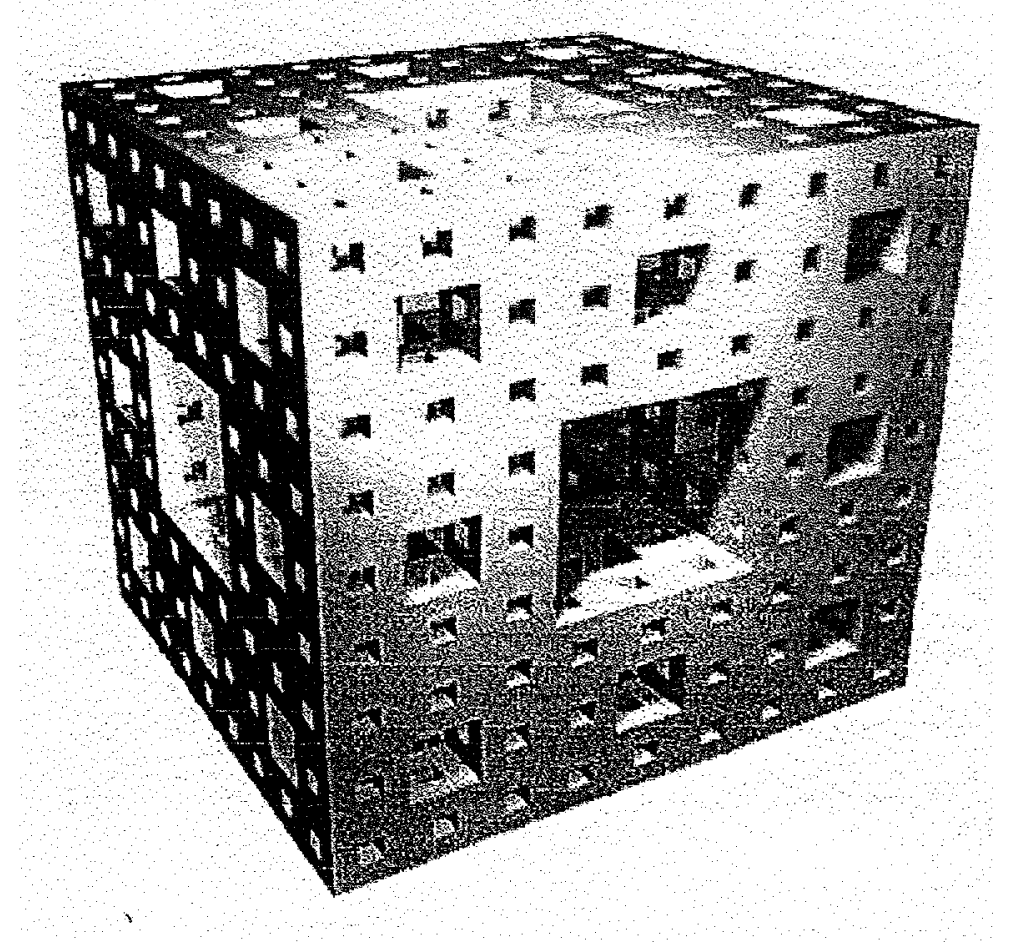

Figura 02- Esponja de Menger, figura fractal clássica, utilizada como modelo em solos. (Extraído da Internet) 
Dada a importância dos conceitos acima, Comegna et al. (1998) começaram por definir os significados desses conceitos.

A Curva de Koch, por exemplo, pode ser gerada com um simples procedimento recursivo começando de um segmento de linha reta de comprimento $L(1)=1$ com $n=0$ (iteração zero) como parâmetro. Dividindo-o em três partes, o terço médio do segmento é substituído por um triângulo equilátero, obtendo daí $01^{\circ}$ gerador para $n=1$ iteração, consistido de 4 segmentos de comprimento $\varepsilon$ cada um igual a $1 / 3$ do valor do segmento original. Aplicando o gerador para todos os quatro segmentos inteiros, obtêm-se uma nova linha inteira, como a mostrada na fig. 03, cujos segmentos são todos iguais ao comprimento $\varepsilon^{2}(\mathrm{n}=2$ iterações). Na fig. 03 são mostradas, também, linhas obtidas, respectivamente, para $n=3$ e $n=4$ iterações. Quando se repete o processo indefinidamente, obtêm-se a curva limite denominada Curva de Koch (fig. 03). Como pode ser observado, a n-ésima iteração de comprimento da curva é igual a:

$$
\varepsilon=\left(\frac{1}{3}\right)^{n} ; \mathrm{N}(\varepsilon)=4^{\mathrm{n}}
$$

e dado que $\varepsilon$ e $n$ tendem para o infinito, obtêm-se imediatamente:

$$
D=\lim n \rightarrow \infty \frac{\log 4^{n}}{\log \left(\frac{1}{3}\right)^{n}}=1,2618595
$$




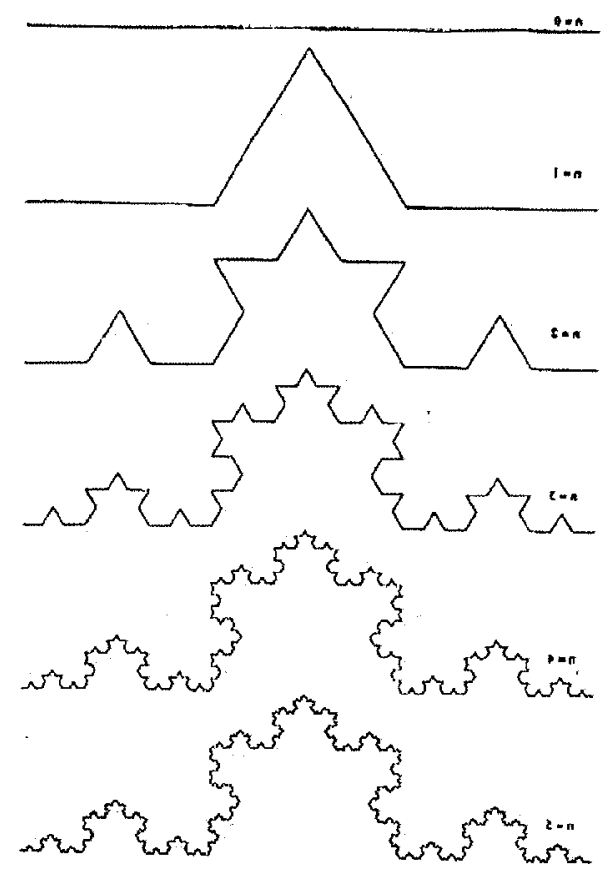

Figura 03 - Processo de geração da Curva de Koch (extraído da internet)

Observou-se que, a dimensionalidade da Curva de Koch não é um número inteiro, mas um valor fracionário. Com procedimentos iterativos similares aos usados na Curva de Koch, muitas variações podem ser obtidas utilizando um quadrado ou um plano elementar de figura geométrica como um gerador, em substituição ao triângulo equilátero. Em tais casos, valores diferentes serão claramente obtidos para a dimensão fractal D.
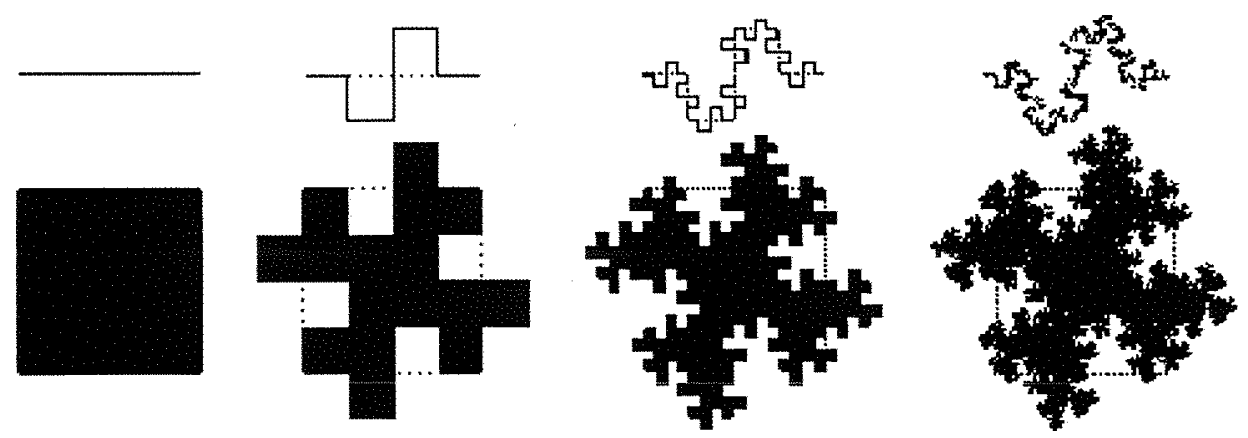

Figura 04 - Curvas de Koch geradas a partir de uma reta (dimensão 1) e um quadrado (dimensão 2) (Extraído da Internet) 
O Conjunto de Cantor é uma outra figura fractal muito importante no conceito moderno de dinâmica não-linear e consiste na remoção de "pedaços" de segmento da reta inicial cada vez menores, resultando um conjunto de pontos derivados da linha original.

Como na Curva de Koch, inicia-se o processo com uma linha reta de comprimento L (1) = 1 com n = 0 (iteração zero) como parâmetro. Em seguida, divide-se o mesmo em três partes e retira-se o terço médio do segmento. Portanto, o $1^{\circ}$ gerador para $n=1$ iteração consiste de 2 segmentos de comprimento $\varepsilon$ cada um igual a $1 / 3$. No limite, o comprimento se aproxima de zero, e então, pode-se dizer que a dimensão fractal está entre zero e um.

$$
\varepsilon=\left(\frac{1}{3}\right)^{n} ; \mathrm{N}(\varepsilon)=2^{\mathrm{n}}
$$

e dado que $\varepsilon$ e $n$ tendem para o infinito, obtêm-se imediatamente:

$$
D=\lim n \rightarrow \infty \frac{\log 2^{n}}{\log \left(\frac{1}{3}\right)^{n}}=0,63092 \ldots
$$

Um outro exemplo de obtenção de figura fractal é o caso do Triângulo de Sierpinsky é que feito a partir da divisão de um triângulo equilátero em quatro triângulos (igualmente equiláteros) removendo-se o triângulo central. $\mathrm{O}$ processo é repetido com os triângulos restantes. Levando-se isto ao infinito tem-se o Triângulo de Sierpinsky com dimensão fractal de $1,26 \ldots$ 

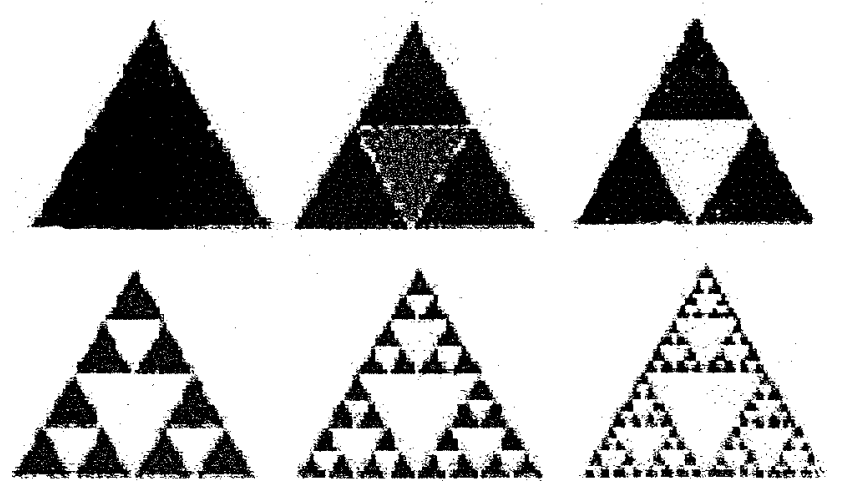

Figura 05 - Processo de geração do Triângulo de Sierpinsky (extraído da internet)

\subsubsection{O processo de difusão como um fenômeno fractal}

Um dos aspectos importantes na matemática fractal em sistemas não-lineares, é a caracterização de atrator estranho, medidas dos contornos fractais em condições iniciais e parâmetros no espaço analisado.

Quando refere-se à aplicação dessa teoria em fluxos ocorrendo em meios porosos, as forças de inércia são pequenas e o equilíbrio envolve um balanço de forças viscosas, tensão superficial e pressão aplicada.

O fluxo de um fluido num meio poroso, tradicionalmente segue a lei de Darcy que depende da pressão hidrostática, da densidade, da condutividade hidráulica no meio poroso, do potencial de fluxo e da direção, entre outros. Para fluídos incompressíveis temos a equação de Laplace.

A randomicidade é uma característica inerente a todos os fenômenos naturais e mesmo em sistemas perfeitos há elementos randômicos. Isto é uma ótima evidência de que muitos fenômenos naturais são bem descritos como fractais. Por causa da extraordinária importância do movimento Browniano ou "processo de caminhamento 
randômico", começou-se discutir o processo de difusão como um processo randômico com propriedades fractais (Feder, 1988).

Hurst, citado por Feder (1988), passou grande parte da sua vida estudando o rio Nilo e as medidas de sua descarga anual em função do tempo, do lago Albert, para determinar o desenho ideal de um reservatório, baseado em registros temporais.

Hurst encontrou que a taxa de reescala observada $(\mathrm{R} / \mathrm{S})$ para muitos registros no tempo pode ser bem descrita pela relação empírica:

$$
R / S=(\tau / 2)^{H}
$$

A pergunta que se faz é: por que vários fenômenos naturais cíclicos podem ser modelados pela estatística de Hurst?

Nesse sentido, Voss (1988) esclarece que num determinado fenômeno natural, como por exemplo a descarga de um rio, existe uma dependência do evento passado e do evento atual, e denomina esta dependência de "efeito de memória" que é considerado na modelagem.

Através de um estudo de densidade de probabilidade de posição de uma partícula num movimento randômico em determinado tempo, é que se introduziu o conceito do expoente de Hurst para o movimento browniano. Mandelbrot (1983) foi o primeiro a introduzir o conceito de movimento browniano fracionário ( $\mathrm{fBm}$ ) como uma generalização da função randômica $X(t)$ mudando o tradicional expoente $H=0,5$ para um número real entre 0 e 1 na equação:

$$
x=\frac{X(t)-X\left(t_{0}\right)}{\sqrt{2 D \sigma} \times\left(\frac{t-t_{o}}{\sigma}\right)^{H}}
$$

O movimento de uma "partícula browniana", vista sob um microscópio, consiste aparentemente de passos que têm uma direção randômica, cujo comprimento tem valor 
característico. Portanto, caminhamento randômico é o termo freqüentemente utilizado no contexto do movimento browniano. No entanto, o deslocamento dessa partícula elevado a um certo expoente varia linearmente com o tempo, e é aí que aparece o padrão fractal do movimento. Esse expoente é ajustável para cada tipo de movimento e depende das situações experimentais.

Analisando a "Taxa de reescala de Hurst" - um processo estatístico - observou-se que a estatística de muitos fenômenos naturais pode ser, de fato, representada pelo movimento browniano fracionário $(\mathrm{fBm})$, um exemplo de processo randômico com características fractais, quando o processo de difusão pode ser bem entendido em termos de movimento browniano.

É importante salientar que o movimento browniano fracionário ( $\mathrm{fBm}$ ) é um fenômeno em que incrementos passados estão relacionados com incrementos futuros. Quando o expoente $\mathrm{H}=0,5$ (eq. 11), esta correlação não existe e passa-se a ter o movimento browniano regular $(\mathrm{rBm})$, que é o limite do processo randômico, o caso clássico geralmente assumido.

$\mathrm{O}$ autor introduz o conceito de movimento persistente $(0,5<\mathrm{H}<1)$ que é a correlação entre incrementos futuros e passados, ou seja, se há um incremento positivo no evento passado, isto irá se repetir no evento futuro com explícita dependência do tempo. Um exemplo de processo persistente (com $\mathrm{H}=0,92)$ é a estatística de ondas oceânicas, que nesse caso sugere que se a força da onda tem aumentado para um período de tempo (t) é esperado que continue o aumento para um similar período de tempo.

$\mathrm{O}$ movimento anti-persistente $(0<\mathrm{H}<0,50)$, como o movimento horizontal da água no solo, um incremento no passado reflete num decréscimo no futuro e vice-versa.

Como muitas observações na natureza consistem de registro no tempo ou em séries de observações (como descarga de rios, precipitação, etc...), estes fenômenos podem ser analisados em termos de taxa de reescala de Hurst.

A difusão anômala (expoente de Hurst diferente de 0,5 para o tempo) é um importante conceito na discussão do fenômeno de transporte fractal, com aplicações para a dinâmica da água no solo em recentes trabalhos da literatura. 
Voss (1988) introduziu métodos de geração de movimento browniano regular e fracionário de superficies e nuvens, que denominou de algoritmo de "adição randômica sucessiva". Com esse processo obteve-se curvas auto-afins, com dimensão fractal dada pela eq. 12:

$$
D=2-H
$$

\subsubsection{O uso da Teoria do Caos e Fractais na ciência do solo}

Os fractais podem, mais uma vez, estimular pesquisadores a explorar os aspectos universais, com respeito às propriedades dos meios porosos naturais, como por exemplo, os solos, que são controlados mais por auto-similaridade do sistema do que por randomicidade. Além disso, como os solos são constituídos de frações de rochas e são porosos, em muitos casos, podem ser representados como objeto fractal tanto para a matriz porosa quanto para estrutura do complexo poroso, nas diferentes escalas de microporosidade e macroporosidade.

Figuras fractais clássicas como a Esponja de Menger ou o Carpete de Sierpinsky são utilizados como modelos para estrutura e textura em solos, em vários estudos encontrados na literatura (Tyler \& Wheatcraft, 1990; Perfect \& Kay, 1991, entre outros).

A quantificação do espaço poroso e da matriz do solo também foi estendido, recentemente, para modelos tradicionais de condutividade hidráulica e retenção da água no solo (Tyler \& Wheatcraft, 1989; Rieu \& Sposito, 1991a e 1991b; Filgueira,1999; Gimenéz et al,1999).

Os solos raramente são perfeitamente auto-similares. Entretanto, os solos apresentam auto-similaridade em certas escalas no sentido estatístico, e assim, podem ser considerados como um fractal estatístico ou estocástico (fractais naturais). Os fractais também oferecem a oportunidade para desenvolver novos modelos conceituais de 
heterogeneidade relativa para o meio poroso (Durant \& Crestana, 1993; Durant et al, 1991).

Uma área bastante explorada recentemente pela pesquisa quanto à aplicação dos fractais, refere-se ao fenômeno "fingering", que trata do comportamento da frente de molhamento durante o processo de infiltração de um fluído num meio poroso, quando apresenta fluxos preferenciais.

$\mathrm{Na}$ área de fluxo da água no solo - um processo de difusão - alguns trabalhos de referência nessa área têm sido desenvolvidos para movimento horizontal em colunas de solo (Guerrini \& Swartzendruber,1992, 1994, 1997 e 1998; Santos, 1997; Santos \& Guerrini,1998) e movimento vertical (Guerrini et al, 1997), associando o processo de infiltração ao movimento browniano fracionário $(\mathrm{fBm})$, que, como já foi citado, é um movimento reconhecidamente fractal.

Apesar das inúmeras aplicações e utilidades, o consenso para a aplicação de fractais ainda tem um longo caminho pela frente. Faltam muitas ferramentas e vários problemas continuam sem solução. Uma teoria completa e unificada é necessária e a pesquisa prossegue neste sentido. 


\section{REVISÃO BIBLIOGRÁFICA}

\subsection{Aplicação de Caos e Fractais no movimento da água no solo}

Num estágio anterior à compreensão e utilização de técnicas de irrigação, diversos estudos têm sido conduzidos no intuito de conhecer melhor o movimento da água no solo. Esse movimento, que pode ser enquadrado como não convencional quando comparado com aqueles mais conhecidos da Física, tem sido descrito tradicionalmente, na literatura de Física do solo, através da Lei de Darcy, desenvolvida inicialmente para solos saturados. Essa lei mostra que o fluxo de água no solo é diretamente proporcional ao gradiente de potencial hidráulico, sendo que a proporcionalidade é dada pela condutividade hidráulica do solo, considerada constante para solos saturados.

Posteriormente, a então conhecida Lei de Darcy-Buckingham, estendida para condições insaturadas, passou a ser usada de forma generalizada, muito embora assumindo hipóteses de trabalho nem sempre adequadas. Assim, de forma imprópria, muitos cientistas já utilizaram e ainda utilizam, a lei de Darcy para solos insaturados. De fato, Darcy ${ }^{1}$, citado por Libardi (1973) e Guerrini (1988), desenvolveu seus trabalhos inicialmente para solos arenosos e saturados, sendo que Buckingham ${ }^{2}$, também citado pelos autores acima, estendeu os estudos para solos não saturados, onde a condutividade hidráulica passa a ser uma função da umidade do solo.

Nos últimos anos, devido ao desenvolvimento de melhores técnicas de medida dos parâmetros físicos e hídricos do solo, um grande impulso tem sido dado às investigações

\footnotetext{
${ }^{1}$ DARCY, H. Les fontaines publique de la Ville de Dijos, Paris, Victor Dalmont, 1856. 502 p.
} 
científicas dessa área, e conseqüentemente, às técnicas de manejo de irrigação. Esses parâmetros referem-se, principalmente, à condutividade hidráulica, à difusividade da água no solo e ao potencial mátrico, cujos conhecimentos são essenciais em fisica da água no solo. Uma revisão completa dos diversos métodos de laboratório e de campo para a determinação desses parâmetros e/ou funções, em solos não saturados, pode ser encontrada em vários trabalhos de literatura.

Num trabalho de grande importância, Nielsen et al. (1962) fazem considerações experimentais da análise da difusão de água no solo, em problemas de fluxo insaturado e concluem sobre a inabilidade da solução tradicional da equação de difusão (Lei de DarcyBuckingham em conjunto com a Equação da Continuidade) para descrever o movimento da água a diferentes pressões. Esses autores mostraram que a posição da frente de molhamento não variava com a raiz quadrada do tempo, como era previsto pela interpretação tradicional da Lei de Darcy-Buckingham, quando pressões negativas eram aplicadas à entrada de água em colunas horizontais de solo em laboratório.

Em seguida, Elrick (1963); Rawlins \& Gardner (1963); Peck (1964) também mostraram que, experimentalmente, a frente de molhamento apresenta um comportamento não-linear com relação à raiz quadrada do tempo, colocando em dúvida a solução tradicional da equação de difusão.

Miyazaki et al. (1984) analisando a infiltração, a condutividade e a difusividade da água no solo, através da radiação gama $\left({ }^{137} \mathrm{Cs}\right)$ em experimentos em colunas horizontais e verticais, chegaram à conclusão que essa não-linearidade ocorre não só para a umidade da frente de molhamento, mas para qualquer valor de umidade do solo, tendendo a desaparecer para umidades próximas à saturação, onde o coeficiente linear da reta $\mathbf{x}$ vs. $\mathbf{t}^{1 / 2}$ tende para zero. Estes mesmos autores estudaram, também, a equação de Richard (eq. 13) para fluxo vertical descendente, que é o objeto de estudo do presente trabalho, e considerando a solução dessa equação para um solo semi-finito e para as condições de

\footnotetext{
${ }^{2}$ BUCKINGHAN, E. Studies on the movement of soil moisture. WASHINGTON, USDA/BUREAU of Soil, 1907. 61 p. (USDA- Bulletin,38)
} 
contorno $\left\{\begin{array}{l}\theta=\theta, \mathrm{t}=0, \mathrm{Xn}>0 \\ \theta=\theta_{0,}, t \geq 0, \mathrm{Xn}=0\end{array}\right.$ para $\mathrm{n}=1,2,3, \ldots$ propuseram uma solução analítica baseando-se em Philip (1957a,1969b), dada pela eq. 14.

$$
\begin{aligned}
& \frac{\partial \theta}{\partial x}=\frac{\partial}{\partial_{x}}\left(D \times \frac{\partial \theta}{\partial x}\right)-\frac{\partial K}{\partial x} \\
& x=\phi t^{\frac{1}{2}}+\chi t+\varphi t^{\frac{3}{2}}+\omega t^{2}+\ldots+\varepsilon 1+\varepsilon 2
\end{aligned}
$$

onde: $\theta \mathrm{i}$ é a umidade inicial, $\theta$ o é a umidade na entrada, $\mathrm{D}$ é a difusividade, $\mathrm{K}$ é a condutividade hidráulica. Os parâmetros $\phi, \chi, \omega, \psi$ são coeficientes que dependem unicamente da umidade e $\varepsilon$ refere-se ao erro sendo $\varepsilon 1$ referente ao erro experimental e $\varepsilon 2$ referente ao erro de truncamento da série de Philip.

Kao \& Hunt (1996) estudaram modelos de infiltração das equações de GreenAmpt e Philip como um modelo simplificado, representando a porosidade média por tubos capilares, para prever o movimento da frente de molhamento durante a infiltração vertical e horizontal, em solos secos e com umidade inicial, com o objetivo de simplificar os fundamentos fisicos de fluxo de fluídos insaturados e reduzir o número de parâmetros necessários a serem medidos no campo. Os autores comentam que a equação de Richard, uma equação diferencial parcial não-linear, pode ser reduzida a uma equação diferencial ordinária, pela transformação de Boltzmann (eq. 3), e que esta solução parcial implica que a localização da frente de molhamento avança proporcionalmente à raiz quadrada do tempo quando o valor de $\lambda$ correspondendo à frente de molhamento é constante:

$$
\lambda=x \mathrm{t}^{\frac{-1}{2}}
$$

Guerrini \& Swartzendruber (1992) observaram também desvios para os conceitos tradicionais do movimento da água no solo, e fazendo uma análise detalhada sobre o 
fenômeno de absorção horizontal da água no solo, concluíram que a não-linearidade acima citada, realmente ocorre de uma forma genérica, onde os solos em questão são chamados de semi-rígidos, devendo haver um rearranjo interno das partículas do solo à passagem de água, através de um remanejamento das partículas durante o processo de infiltração. Esta mudança na microestrutura do solo pode estar alterando a geometria do espaço poroso com provável redução no tamanho médio dos poros. Em contrapartida, os solos rígidos seriam aqueles para os quais o expoente do tempo seria sempre 0,50 quando não haveria rearranjo de partículas, sendo que no outro extremo, estariam os solos expansivos para os quais há uma diminuição efetiva da densidade global com a umidade (Guerrini \& Ferraz, 1983). O expoente do tempo, designado genericamente como $n$, mostrou-se sempre menor que o tradicional valor esperado de 0,50 para os solos semirígidos, onde a solução da equação de difusão inclui um dependência explícita do tempo para as funções de condutividade e difusividade da água no solo

Este comportamento, não previsto pela teoria tradicional, foi estudado com mais detalhes por Guerrini \& Swartzendruber (1994 e 1997), os quais mostraram que o expoente do tempo ( $n$ ) cresce na direção do tradicional valor de 0,50 quando o solo se aproxima da saturação, identificando este fenômeno como fractal, e comparando o expoente $(n)$ com o expoente $\mathrm{H}$ de Hurst $(\mathrm{H}=0,50)$, que o caracteriza como movimento Browniano regular (rBm). No caso de solos não saturados, o valor de $n=\mathrm{H} \neq 0,50$ e o processo de infiltração horizontal da água no solo pode ser identificado como movimento Browniano fracionário (fBm) (Feder, 1988).

Santos (1997) num estudo semelhante, para diferentes pressões de entrada de água em coluna horizontal de solo, também concluiu que o movimento da água no solo um processo de difusão - caracteriza-se como um movimento fractal, obtendo um valor para o expoente $n$ da equação $x=t^{n}$ diferente de 0,50 .

O uso de uma equação não-linear, do tipo curva de potência, onde $n$ é o expoente do tempo, é essencial nesta análise, estando este expoente relacionado à dimensão fractal do movimento em questão, como é bem discutido por Feder (1988) para fenômenos de difusão em geral. 
Baseados nos trabalhos de Miyazaki et al. (1984), Guerrini et al. (1995), ajustaram os dados de umidade às duas equações $x=\lambda_{1}(\theta) t^{0,50}$ e $x=\lambda_{2}(\theta) t^{n}$ para vários níveis de umidade, fazendo uma comparação entre a análise tradicional e fractal para o caso da absorção horizontal. Observaram que os valores do expoente $\boldsymbol{n}$ são sempre menores que 0,50 e tendendo para este valor máximo próximo à saturação do solo, explicando os desvios da raiz quadrada do tempo e evidenciando mais uma vez, o caráter fractal da infiltração horizontal de água no solo.

Guerrini et al. (1996) estudaram, em laboratório, quatro equações para ajuste de dados de observação visual do deslocamento da frente de molhamento, para o movimento horizontal da água no solo, usando o software Origin 3.5 (Microcal Software, Inc., 1995) sendo as quatro equações: Weibull, equação de potência simples: $x(t)=\lambda t^{n}$, equação de potência similar: $x(t)=\lambda t^{0,50}$, e equação sigmoidal, onde $\mathrm{x}$ é a posição da frente de molhamento, $\lambda$ é uma variação da variável de Boltsmann, dependente da umidade $\theta, t$ o tempo e $n$ o expoente da equação que se identifica com o expoente de Hurst. Nesse estudo, a equação de potência simples apresentou melhores resultados, e a equação de Weibull apresentou ótimo ajuste para ambos os solos estudados. Porém, o valor de $\chi^{2}$ indica bastante semelhança à equação de potência simples para intervalos de observação menores. Concluíram também que, para um período de tempo maior que 12 horas, o movimento da frente de molhamento se torna extremamente lento, principalmente para pressões mais negativas, não apresentando mais caráter fractal, passaria a não caracterizar mais um processo de difusão.

A Teoria dos Fractais permite prever o movimento da água no solo, baseando-se em medidas de porosidade, densidade e capacidade de retenção de água no solo. Rawls et al. (1993) usaram a geometria fractal para relatar as dificuldades de se medir as propriedades hidráulicas do solo. As características de transportar e reter água no solo podem ser relatadas, intimamente, como características fractais do espaço poroso.

Guerrini \& Swartzendruber (1998) estudaram três modelos matemáticos para ajuste de umidade em função do tempo. Os autores questionam se o comportamento 
obtido para o experimento desenvolvido para fluxo horizontal, será similar em infiltração vertical ascendente e descendente de água no solo. Neste presente estudo foi utilizada uma equação de três parâmetros proposta pelos autores, e os resultados obtidos serão discutidos posteriormente.

Perfect \& Kay (1995a) compararam o modelo convencional da equação de Weibull para agregados do solo considerados cubos euclidianos, modificando o modelo e considerando-o como cubos fractais e concluíram que o novo modelo apresentou um ajuste bem melhor do que o convencional e que a dimensão fractal (D) aumentou com o aumento do teor de argila, e talvez seja possível predizer ainda, a distribuição e tamanho de poros, agregados de solos e fragmentação do solo, pela nova teoria.

Filgueira et al. (1995) relataram que a distribuição de agregados de diferentes tamanhos no solo é uma conseqüência da estrutura do mesmo, e uma forma de se expressar esta quantidade é a representação fractal do solo, que está baseada na distribuição da porosidade e tamanho das partículas e, com base na Teoria dos Fractais, a dimensão fractal é um indicador da fragmentação do solo, e consequentemente, da estrutura do mesmo. Baseando-se na teoria desenvolvida por Rieu e Sposito (1991a) ${ }^{3}$, os autores avaliaram a dimensão fractal de agregados para dois tipos de solos: um sob vegetação e outro, sob solo cultivado. Os autores observaram que a dimensão fractal D mostra diferenças entre os tratamentos e pode ser utilizada como um parâmetro para caracterizar a degradação de um solo sujeito a práticas de cultivo. Concluíram que a teoria proposta adaptou-se bem aos dados experimentais obtidos e os coeficientes apresentaram resultados coerentes para predizer algumas propriedades do solo.

Young \& Crawford (1991) num trabalho de revisão relataram que a teoria fractal é aplicada à estrutura do solo em vários trabalhos anteriores. Eles sugeriram que a ligação feita em trabalhos anteriores entre a dimensão fractal e a curva de retenção da água no solo é baseada em simplificadas suposições, o que complica a interpretação dos resultados. Eles apresentam um método simples para estimar a dimensão fractal D de agregados naturais, o que evita algumas dessas suposições, usando solos sob diferentes 
sistemas de manejo e mostraram que a dimensão fractal $\mathrm{D}$ variou de 2,75 a 2,93, podendo usar o valor de D para quantificar a heterogeneidade em solos explorados.

Rawls \& Brakensiek (1995) reuniram também material publicado na literatura, para estimar características do solo como matriz e macroporosidade, e relataram que, modelando-se o fluxo da água no solo e através dele, em regiões semi-áridas, esse fluxo pode ser dividido em matricial e gravitacional. Os autores comentam que, as propriedades fisicas do solo, como macroporosidade, distribuição e tamanho de poros, porosidade e condutividade hidráulica saturada, têm sido precisas para inúmeras metodologias, embora requeiram trabalhosos procedimentos de campo e/ou laboratório (Edwards et $\mathrm{al}^{4}{ }^{4}, 1988$; Ehlers et al. ${ }^{5}, 1983$; Lorgsdon et al. ${ }^{6}, 1990$; Watson e Luxmoore, $1986^{7}$, citados pelos autores). Então, baseados em várias fontes de dados de complexidade variada, os autores reuniram procedimentos para estimar estas características através da Teoria Fractal. Um exemplo, é a utilização do Carpete de Sierpinski (uma figura fractal clássica) para representar a porosidade do solo citado por Tyler \& Wheatcraft (1990), e usando propriedades de retenção de água para solos naturais.

Tyler \& Wheatcraft (1990) propuseram o desenvolvimento de um modelo físico para textura e estrutura do solo baseado na geometria fractal. A motivação para a utilização do modelo fractal para textura do solo é que a distribuição de algumas dessas partículas é granular e tem mostrado auto similaridade em escala, uma das características típicas de estruturas fractais. Usando estes modelos, baseados no Carpete de Sierpinski, os autores sugeriram que a geometria do meio poroso pode ser representada como conceito fractal em escala. O Carpete de Sierpinski é uma figura fractal que possui "buracos" ou poros auto similares em uma série de tamanho de escala, conforme citado

\footnotetext{
${ }^{4}$ EDWARDS,W.M.;NORTON,L.D.;REDMOND,C.E. Characterizing macropores that effect infiltration into nontilled soil. Soil Science Society America Journal,V.52, P.483-487. 1988.

${ }^{5}$ EHLERS,W.; KOPKE,U.; HESSE,F. et al. Penetration resistance and growth of oats in tilled and untilled loose soil. Soil Tillage Research, V.3, p. 261-275. 1983.

${ }^{6}$ LORGSDON,S.D; ALLMARAS,R.R.; WU, L.et al. Macroporosity and its relation to saturated hydraulic conductivity unde different tillage practices. Soil Science Society America Journal, V.54, P.1096-1101.1988.
} 
anteriormente. Eles avaliaram as propriedades de retenção para quatro exemplos de Carpete de Sierpinski, regulares e randômicos, e relataram estas propriedades, baseandose nos modelos empíricos de Brook \& Corey ou Campbel, chegando-se à expressão $\psi=\psi_{a}\left(\frac{\theta}{\theta_{s}}\right)^{\frac{1}{D-2}}$ onde D é a dimensão fractal do Carpete de Sierpinski, $\psi$ é o potencial matricial e $\psi_{\mathrm{a}}$ é a pressão de entrada de ar.

O novo modelo de retenção foi então utilizado para estimativa da condutividade hidráulica do meio poroso. Os autores encontraram dimensão fractal para um conjunto de solos na faixa de 1,71 a 1,95 com o aumento da dimensão fractal associado com a textura mais fina do solo, ou seja, maior teor de argila.

A aplicação de uma aproximação para a geometria fractal sugere que uma maior compreensão de tamanho e dịstribuição de poros no solo pode ser obtido com aplicações simples de fractais, tal como o modelo Carpete de Sierpinski, representando o meio poroso. Nos solos que apresentam distribuição fractal para porosidade, as análises mostradas no trabalho sugerem que propriedades de retenção podem ser estimadas para uma ampla faixa de pressão capilar, baseados em número limitado de dados.

Perfect et al. (1996) estudaram também, sob a ótica da teoria do caos e fractais, as curvas de retenção da água no solo que, pelo método tradicional, são obtidas através de medidas de umidade volumétrica $(\theta)$ e potencial matricial $(\psi)$. Com o recente desenvolvimento da geometria fractal, os autores estudaram um novo modelo fractal de três parâmetros. Dos parâmetros da equação utilizada $\theta=\left(\frac{\psi}{\psi_{a}}\right)^{D-3}$, a dimensão fractal D foi menos sensível à variação da porosidade média. Estes parâmetros foram condizentes com os citados pela literatura para estes mesmos solos. A vantagem é que uma menor escala de estudo pode ser utilizada para agregação do solo. Além disso, os autores salientam que é preciso incorporar o efeito da histerese na nova equação.

\footnotetext{
${ }^{7}$ WATSON,K.W.; LUXMOORE,R.J. Estimating macroporosity in a watershed by use of o tension infiltration. Soil Science Society America Journal, V.50, P.578-582. 1986.
} 
Perfect \& Kay (1995b) num trabalho de revisão, pesquisaram na literatura a aplicação de fractais determinísticos e estocásticos em agricultura e pesquisa do solo, e relataram que a aplicação de fractais nessa duas áreas se divide em três grandes grupos: descrição das propriedades fisicas do solo, modelagem dos processos fisicos e quantificação da variabilidade espacial dos solos. Em termos de propriedades fisicas, os fractais têm sido usados para descrever densidade do solo, porosidade e distribuição de poros, tamanho, forma e distribuição de agregados e microtopografia de solos. Em termos de processos fisicos, a teoria dos fractais tem sido usada para modelos de absorção, transporte de água e solutos, desagregação e fragmentação. Em termos de variabilidade espacial, tem sido usada para quantificar a distribuição das propriedades do solo e processos usando semivariogramas, espectro de potência e espectro multifractal. Entretanto, maiores investigações são necessárias para especificação de diferentes modelos fractais, e coletar dados para testes desses modelos. Os autores concluíram que a Teoria do Caos e Fractais proporciona a possibilidade de quantificar e integrar informações sobre fenômenos biológicos, químicos e físicos do solo, medidos para diferentes escalas espaciais.

Dentre as aplicações da Teoria dos Fractais na ciência do solo, Durant et al. (1991) e Durant \& Crestana (1993) estudaram, através da Teoria Fractal, o fenômeno "fingering", ligado à frente de molhamento, durante a infiltração da água no solo, e concluíram que a dimensão fractal pode ser usada como um critério para caracterizar a dinâmica deste fenômeno em solos.

Gardner \& Hsiek (1959), citado pelos autores acima, foram os primeiros a demonstrarem o fenômeno "fingering" para a frente de molhamento durante o processo de infiltração da água em duas camadas de solo. Hill \& Parlange (1972) demostraram experimentalmente em solos que os "fingers" ocorrem no processo de infiltração vertical descendente, em solos com duas camadas com textura diferente, sendo a camada superior de textura mais fina. Mandelbrot (1983) levou adiante o conceito de fractal para descrever uma geometria complexa relatando autosimilaridade em escala de observação. O propósito do trabalho desses autores foi usar o Teoria dos Fractais como ferramenta 
para estimar a tensão superficial efetiva e descrever o fenômeno "fingering" durante a infiltração da água, em duas camadas de solo.

Pachepsky \& Timlin (1998) desenvolveram uma equação de transporte de água no solo, usando um modelo físico de percolação em agregados, aplicando a lei de conservação de massa assumindo a condutividade hidráulica como um produto da umidade e dependente da distância.

As propriedades fisicas do solo como porosidade, agregados e tamanho de poros possuem autosimilaridade em escala, sendo o solo, sob muitos aspectos, um meio fractal assumindo características de fluxo anômalo, ou seja, o coeficiente de difusividade tem uma dependência explícita do tempo. A difusividade da água no solo depende da umidade e decresce com o tempo obedecendo a uma curva de potência. Conforme mencionado anteriormente, foi encontrada uma solução para transporte de água em meio insaturado com dependência explícita do tempo e é sugerido o $\mathrm{fBm}$ como um modelo para o movimento da água no solo. (Guerrini \& Swartzendruber, 1992 e 1994). Os autores desenvolveram um modelo de transporte de água no solo considerando-o como um meio fractal e buscaram explorar a extensão da manifestação anômala em movimento horizontal, em colunas de solo, com dados publicados na literatura.

Um outro enfoque da Teoria dos fractais é o estudo do movimento vertical da água no solo. A infiltração vertical da água no solo tem sido bastante considerada devido a sua importância prática, principalmente no que se refere ao manejo de sistemas irrigados, por causa dos efeitos significativos da gravidade no aumento da infiltração ao longo do tempo e conseqüentemente, à região de penetração da água.

As soluções analíticas mais clássicas para estudar o movimento vertical da água no solo são atribuídas a Green-Ampt \& Philip.

Philip $^{8}$ (1969), citado por Kao \& Hunt (1996) define a relação entre a infiltração acumulada (I) e o tempo (t) como uma série assintótica infinita dada pela equação 09 :

$$
I=S \mathrm{t}^{\frac{1}{2}}+A \mathrm{t}
$$

\footnotetext{
${ }^{8}$ PHILIP,J.R. Theory of infiltration. In: CHOW, V. te. Advances in hydroscience. San Diego: Academic Press, 1969. p.215-305.
} 
onde A é a constante determinada por integração numérica e $\mathrm{S}$ é a sortividade.

Esse movimento, que pode ser enquadrado como não convencional quando comparado com aqueles mais conhecidos da Física, tem sido descrito tradicionalmente, na literatura de Física do solo, através da Lei de Darcy, desenvolvida inicialmente para solos saturados. Essa lei mostra que o fluxo de água no solo é diretamente proporcional ao gradiente de potencial hidráulico, sendo que a proporcionalidade é dada pela condutividade hidráulica do solo, considerada constante para solos saturados.

Guerrini et al. (1997) estudaram visualmente a velocidade da frente de molhamento, em colunas verticais de solo, em laboratório, e concluíram que uma equação de função potência mostra a não-linearidade desse movimento, o que indica um caminho de pesquisa no sentido de se descobrir o comportamento e a dimensão fractal desse processo. Os autores observaram que a dimensão fractal do movimento da água no solo aumenta com a densidade da amostra.

Pode-se afirmar, baseado na literatura, que a Teoria dos Fractais é uma ferramenta moderna e bastante útil para analisar, sob diferente ponto de vista, o fenômeno da infiltração da água no solo, passo essencial para a compreensão e uso de técnicas de irrigação.

Conforme salientado anteriormente, diversos estudos têm sido conduzidos no intuito de conhecer melhor o movimento da água no solo. Neste estudo será abordado o movimento vertical da água no solo, um processo de difusão, sob a ótica da teoria do Caos e fractais.

\subsection{Estudo de erros experimentais}

No sistema água-solo, o objetivo de se modelar o fenômeno de infiltração com modelos exponenciais, é permitir uma previsão ao longo do tempo do comportamento do fluxo. 
Como em qualquer outra área, erros experimentais nas medidas podem ocasionar distorções no comportamento do modelo. Foram feitas várias tentativas de ajuste, com eliminação de alguns pontos experimentais, e o estudo de propagação de erro para verificar a aplicabilidade do modelo em fluxo vertical da água no solo.

Como salientado anteriormente, os dados de umidade foram obtidos através de tensiômetros Bacchi (1988), medindo-se o potencial mátrico de cada ponto e depois a umidade do solo foi estimada através do modelo de Van Genutchten (1980):

$$
\theta=\theta_{r}+\frac{\left(\theta_{s}-\theta_{r}\right)}{\left[1+\left(\alpha \Psi_{m}\right)^{n}\right]^{n}} \quad \text { ou } \quad \Psi_{m}=\frac{1}{\alpha} \times\left[\left(\frac{\theta_{s}-\theta_{r}}{\theta-\theta_{r}}\right)^{\frac{1}{m}}-1\right]^{\frac{1}{n}}
$$

onde: $\theta$ r é a umidade residual no solo, $\theta$ s é a umidade na saturação, $\theta$ é a umidade atual, $\psi$ m é o potencial mátrico e $m, n$ e $\alpha$ são parâmetros de ajuste da equação.

\subsubsection{Erros sistemáticos, acidentais e grosseiros de uma medida experimental}

Ao contrário do que sempre se acreditou, a nova ciência do Caos e da Complexidade diz que a física não é uma ciência exata, os valores determinados normalmente não são valores reais, mas uma faixa na qual o valor verdadeiro é provável. Todos os experimentos ou cálculos têm inerentes a si próprio, uma imprecisão que é caracterizado por incertezas. Portanto, torna-se necessário um estudo sobre erros experimentais.

Os erros que uma determinada medida experimental pode conter se classificam em erros acidentais, sistemáticos e grosseiros.

Os erros sistemáticos são aqueles relacionados à exatidão do método utilizado. São conseqüência de uma falha no equipamento e/ou procedimento experimental. Não há método para se detectar e eliminar erros sistemáticos, exceto verificar várias vezes os equipamentos e os procedimentos experimentais. A suspeita pode aparecer da comparação de resultados obtidos com resultados obtidos por outros pesquisadores. 
O erro sistemático de uma medida, obtida com um único método, não é possível ser estimado.

Os erros acidentais se referem aos erros de precisão da metodologia utilizada. Eles são praticamente inevitáveis, mas podem ser minimizados por cuidados do experimentador e muitas repetições. É o erro apresentado pelo experimentador.

Os erros grosseiros são aqueles cometidos pela pessoa responsável pelas leituras e/ou anotações dos dados.

Um exemplo de erro experimental é a medida da aceleração da gravidade - $\mathrm{g}=$ $9,81 \mathrm{~m} / \mathrm{s}^{2}$. Supondo que esse seja o valor exato (correto), mede-se experimentalmente, partindo-se do pressuposto que não haja erros grosseiros e supondo também, que o método não apresente erros sistemáticos (exatidão), ou seja, esteja 100\% calibrado e sem apresentar nenhum tipo de distorção. Ainda assim, os valores experimentais variariam em torno de 9,81: 9,75;9,78;9,88; etc.(sempre em $\mathrm{m} / \mathrm{s}^{2}$ ) que corresponde à variação de precisão das medidas.

Os erros são inerentes a qualquer medida experimental. Os erros acidentais nunca são zerados, só podem ser minimizados.

Um outro exemplo de erro de medida experimental se refere a medidas de umidade $(\theta)$.

Os principais métodos utilizados para medida do teor de água no solo são o método gravimétrico (considerado como padrão), a atenuação da radiação gama, a sonda de neutrons, a tensiometria, o TDR, os sensores elétricos, etc.

As funções hídricas do solo, como por exemplo, condutividade hidráulica, densidade de fluxo e infiltração da água, são dependentes da umidade $(\theta)$.

Quase todas essas funções hídricas apresentam variação exponencial, e como conseqüência, a propagação de erros se torna muito grande.

Guerrini (1982) analisou a propagação de erros na função de difusividade da água no solo $(\mathrm{D}(\theta))$ e concluiu que os erros podem chegar a mais de $100 \%$. 


\subsubsection{Precisão, exatidão e algarismos significativos}

A precisão indica a reprodutibilidade de uma medida que está diretamente relacionada com o desvio padrão da medida. $\mathrm{O}$ número de algarismos sobre os quais estamos razoavelmente seguros em uma medida experimental é chamado de números de algarismos significativos. Esses devem expressar de maneira razoável a precisão de uma medida. Por conseguinte, esse número indica a confiança que uma determinada medida merece e o número correto desses algarismos serve para evitar números ilusórios $\mathrm{e}$ cálculos desnecessários.

A exatidão indica o grau de proximidade entre o valor encontrado e o valor verdadeiro. Portanto, para se conhecer a exatidão de uma medida, os resultados devem ser comparados com um valor padrão considerado como verdadeiro. Muitas vezes esse padrão é fornecido por outra metodologia ou até mesmo por valores teóricos (Chieppe, 1993).

\subsubsection{Variações de $\theta(t)$ ou $\omega(t)$}

O tensiômetro tem sido o instrumento mais usado para a determinação do momento oportuno de irrigação, mediante a medição do potencial da água no solo, na região do sistema radicular da cultura.

Quantificar os erros por meio de uma análise da variância total e identificar em que proporção eles se devem ao instrumento ou a localização, foi o objetivo do estudo de Villagra (1988).

Como a faixa de resposta dos tensiômetros é particularmente pequena, o tensiômetro tem sua função principal no controle de irrigação intensiva, mas, podem ser usados também para monitorar gradientes de potencial, cujos dados podem ser utilizados em equações de fluxo, e com a determinação prévia da condutividade hidráulica, $K(\theta)$, pode-se estimar o movimento da água no solo. 
A desvantagem no uso dos tensiômetros é que o equipamento mede diretamente o potencial da água no solo e indiretamente a umidade $(\theta)$. Essa transferência requer conhecimento das curvas de retenção, característica para cada solo.

Em todos os trabalhos sobre tensiometria não se consideram os erros envolvidos no uso do tensiômetro para medidas do potencial mátrico da água no solo $(\psi \mathrm{m})$. Uma exceção é o trabalho de Greminger et al. (1985) que mostra através da técnica da geoestatística, as variâncias que podem ser obtidas com o uso de tensiômetros no campo (Villagra,1988).

Villagra (1988), estudando a variabilidade de medidas com o tensiômetro em Terra Roxa Estruturada, realizou uma análise dos componentes de variância das medidas e dividiu-as em variância instrumental e de localização dos tensiômetros. Pode-se observar que as variâncias aumentaram à medida que o potencial mátrico também aumentou (ou seja, mais negativo). Isso pode ser devido às características do instrumento, sendo a cápsula do tensiômetro sua parte mais determinante, no que se refere aos erros cometidos. Pode-se pensar, que para maiores potenciais, a condutividade da cápsula seria limitante quanto à resposta do instrumento. Por outro lado, comparando um estudo realizado por Saraiva da Costa $^{9}$ citado por Villagra (1988), a condutividade hidráulica das cápsulas nunca foi um fator limitante para esse solo estudado. As maiores variâncias observadas para valores mais elevados de potencial mátrico se devem, em grande parte, às características próprias do solo, pois a condutividade hidráulica diminui á medida em que aumenta o potencial mátrico e, em menor parte, a erros operacionais de medição, localização, profundidade das cápsulas e altura da cuba em relação à superficie do solo.

Villagra (1988) afirma também que não se deve considerar, neste caso, que as variâncias das medidas se devem a erros instrumentais (ou de exatidão), mas a erros de operação conjuntamente com as características do solo, o que torna dificil a separação dos dois efeitos. $\mathrm{O}$ autor conclui que, em função da variabilidade espacial do solo e

\footnotetext{
${ }^{9}$ SARAIVA da COSTA,A.C. Balanço hídrico em culturas de feijão (Phaseolus vulgaris L.) e de milho (Zea mays L.) sob condições de campo. Dissertação de mestrado. 1986.
} 
medidas indiretas de umidade, o uso do tensiômetro é recomendado apenas como uma estimativa média dos valores de umidade.

Em cada medida de umidade $(\theta)$, como citado anteriormente, existem erros. Os erros envolvidos no uso da técnica da tensiometria são relativos principalmente à variabilidade espacial das propriedades fisicas do solo.

$\mathrm{O}$ ajuste de $\omega(\mathrm{t})$ envolve mais erros, que correspondem aos de ajuste, além dos embutidos nas medidas de umidade $(\theta) . \mathrm{O} \chi^{2}$ por exemplo, fornece uma medida de erro de ajuste, supondo que não haja outros anteriores, neste caso, nas medidas de $\theta$.

O segundo ajuste, no presente trabalho, $x=\lambda \times \mathrm{t}^{\mathrm{n}}$, já traz embutidos, todos os erros anteriores. Se há muitos erros na obtenção original de $\theta$, esse segundo ajuste fica totalmente comprometido.

O movimento da água no solo é um fenômeno muito dinâmico e irregular, e portanto, não se pode ter uma repetição de dados de umidade para cada tempo, como o recomendado pela estatística para ajustes não-lineares, durante o processo de infiltração. Com isso, a interpretação do fenômeno fica dificultada e cada ponto medido apresenta (ou pode apresentar) grandes erros envolvidos em $t$ (que deriva dos valores de $\theta$ ). 


\section{MATERIAL E MÉTODOS}

Esse trabalho teve como base, dados de umidade em função do tempo, publicados em literatura por Bacchi (1988) usando a técnica de tensiometria. Nesse trabalho foi analisado o processo de infiltração da água no solo, a partir do solo saturado, sendo determinado em cada posição e em cada instante, o teor de água no solo.

O experimento realizado com o uso da tensiometria por Bacchi (1988), foi desenvolvido no Centro de Energia Nuclear na Agricultura (CENA/USP), num Latossolo vermelho-amarelo, de textura média, com teor de argila médio de $26 \%$ e constituiu-se de três parcelas experimentais, constituindo-se repetições.

Foram instalados, em cada parcela, tensiômetros à $15,30,45,60,75,90,105$, 120 e $135 \mathrm{~cm}$ de profundidades. O solo foi saturado e acompanhou-se a variação de umidade durante um período aproximado de 45 dias, sendo inicialmente medido em horas e posteriormente, medido em dias.

A partir dos dados dos potenciais matriciais médios das três parcelas experimentais, foi estimada a umidade volumétrica $\left(\theta, \mathrm{em} \mathrm{cm}^{3} / \mathrm{cm}^{3}\right)$, pelo método de Van Genuchten (1980). Os dados médios das três parcelas experimentais, para cada profundidade e cada tempo de redistribuição da água no solo, são apresentados na Tab. $01 \mathrm{e} 02$. 
Tabela 01 - Dados de umidade $(\theta)$ em função do tempo $(t)$, para cada profundidade, pelo método da tensiometria, para profundidade de $15 \mathrm{~cm}$ a $75 \mathrm{~cm}$.

\begin{tabular}{|c|c|c|c|c|c|c|c|c|c|c|}
\hline Tempo $(x)$ & Tetha15 $(Y)$ & $W 15(Y)$ & Tetha30 (Y) & W30 (Y) & Tetha45 $(\mathrm{Y})$ & $W 45(Y)$ & Tetha60(Y) & $\mathrm{W} 60(\mathrm{Y})$ & Tetha75(Y) & W75 (Y) \\
\hline 0 & 0,374 & 0,92453 & 0,389 & 0,93373 & 0,39 & 0,89474 & 0,419 & 0,94737 & 0,386 & 0,93171 \\
\hline 0,01 & 0,321 & 0,67453 & 0,381 & 0,88554 & 0,376 & 0,82105 & 0,413 & 0,91866 & 0,375 & 0,87805 \\
\hline 0,021 & 0,306 & 0,60377 & 0,372 & 0,83133 & 0,364 & 0,75789 & 0,402 & 0,86603 & 0,36 & 0,80488 \\
\hline 0,031 & 0,298 & 0,56604 & 0,366 & 0,79518 & 0,354 & 0,70526 & 0,393 & 0,82297 & 0,349 & 0.75122 \\
\hline 0,042 & 0,291 & 0,53302 & 0,36 & 0,75904 & 0,347 & 0,66842 & 0,385 & 0,78469 & 0,34 & 0,70732 \\
\hline 0,052 & 0,287 & 0,51415 & 0,354 & 0,72289 & 0,34 & 0,63158 & 0,379 & 0,75598 & 0,333 & 0,67317 \\
\hline 0,063 & 0,283 & 0,49528 & 0,352 & 0,71084 & 0,335 & 0,60526 & 0,374 & 0,73206 & 0,327 & 0,6439 \\
\hline 0,073 & 0,281 & 0,48585 & 0,349 & 0,69277 & 0,331 & 0,58421 & 0,369 & 0,70813 & 0,322 & 0,61951 \\
\hline 0,083 & 0,278 & 0,4717 & 0,346 & 0,6747 & 0,327 & 0,56316 & 0,364 & 0,68421 & 0,319 & 0,60488 \\
\hline 0,104 & 0,274 & 0,45283 & 0,341 & 0,64458 & 0,322 & 0,53684 & 0,358 & 0,6555 & 0,312 & 0,57073 \\
\hline 0,125 & 0,271 & 0,43868 & 0,337 & 0,62048 & 0,317 & 0,51053 & 0,352 & 0,62679 & 0,306 & 0,54146 \\
\hline 0,167 & 0,266 & 0,41509 & 0,332 & 0,59036 & 0,311 & 0,47895 & 0,344 & 0,58852 & 0,298 & 0,50244 \\
\hline 0,208 & 0,262 & 0,39623 & 0,328 & 0,56627 & 0,305 & 0,44737 & 0,338 & 0,55981 & 0,292 & 0,47317 \\
\hline 0,25 & 0,259 & 0,38208 & 0,325 & 0,54819 & 0,302 & 0,43158 & 0,334 & 0,54067 & 0,287 & 0,44878 \\
\hline 0,375 & 0,254 & 0,35849 & 0,32 & 0,51807 & 0,296 & 0,4 & 0,328 & 0,51196 & 0,277 & 0,4 \\
\hline 0,5 & 0,251 & 0,34434 & 0,318 & 0,50602 & 0,293 & 0,38421 & 0,326 & 0,50239 & $0,27 \overrightarrow{1}$ & $0,37 \overline{073}$ \\
\hline 1 & 0,245 & 0,31604 & 0,305 & 0,42771 & 0,282 & 0,32632 & 0,307 & 0,41148 & 0,258 & 0,30732 \\
\hline 1,5 & 0,234 & 0,26415 & 0,296 & 0,37349 & 0,274 & 0,28421 & 0,296 & 0,35885 & 0,249 & 0.26341 \\
\hline 2 & 0,228 & 0,23585 & 0,29 & 0,33735 & 0,269 & 0,25789 & 0,289 & 0,32536 & 0,243 & 0,23415 \\
\hline 3 & 0.22 & 0,19811 & 0,282 & 0.28916 & 0.262 & 0.22105 & 0,28 & 02823 & 0,235 & 0,19512 \\
\hline 4 & 0,215 & 0,17453 & 0,277 & 0,25904 & 0,257 & 0,19474 & 0,273 & 0,2488 & 0,23 & 0,17073 \\
\hline 5 & 0,211 & 0,15566 & 0,273 & 0,23494 & 0,254 & 0,17895 & 0,268 & 0,22488 & 0,226 & 0,15122 \\
\hline 10 & 0,201 & 0,10849 & 0,261 & 0,16265 & 0,243 & 0,12105 & 0,254 & 0,15789 & 0,216 & 0,10244 \\
\hline 15 & 0,195 & 0,08019 & 0,254 & 0,12048 & 0,237 & 0,08947 & 0,246 & 0,11962 & 0,21 & 0,07317 \\
\hline 20 & 0,19 & 0,0566 & 0,248 & 0,08434 & 0,233 & 0,06842 & 0,24 & 0,09091 & 0,207 & 0,05854 \\
\hline 25 & 0,187 & 0,04245 & 0,244 & 0,06024 & 0,229 & 0,04737 & 0,235 & 0,06699 & 0,204 & 0,0439 \\
\hline 30 & 0,184 & 0,0283 & 0,24 & 0,03614 & 0,226 & 0,03158 & 0,231 & 0,04785 & 0,201 & 0,02927 \\
\hline 35 & 0,182 & 0,01887 & 0,237 & 0,01807 & 0,224 & 0,02105 & 0,227 & 0,02871 & 0,199 & 0,01951 \\
\hline 40 & 0,18 & 0,00943 & 0,236 & 0,01205 & 0,222 & 0,01053 & 0,224 & 0,01435 & 0,197 & 0,00976 \\
\hline 45 & 0,178 & 0 & 0,234 & 0 & 0,22 & 0 & 0,221 & 0 & 0,195 & 0 \\
\hline & 3 & & & & & & & & & \\
\hline
\end{tabular}


Tabela 02 - Dados de umidade $(\theta)$ em função do tempo $(\mathrm{t})$, para cada profundidade, pelo método da tensiometria, para profundidade de $90 \mathrm{~cm}$ a $135 \mathrm{~cm}$.

\begin{tabular}{|c|c|c|c|c|c|c|c|c|}
\hline Tempo(X) & Teha90(Y) & w9o(r) & Te ha $105(\mathrm{Y})$ & W105(Y) & e tha $120(Y)$ & W120(Y) & Te na $135 \mathrm{~m})$ & w135n \\
\hline 0 & 0,382 & 0,95767 & 0,373 & 096 & 0,391 & 0,95187 & 0,385 & 0,97253 \\
\hline 0,01 & 0,372 & 0,90476 & 0,363 & 0,90286 & 0,385 & 0,91979 & 0,379 & 0,93956 \\
\hline 0,021 & 0,362 & 0,85185 & 0,353 & 0,84571 & 0,377 & 0,87701 & 0,375 & 0,91758 \\
\hline 0,031 & 0352 & 0,79894 & 0,345 & 0,8 & 0,37 & 0,83967 & 0,37 & 0,89011 \\
\hline 0,042 & 0,344 & 0,75661 & 0,338 & 0,76 & 0,363 & 0,80214 & 0,366 & 0,86813 \\
\hline 0,052 & 0,337 & 0,71958 & 0,331 & 0,72 & 0,358 & 0,7754 & 0,361 & 0,84066 \\
\hline 0,063 & 0331 & 0,68783 & 0,325 & 0,68571 & 0,363 & 0,74866 & 0,357 & 0,81868 \\
\hline 0,073 & 0,326 & 0,66138 & 0,321 & 0,65286 & 0,348 & 0,72193 & 0,354 & 0,8022 \\
\hline 0,083 & 0,321 & 0,63492 & 0,317 & 0,64 & 0,343 & 0,69519 & 0,35 & 0,78022 \\
\hline 0,104 & 0,313 & 0,59259 & 0,31 & 0,6 & 0,335 & 0,65241 & 0,344 & 0,74725 \\
\hline 0,125 & 0,306 & 0,5566 & 0,305 & 0,57143 & 0,329 & 0,62032 & 0,338 & 0,71429 \\
\hline 0,167 & 0297 & 0,50794 & 0.296 & 052 & 0319 & 0,56684 & 0,328 & 0,65934 \\
\hline 0206 & 0291 & 0,47619 & 029 & 0,48571 & 0,312 & 0,52941 & 0,32 & 0,61538 \\
\hline 025 & 0286 & 0.44974 & 0286 & 0,46286 & 0,307 & 0,50267 & 0,314 & 0,58242 \\
\hline 0,375 & 0,278 & 0,40741 & 0277 & 0,41143 & 0298 & 0,45455 & 0,303 & 0,52198 \\
\hline 0,5 & 0274 & 0,38624 & 0273 & 0,38857 & 0293 & 0,42781 & 0.298 & 0,49451 \\
\hline 1 & 0261 & 0,31746 & 0.261 & 0,32 & 0276 & 0,3369 & 0279 & 0,39011 \\
\hline 1,5 & 0.253 & 0,27513 & 0253 & 0,27429 & 0267 & 0,28877 & 0.269 & 0,33516 \\
\hline 2 & 0.247 & 0,24339 & 0247 & 024 & 0261 & 0,25668 & 0262 & 0,2967 \\
\hline 3 & 0239 & 0,20106 & 024 & 0,2 & 0,253 & 0,2139 & 0253 & 0,24725 \\
\hline 4 & 0235 & 0,17989 & 0236 & 0,17714 & 0248 & 0,18717 & 0246 & 0,20879 \\
\hline 5 & 0232 & 0,16402 & 0233 & 0,16 & 0.244 & 0,16578 & 0242 & 0,18681 \\
\hline 10 & 0.221 & 0,10582 & 0226 & 0,12 & 0234 & 0,1123 & 0232 & 0,13187 \\
\hline 15 & 0216 & 0,07937 & 0221 & 0,09143 & 0228 & 0,08021 & 0226 & 0,0989 \\
\hline 20 & 0212 & 0,0582 & 0218 & 0,07429 & 0224 & 0,05882 & 0222 & $0,07 \oplus 92$ \\
\hline 25 & 0209 & 0,04233 & 0215 & 0,05714 & 0221 & 0,04278 & 0218 & 0,05495 \\
\hline 30 & 0206 & 0,02646 & 0212 & 0,04 & 0.218 & 0,02674 & 0,214 & 0,03297 \\
\hline 35 & 0204 & 0,01587 & 0209 & 0,02286 & 0216 & 0,01604 & 0211 & 0,01648 \\
\hline 40 & 0,202 & 0,00529 & 0207 & 0,01143 & 0.214 & 0,00535 & 0209 & 0,00549 \\
\hline 45 & 0201 & 0 & 0,205 & 0 & 0213 & 0 & 0208 & 0 \\
\hline
\end{tabular}

Neste estudo, baseado em alguns resultados iniciais já obtidos e citados na literatura, (Guerrini et al., 1997), foi analisado o movimento vertical da água no solo durante um processo de infiltração, à semelhança do movimento horizontal, que sendo também um processo de difusão, pode ser comparado com o movimento Browniano fracionário, um processo fractal já citado anteriormente. A partir dos dados de umidade em função do tempo, obtidos pela técnica da tensiometria (Bacchi, 1988) em cada posição, foi feito um ajuste dos dados por uma equação de três parâmetros (bipotência) proposta por Guerrini \& Swartzendruber (1998), para umidade normalizada $(\omega)$ : 


$$
\omega(t)=\left[1-\left(\frac{t i}{t s}\right)^{m}\right] /\left[1-A \times\left(\frac{t i}{t s}\right)^{m}\right]
$$

onde $t i, m$ e $A$ são parâmetros de ajuste da equação proposta sendo que $m>0$ e $A<1, t i=$ $t$ (em dias) para $\theta=\theta \mathrm{i}\left(\mathrm{cm}^{3} / \mathrm{cm}^{3}\right.$, umidade em cada instante), $t s$ (em dias) corresponde ao tempo na umidade na saturação, ou seja, no instante inicial,.

A umidade normalizada permite uma base comum de comparação entre diversos tipos de solo e a relação n versus $\theta$ foi convertida para uma base normalizada $n$ versus $\omega$ :

$$
\omega=\frac{\left(\theta-\theta_{i}\right)}{\left(\theta_{s}-\theta_{i}\right)}
$$

onde: $\theta \mathrm{i}$ e $\theta$ s são umidade inicial e final respectivamente.

Para a determinação dos valores de $t$ no conjunto $(x, t)$ para dada umidade $\theta$, a maneira mais conveniente para a solução de $t$ na eq. 17 é:

$$
t=\left[\frac{1-\omega(t)}{1-\omega(t) \times A}\right]^{\frac{1}{m}} \times t s
$$

Portanto, para uma determinada umidade, o $\boldsymbol{t}$ associado com um dado valor de $\boldsymbol{x}$ (posição, em cm) é calculado pela eq. 19, usando a umidade em questão e os três parâmetros da curva ajustada pertencentes ao ponto $x$, e que são $t s, A$ e $\boldsymbol{m}$.

Foi testado também outro modelo, proposto pelos mesmos autores, que é a equação de Weibull, um modelo estatístico:

$$
\omega(\mathrm{t})=1-\mathrm{e}^{-b(t s-t)^{c}}
$$


onde: $b$ e $c$ são parâmetros de escala e de forma respectivamente e ts é o tempo na umidade de saturação.

Após o ajuste de umidade em função do tempo, para análise da posição da umidade no tempo, foi utilizada a equação proposta por Guerrini (1992); Guerrini \& Swartzendruber (1994):

$$
x=\lambda t^{n}
$$

onde: $\lambda$ é uma função semelhante à variável de Boltzman, $x$ é a posição de umidade, $t$ é o tempo considerado e $n$ é o parâmetro de ajuste da eq. (21).

Baseando-se no estudo de Feder (1988), o expoente $\boldsymbol{n}$ da equação assemelha-se ao expoente $\mathrm{H}$ de Hurst $(\mathrm{n}>0,50)$ para fluxos verticais. $\mathrm{O}$ autor introduz o conceito de movimento persistente $(\mathrm{H}>0,50)$ que é a correlação entre incrementos futuros e passados, ou seja, se há um incremento positivo no evento passado isso irá se repetir no evento futuro, que parece ser o caso do movimento vertical da água no solo e o movimento antipersistente $(\mathrm{H}<0,50$ - movimento horizontal da água no solo) um incremento no passado, reflete num decréscimo no futuro e vice-versa.

Assim, neste trabalho, através das curvas dadas pela relação do deslocamento de umidade $(x)$ em função do tempo $(t)$ para cada nível de umidade (desde o solo saturado ao secamento) foi obtido o parâmetro $n$ da eq. (21) e comparou-se com o expoente H de Hurst, baseando-se nos trabalhos de Feder (1988), Guerrini \& Swartzendruber (1994,1997), Santos (1997); Santos \& Guerrini (1998). 


\section{RESULTADOS E DISCUSSÃO}

Baseando-se nos dados de Bacchi (1988) ajustou-se os valores do tempo para cada posição e em cada umidade normalizada ( $\omega$ ) (Anexo I), pela equação bipotência proposta por Guerrini \& Swartzendruber (1998).

$\mathrm{O}$ modelo proposto se ajustou bem aos dados experimentais, com os valores de $\chi^{2}$ inferiores à 0,00088 (Anexo I).

Após o ajuste pela equaçào bipotência, os valores dos parâmetros $t s, A$ e $m$ foram utilizados na eq. 19 e calculou-se o tempo para cada umidade normalizada $(\omega)$, em função da profundidade, cujos resultados são apresentados na Tabela 03 .

Tabela 03 - Valores do tempo $(t)$ em cada posição (conjunto $x, t$ ) para cada umidade normalizada

\begin{tabular}{|c|c|c|c|c|c|c|c|c|c|}
\hline$w(x)$ & T15(Y) & $T 30(Y)$ & T45(Y) & $T 60(Y)$ & $775(Y)$ & T90 (Y) & T105(Y) & $T 120(Y)$ & $\mathrm{T} 135(\mathrm{Y})$ \\
\hline 0 & 5068794 & 52,38589 & 81,96174 & 74,02942 & 128,32781 & 2565478 & 1129,41658 & 14584402 & 12725689 \\
\hline 0,1 & 33,42077 & 40,0505 & 6355853 & 58,9265 & 105,00824 & 21386236 & 94359224 & 122,69925 & 108,32256 \\
\hline 0,2 & 20,97976 & 29,6656 & 4783166 & 45,65974 & 83,91832 & 174,49457 & 77180884 & 101,14555 & 90,47064 \\
\hline 0,3 & 12,37505 & 21,10907 & 34,65372 & 34,19357 & 65,08361 & 13855309 & 614,56235 & 8125206 & 73,76308 \\
\hline 0,4 & 6,72812 & 1425164 & 23,88754 & 24,48853 & 48,53347 & 106,16549 & 472,43681 & 63,10084 & 5827451 \\
\hline 0,5 & 327246 & 8,95536 & 15,38384 & 16,50006 & 34,3023 & 77,4852 & 346,13659 & 46,79185 & 44,09729 \\
\hline 0,6 & 1,35447 & 5,07133 & 8,97778 & 10,17688 & 22,43155 & 52,70264 & 236,53918 & 32,45102 & 31,35005 \\
\hline 0,7 & 0,43437 & 2,43632 & 4,48358 & 5,45813 & 129731 & 32,06519 & 144,7895 & 2024495 & 20,19339 \\
\hline 0,8 & 0,08745 & 086694 & 1.68509 & 226828 & 5,996 & 15.91779 & 72,49306 & 10,41142 & 1086348 \\
\hline 0,9 & 0,00565 & 0,1482 & 0,31628 & 0,50557 & 1,60274 & 4,80765 & 2221722 & 3,34035 & 376443 \\
\hline
\end{tabular}

* $\omega=$ umidade normalizada variando de 0,0 a 0,9; T15 corresponde ao tempo necessário para que o ponto $15 \mathrm{~cm}$ seja atingida pela umidade normalizada correspondente, e assim, sucessivamente, até à profundidade de $135 \mathrm{~cm}$. 
Observa-se que em função dos dados apresentados, nas diferentes profundidades, alguns valores apresentaram desvios em relação aos demais.

Em função disso, no presente trabalho são apresentados seis casos de ajuste dos dados experimentais, uma vez que, como os dados analisados foram publicados na literatura (Bacchi, 1988), não se pode analisar possíveis erros sistemáticos ou de precisão.

Nas Tabelas 01 e 02 são apresentados os dados originais de medidas de umidade em função do tempo, no processo de infiltração vertical, em processo de secamento (Bacchi,1988).

Nas Tabelas 04, 05, 06 e 07 são apresentados os dados de ajuste, pela eq. 21, que originou os valores do expoente $\boldsymbol{n}$ que foram comparados com o expoente $\mathrm{H}$ de Hurst, como é definido por Feder (1988) e utilizado para modelar fenômenos naturais que variam no tempo. Os expoentes $\boldsymbol{n}$ diferentes de 0,5 caracterizam o movimento da água no solo - um processo de difusão - como um movimento browniano fracionário.

Os dados de ajuste encontram-se no Anexo II. Os seis casos analisados são apresentados a seguir:

Caso 1: o ajuste foi feito sem os três últimos pontos experimentais, referentes à profundidade de 105, 120 e $135 \mathrm{~cm}$.

Caso 2: ajustes sem os dois últimos pontos (120 e $135 \mathrm{~cm})$.

Caso 3: ajustes com todos os pontos experimentais.

Caso 4: ajustes somente com a retirada do ponto $105 \mathrm{~cm}$ (maior tempo de infiltração de água).

Caso 05: sem os pontos que aparentemente apresentaram maiores desvios em relação aos demais: $90 \mathrm{~cm}$ e $105 \mathrm{~cm}$.

Caso 6: foram feitos ajustes após o estudo e incorporação de erros de ajuste para $\omega$ vs. $t$ através da equação de propagação de erros aplicada na eq. (19): 


$$
e t=\sqrt{\left(\frac{\partial t}{\partial t s}\right)^{2} \times e t s^{2}+\left(\frac{\partial t}{\partial a}\right)^{2} \times e a^{2}+\left(\frac{\partial t}{\partial m}\right)^{2} \times e m^{2}}
$$

onde: $\frac{\partial t}{\partial t s}, \frac{\partial t}{\partial a} e \frac{\partial \mathrm{t}}{\partial \mathrm{m}}$ são as derivadas parciais da equação de ajuste de $t$ vs $\omega$ e $e t s$, ea e em são os valores dos erros de ajuste de cada um dos parâmetros.

Os seis casos aqui apresentados foram uma tentativa de se observar a tendência dos dados experimentais de Bacchi (1988) quando eliminou-se alguns pontos experimentais, uma vez que alguns dos mesmos apresentaram valores discrepantes devido, possivelmente, a algum erro sistemático de medida, no ajuste do tempo em função da posição.

Nas Tabelas 04, 05, 06, 07 e 08 são apresentados os valores do expoente $\boldsymbol{n}$ da equação $x=\lambda \times t^{n}$ para os valores de umidade normalizada ( $\left.\omega\right)$ variando de 0,0 a 0,9 , em função dos ajustes estudados.

Tabela 04 - Valores do expoente $\boldsymbol{n}$ do ajuste $\boldsymbol{x}$ vs. $\boldsymbol{t}$, para cada umidade normalizada: Caso 01 e Caso 02

\begin{tabular}{|c|c|c|c|c|c|c|c|c|}
\hline & \multicolumn{6}{|c|}{ Caso 1} & \multicolumn{4}{c|}{ Caso 2 } \\
\hline$\omega$ & $\chi^{2}$ & $\mathrm{R}^{2}$ & $n$ & Erro $( \pm)$ & $\chi^{2}$ & $\mathrm{R}^{2}$ & $n$ & Erro $( \pm)$ \\
\hline 0,0 & 175,44102 & 0,86076 & 0,63549 & 0,1535 & 389,69456 & 0,74686 & 0,61185 & 0,20659 \\
\hline 0,1 & 147,06578 & 0,88328 & 0,59737 & 0,13192 & 279,21 & 0,82272 & 0,31233 & 0,07574 \\
\hline 0,2 & 123,3611 & 0,90209 & 0,55894 & 0,11339 & 251,68611 & 0,8402 & 0,30404 & 0,06978 \\
\hline 0,3 & 103,46358 & 0,91789 & 0,52064 & 0,09733 & 224,9573 & 0,85717 & 0,29491 & 0,06391 \\
\hline 0,4 & 86,67563 & 0,93121 & 0,48233 & 0,08326 & 198,91443 & 0,87371 & 0,28482 & 0,05808 \\
\hline 0,5 & 72,4314 & 0,94251 & 0,44381 & 0,0708 & 173,40618 & 0,8899 & 0,27356 & 0,05225 \\
\hline 0,6 & 60,26567 & 0,95217 & 0,40426 & 0,05961 & 148,21027 & 0,9059 & 0,26077 & 0,0463 \\
\hline 0,7 & 49,78242 & 0,96049 & 0,36284 & 0,04939 & 122,96543 & 0,92193 & 0,24583 & 0,04013 \\
\hline 0,8 & 40,61147 & 0,96777 & 0,31734 & 0,039751 & 96,98055 & 0,93843 & 0,2274 & 0,03343 \\
\hline 0,9 & 32,2888 & 0,97437 & 0,26162 & 0,02954 & 68,46531 & 0,95653 & 0,20152 & 0,02548 \\
\hline
\end{tabular}


Tabela 05 - Valores do expoente $\boldsymbol{n}$ do ajuste $\boldsymbol{x}$ vs. $\boldsymbol{t}$, para cada umidade normalizada: Caso 03 e Caso 04

\begin{tabular}{|c|c|c|c|c|c|c|c|c|}
\hline & \multicolumn{5}{|c|}{ Caso 3} & \multicolumn{4}{c|}{ Caso 4} \\
\hline$\omega$ & $\chi^{2}$ & $\mathrm{R}^{2}$ & $n$ & Erro $( \pm)$ & $\chi^{2}$ & $\mathrm{R}^{2}$ & $n$ & Erro $( \pm)$ \\
\hline 0,0 & 902,39737 & 0,61109 & 0,59732 & 0,25754 & 956,44196 & 0,60617 & 0,60495 & 0,27564 \\
\hline 0,1 & 1113,01831 & 0,52032 & 0,24404 & 0,12197 & 864,00249 & 0,64423 & 0,58882 & 0,24847 \\
\hline 0,2 & 1054,19394 & 0,54567 & 0,24387 & 0,115 & 778,13438 & 0,67951 & 0,56884 & 0,22407 \\
\hline 0,3 & 993,26132 & 0,57193 & 0,24248 & 0,10808 & 698,41735 & 0,71242 & 0,54648 & 0,2018 \\
\hline 0,4 & 929,76057 & 0,5993 & 0,24003 & 0,10113 & 623,12475 & 0,74342 & 0,5219 & 0,18104 \\
\hline 0,5 & 862,92115 & 0,62891 & 0,23621 & 0,094051 & 551,31471 & 0,77299 & 0,49506 & 0,16127 \\
\hline 0,6 & 791,43573 & 0,6589 & 0,23108 & 0,086711 & 481,70060 & 0,80165 & 0,46548 & 0,14191 \\
\hline 0,7 & 712,93076 & 0,69274 & 0,22402 & 0,07883 & 412,63881 & 0,83009 & 0,43195 & 0,12228 \\
\hline 0,8 & 622,44334 & 0,73174 & 0,21427 & 0,06991 & 341,49627 & 0,85938 & 0,39165 & 0,1013 \\
\hline 0,9 & 506,01395 & 0,78192 & 0,19883 & 0,05845 & 262,06584 & 0,89209 & 0,33636 & 0,0765 \\
\hline
\end{tabular}

Tabela 06 - Valores do expoente $\boldsymbol{n}$ do ajuste $\boldsymbol{x}$ vs. $\boldsymbol{t}$, para cada umidade normalizada: Caso 05.

\begin{tabular}{|c|c|c|c|c|}
\hline & \multicolumn{4}{|c|}{ Caso 5 } \\
\hline$\omega$ & $\chi^{2}$ & $\mathrm{R}^{2}$ & $n$ & Erro $( \pm)$ \\
\hline 0,0 & 384,91279 & 0,85744 & 1,4545 & 0,37065 \\
\hline 0,1 & 308,3676 & 0,88579 & 1,31873 & 0,30214 \\
\hline 0,2 & 249,38771 & 0,90763 & 1,19438 & 0,24741 \\
\hline 0,3 & 202,83223 & 0,92488 & 1,0787 & 0,20248 \\
\hline 0,4 & 165,41029 & 0,93874 & 0,96943 & 0,1649 \\
\hline 0,5 & 134,90316 & 0,95004 & 0,8645 & 0,13308 \\
\hline 0,6 & 109,733 & 0,95936 & 0,76203 & 0,10587 \\
\hline 0,7 & 88,70509 & 0,96715 & 0,65963 & 0,08235 \\
\hline 0,8 & 70,81368 & 0,97377 & 0,55322 & 0,06159 \\
\hline 0,9 & 54,92905 & 0,97966 & 0,43214 & 0,04224 \\
\hline
\end{tabular}


Tabela 07 - Valores do expoente $n$ do ajuste $\boldsymbol{x}$ vs. $\boldsymbol{t}$, para alguns valores de umidade normalizada $(\omega)$, com incorporação do erro no tempo, com todos os pontos experimentais.

\begin{tabular}{|c|c|c|c|c|c|c|}
\hline \multicolumn{5}{|c|}{ Caso 6 } & (+ erro) & \multicolumn{3}{|c|}{ Caso 6 (- erro) } \\
\hline$\omega$ & $\chi^{2}$ & $\mathrm{R}^{2}$ & $n$ & $\chi^{2}$ & $\mathrm{R}^{2}$ & $n$ \\
\hline 0,0 & 1201,47611 & 0,37701 & 0,14569 & & & 1,09682 \\
\hline 0,1 & 1267,77904 & 0,34263 & 0,24673 & 1276,6408 & 0,33804 & 0,24096 \\
\hline 0,5 & 985,07013 & 0,48922 & 0,23658 & 983,68742 & 0,48994 & 0,23623 \\
\hline 0,8 & 985,10375 & 0,48921 & 0,23654 & 986,32291 & 0,48857 & 0,2363 \\
\hline 0,9 & 577,80469 & 0,7004 & 0,19889 & 578,80055 & 0,69988 & 0,19871 \\
\hline
\end{tabular}

Os melhores ajustes observados foram obtidos quando se eliminou os três últimos pontos experimentais (Caso 1), referentes à profundidade de $105 \mathrm{~cm}, 120 \mathrm{~cm}$ e $135 \mathrm{~cm}, \mathrm{e}$ quando se eliminou somente o ponto correspondente a $105 \mathrm{~cm}$ de profundidade (caso 5). Porém, numa análise fractal do fenômeno de infiltração da água no solo, um melhor ajuste não significa que irá representar o melhor comportamento da natureza.

Nos casos 1 e 4 houve pouca variação do expoente $\boldsymbol{n}$ com valores próximos de 0,5, como pode ser visto na Figura 06 . Em razão disso, esses casos foram escolhidos para serem analisados com mais detalhe sob a ótica do caos e fractais. Entretanto, é necessário que fique claro o caso 5, por exemplo, poderia ser um bom representante do fenômeno (valores de $\chi^{2}$ menores), uma vez que não possuímos quantidades de dados experimentais suficientes para um maior subsídio na escolha dos casos analisados.

Observou-se também que, para a profundidade de $90 \mathrm{~cm}$, os tempos medidos para que o ponto considerado atingisse determinada umidade, foram significativamente maiores (no conjunto $x, t$ ) inclusive em relação às profundidades de $105 \mathrm{~cm}, 120 \mathrm{~cm}$ e 135 $\mathrm{cm}$. 
O final do processo de difusão da água no solo é mais rápido tanto para o molhamento como para o secamento. No caso do molhamento, a umidade de saturação caminha mais rapidamente que as umidades mais baixas, e no caso do secamento, as umidades baixas caminham mais rapidamente que a umidade de saturação.

Como pode ser visto nas Tabelas 04, 05, 06, 07 e 08, o cálculo da propagação de erros mostrou que não há variação significativa na função $\boldsymbol{n}(\omega)$ quando somado ou subtraído o erro propagado em $t$, segundo a eq. (23) (Caso 06).

Uma hipótese para os desvios dos valores observados seria em função da formação de "fingers" durante o processo de infiltração, causando um fluxo preferencial, influenciando na leitura dos tensiômetros nos pontos considerados. Como se sabe, fluxos preferenciais são causados pela instabilidade do fenômeno de infiltração da água no solo, uma das razões que o caracteriza como fractal.

Para os seis casos analisados, pelos valores dos parâmetros $\chi^{2}$ e $\mathrm{R}^{2}$, os melhores ajustes eram para os maiores teores de água no solo. Observa-se que quanto maior o teor de água no solo, maior a exatidão dos valores medidos em relação ao modelo adotado.

Fazendo-se uma análise do movimento da água no solo, observou-se que para a infiltração vertical, baseando-se nos dados de Bacchi (1988) e nos ajustes propostos, o valor do expoente $\boldsymbol{n}$ da equação potência proposta decresceu com o aumento da umidade, como pode ser observado na Figura 06, ou seja, no início do experimento (solo saturado) o expoente $\boldsymbol{n}$ foi menor, aumentando à medida que o solo secava. 


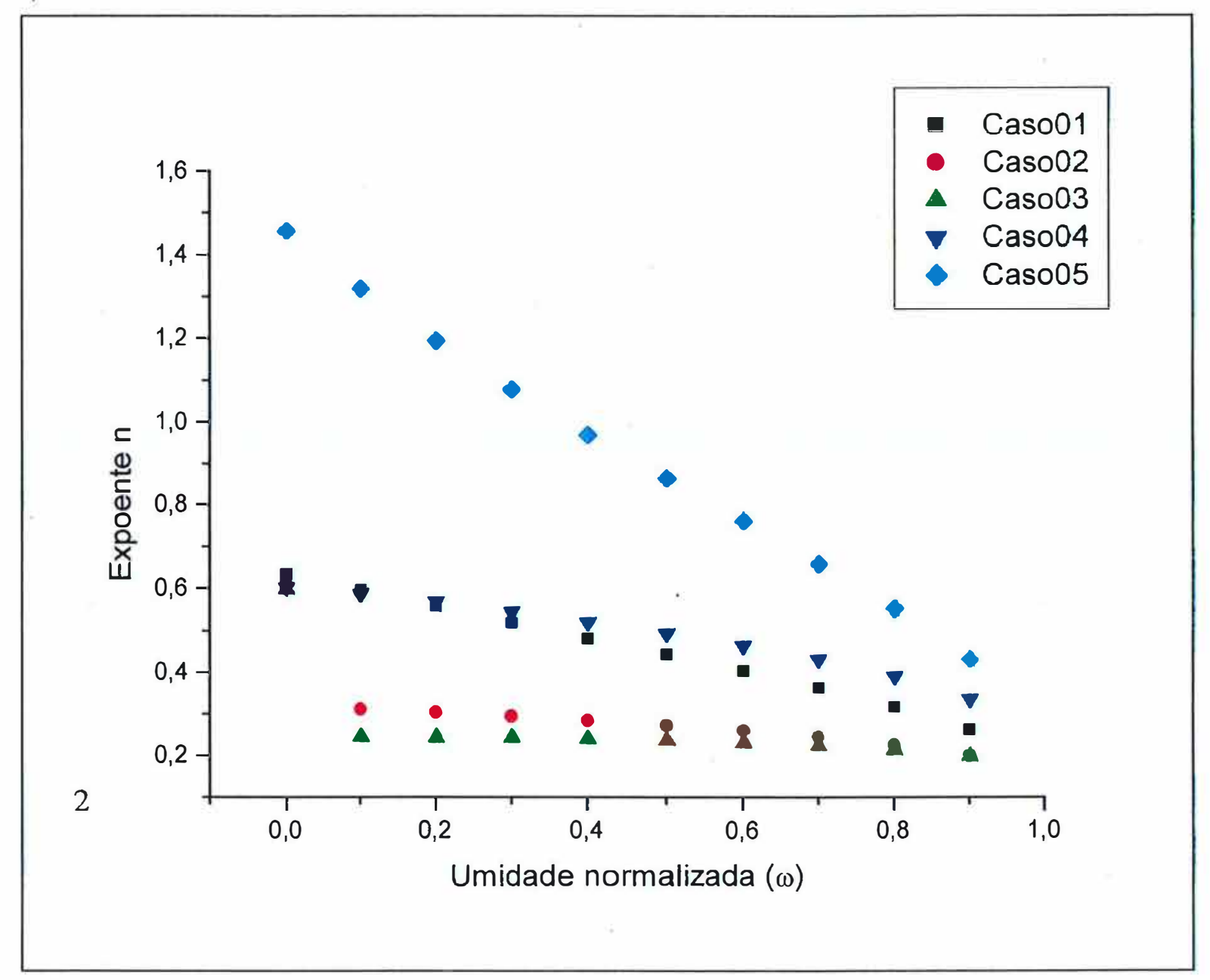

Figura 06 - Valores do expoente (n) em função da umidade normalizada para infiltração vertical (Caso 01, 02, 03, 04, 05).

A tendência de decréscimo no valor do expoente $\boldsymbol{n}$ foi observada nos seis casos analisados, com valores bastante próximos.

Fazendo-se a análise conjunta dos melhores resultados de ajuste para a infiltração vertical (Caso 01 e Caso 04) e infiltração horizontal de Santos (1997) (nível, horiz02 e horiz03) e Guerrini \& Swartzendruber (1994) (solos Russel e Salkum), tem-se a Figura 07: 


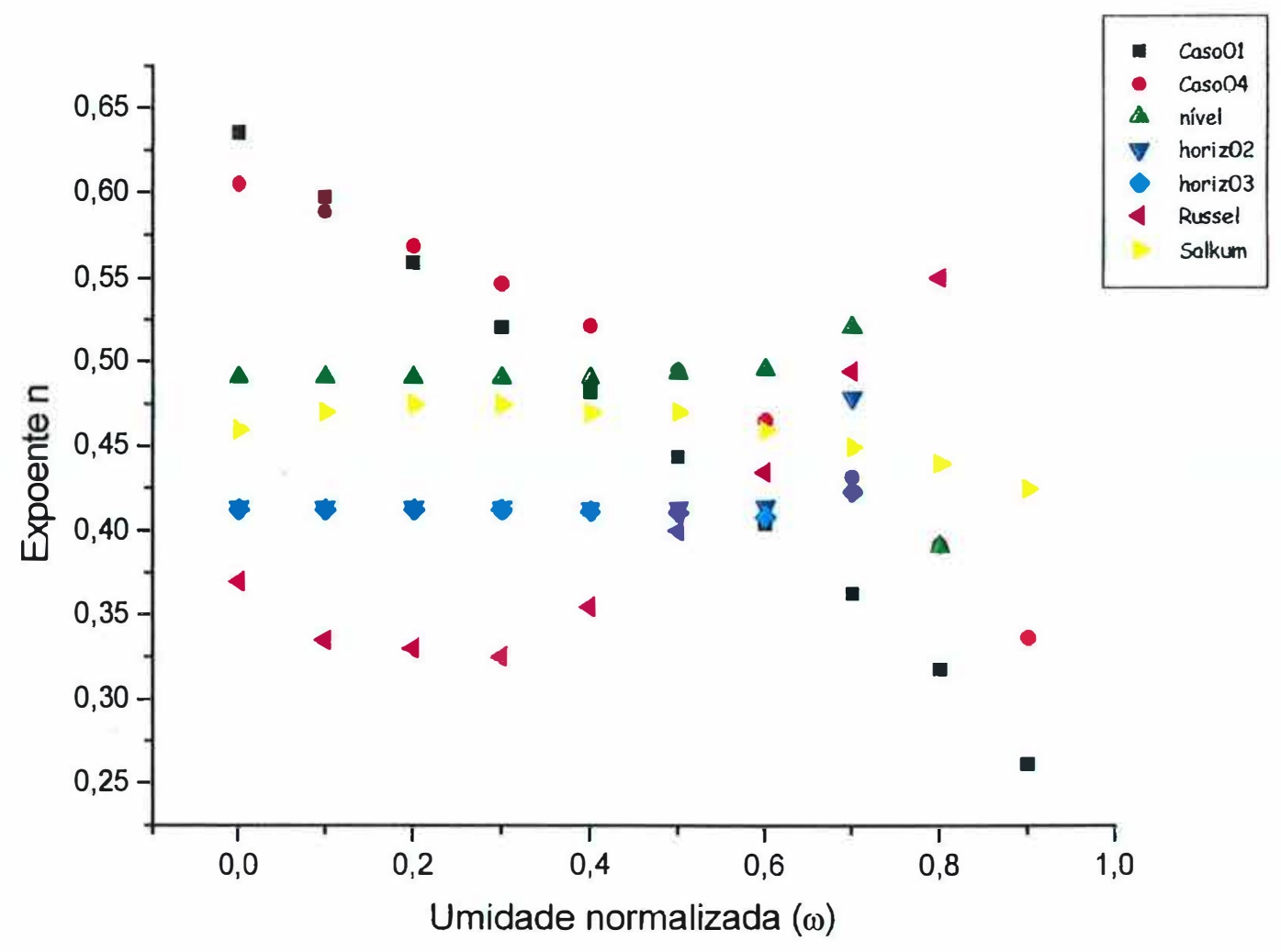

Figura 07 - Valores do expoente (n) em função da umidade normalizada para experimentos em colunas horizontais (nível, horiz02, horiz03, Russel e Salkum) e infiltração vertical (Caso 01 e Caso 04).

Observa-se na Figura 07 que pode haver um ponto comum para os valores do expoente $\boldsymbol{n}$ próximo do valor 0,5 para umidade normalizada (1) próxima de 0,5 a 0,6. Esse fato pode estar indicando um atrator nessa região, ou seja, um ponto para o qual a dinâmica do fenômeno converge. No entanto, aqui também, os dados disponíveis são insuficientes para se chegar numa posição mais conclusiva. Isso é significativo pois, quando o expoente $\boldsymbol{n}=0,5$ indica um Movimento Browniano Regular (rBm), ou seja, um 
processo de difusão regular modelado por um movimento browniano perfeito, onde não há dependência do tempo para as funções hídricas e nem efeito memória.

Segundo Guerrini \& Swartzendruber (1992), $D_{2}(t)=2 n t^{2 n-1}$ e quando $n=1 / 2$, $D_{2}(t)=1$. Se o expoente $n$ fosse $1, D_{2}(t)=2 t$, e haveria dependência do tempo para a difusividade na saturação.

Para todos os casos o expoente do tempo foi sempre diferente de 0,5 , e quando comparado com o expoente $\mathrm{H}$ de Hurst, temos o movimento browniano fracionário (Feder, 1988), como já comentado.

Na Figura 07 observa-se que o expoente $\boldsymbol{n}(\omega)$ é crescente para o processo de molhamento em fluxos horizontais nos trabalhos considerados e $\boldsymbol{n}(\omega)$ é decrescente para o processo de secamento em fluxos verticais (Guerrini \& Swartzendruber,1992; Santos, 1997; Santos \& Guerrini,1998).

A grande instabilidade no fenômeno e a pouca disponibilidade de dados para análises mais conclusivas podem ser vistas no trabalho de Pachespky \& Timlin (1998), que a partir de dados de infiltração horizontal da água no solo, publicados na literatura para cinco experimentos diferentes, observaram resultados contraditórios em relação ao comportamento do expoente $\boldsymbol{n}$ que não apresentou nenhuma tendência no modelo matemático proposto. Esses autores sugerem um modelo de ajuste que, a partir de determinado tempo, o fluxo da água no solo não assuma mais características fractais, não se caracterizando mais como um fenômeno de difusão.

Como o início do processo de difusão da água no solo é sempre mais lento, podese pensar numa força de atrito variável com o tempo para ambos os processos (molhamneto e secamento). Como em outros casos, aqui também, o atrito estático (início do movimento) é sempre maior que o atrito dinâmico (final do movimento) e seria uma hipótese para explicar as tendências contrárias observadas para variação da função $n(\omega)$. 


\section{CONCLUSÕES}

Baseando-se nos resultados dessa pesquisa, conclui-se serem necessários dados experimentais específicos para o estudo de infiltração vertical da água no solo, e a importância de se fazer um estudo de propagação de erros nas medidas experimentais.

Como já salientado, a pouca disponibilidade de informações referentes à análise fractal do movimento da água no solo dificulta a obtenção de resultados mais conclusivos. Entretanto, alguris pontos podem aqui ser mencionados:

1. O comportamento do expoente $\boldsymbol{n}$ para fluxos verticais teve uma relação inversa com o teor de água no solo, ou seja, decresceu com o aumento da umidade, ainda que de forma inesperada.

2. Quando comparou-se o movimento vertical com o movimento horizontal da água no solo, observou-se um ponto comum de valores do expoente $\boldsymbol{n}$ em torno de 0,5 com a umidade normalizada $(\omega)$ próxima de 0,5 a 0,6 , o que pode estar indicando a presença de um atrator nesta região.

3. $\mathrm{O}$ expoente $\mathrm{n}$ foi sempre diferente de 0,5 , indicando um movimento browniano fracionário ( $\mathrm{fBm}$ ) durante todo o processo analisado, o que está de acordo com a expectativa de Mandelbrot (1983) para fenômenos naturais fractais.

4. Os experimentos de fluxos horizontais em colunas de solo (molhamento) descritos na literatura e estes experimentos de secamento em fluxos verticais aqui analizados, indicam que o fenômeno fractal de infiltração da água no solo não está totalmente compreendido. Serão necessárias outras pesquisas mais específicas para se saber até onde e quando pode ser caracterizado o fenômeno como fractal, quais as 
relações das dimensões fractais da dinâmica da água com as dimensões fractais da estrutura do meio, etc. 

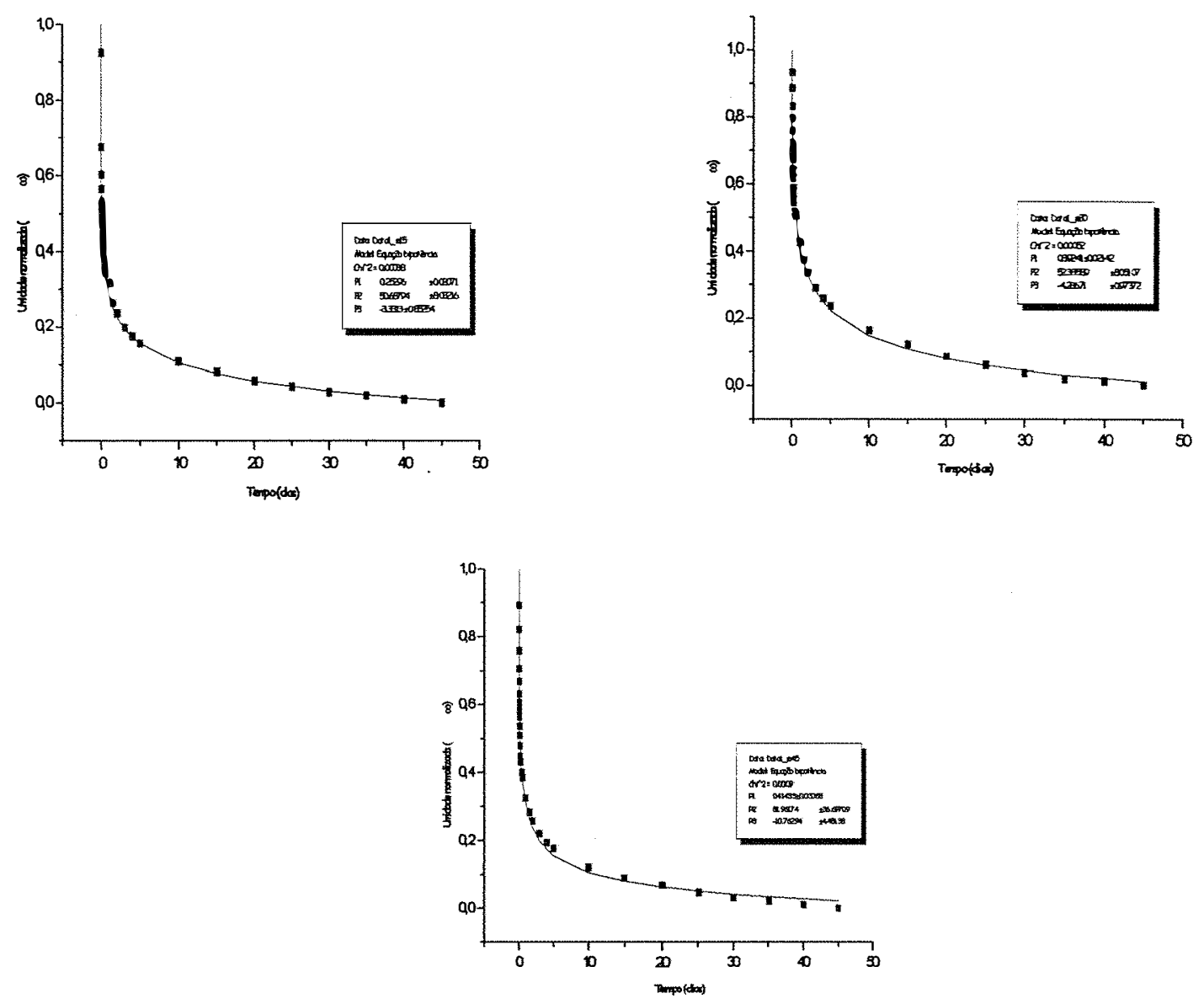

Figura 01 - Umidade normalizada $(\omega)$ em função do tempo (t), ajustada pela equação bipotência para as posições $15 \mathrm{~cm}, 30 \mathrm{~cm}$ e $45 \mathrm{~cm}$. 

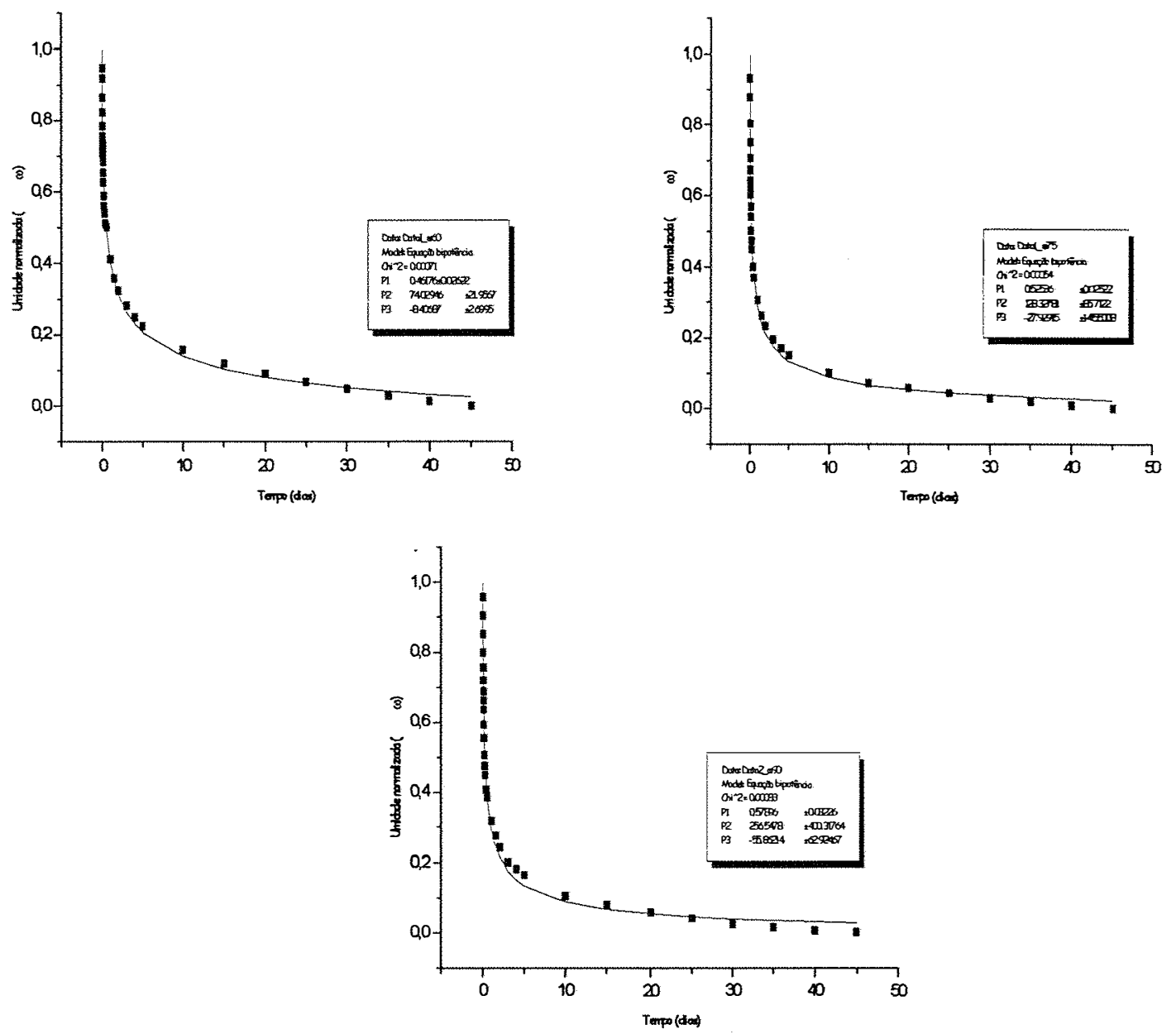

Figura 02 - Umidade normalizada $(\omega)$ em função do tempo (t), ajustada pela equação bipotência para as posições $60 \mathrm{~cm}, 75 \mathrm{~cm}$ e $90 \mathrm{~cm}$. 

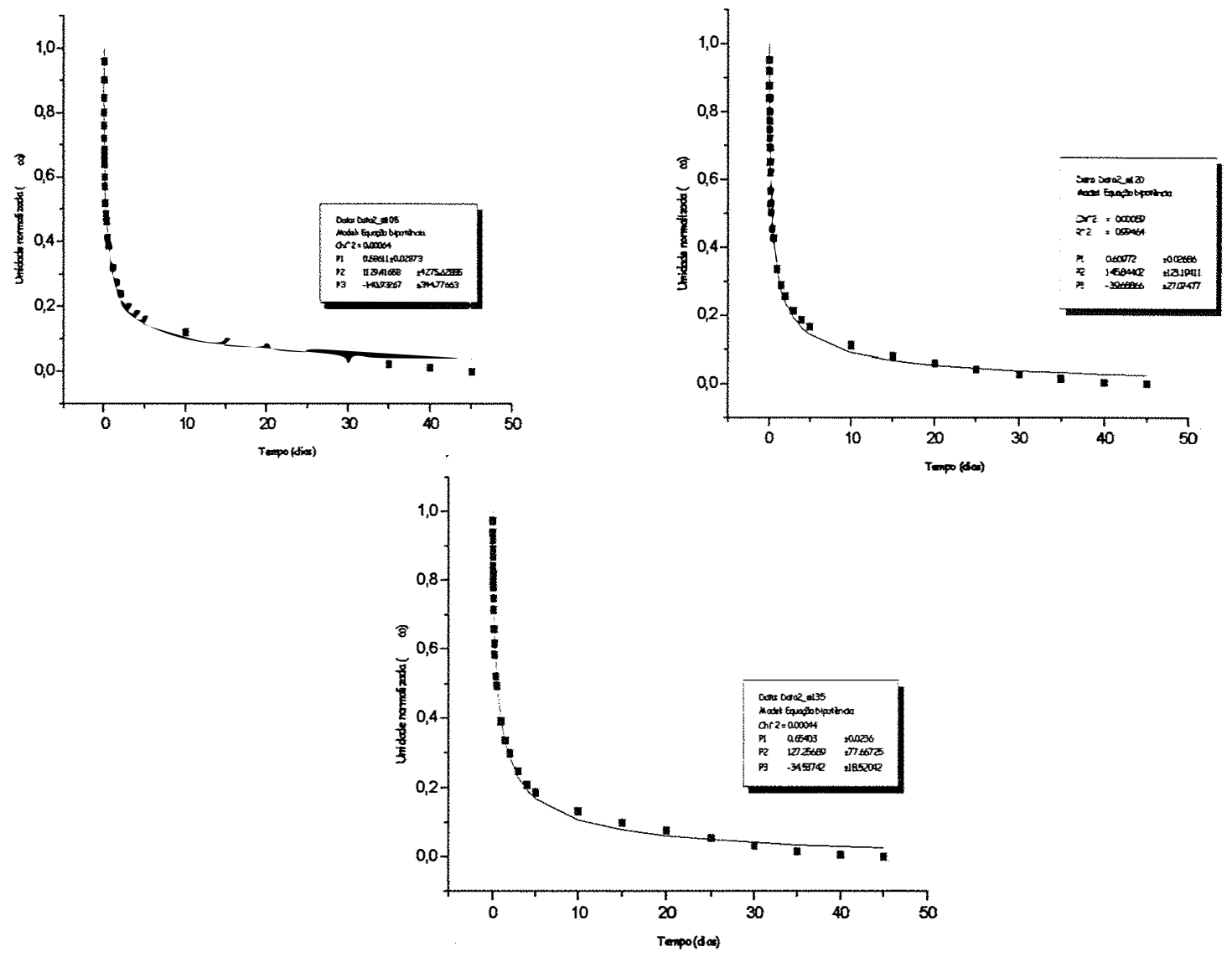

Figura 03 - Umidade normalizada $(\omega)$ em função do tempo $(t)$, ajustada pela equação bipotência para as posições $105 \mathrm{~cm}, 120 \mathrm{~cm}$ e $135 \mathrm{~cm}$. 


\section{ANEXO II}

Tabela 01 - Posição em cm de $x(\omega)$ em função do tempo (dias) em cada nível de umidade (Caso 1)

\begin{tabular}{|c|c|c|c|c|c|c|c|c|c|c|}
\hline Po siçāo(Y) & TWOO(X1) & TW01(X2) & TW02(X3) & TW03(X4) & TW04(X5) & TW05(X6) & TW06(XT) & TW07(X8) & TW08(X9) & TWO9(X10) \\
\hline 0 & 0 & 0 & 0 & 0 & 0 & 0 & 0 & 0 & 0 & $\overrightarrow{0}$ \\
\hline 15 & 50,68794 & 33,42077 & 20,97976 & 12,37505 & 6,72812 & $3,272.46$ & 1,35447 & 0,43437 & 0,08745 & 0,00565 \\
\hline 30 & 52,38589 & 40,0505 & 29,6656 & 21,10907 & 14,25164 & 8,95536 & 5,07133 & 2,43632 & 0,86694 & 0,1482 \\
\hline 45 & 81,96174 & 63,55853 & 47,83166 & 34,65372 & 23,88754 & 15,38384 & 8,97778 & 4,48358 & 1,68509 & 0,31628 \\
\hline 60 & 74,02942 & 58,92653 & 45,65974 & 34,19357 & 24,48853 & 16,50006 & 10,17688 & 5,45813 & 2,26828 & 0,50557 \\
\hline 75 & 128,32781 & 105,00824 & 83,91832 & 65,08361 & 48,53347 & 34,3023 & 22,43155 & 12,9731 & 5,996 & 1,60274 \\
\hline 90 & 256,5478 & 213,86236 & 174,49457 & 138,55309 & 106,16549 & 77,4852 & 52,70264 & 32,06519 & 15,91779 & 4,80765 \\
\hline
\end{tabular}
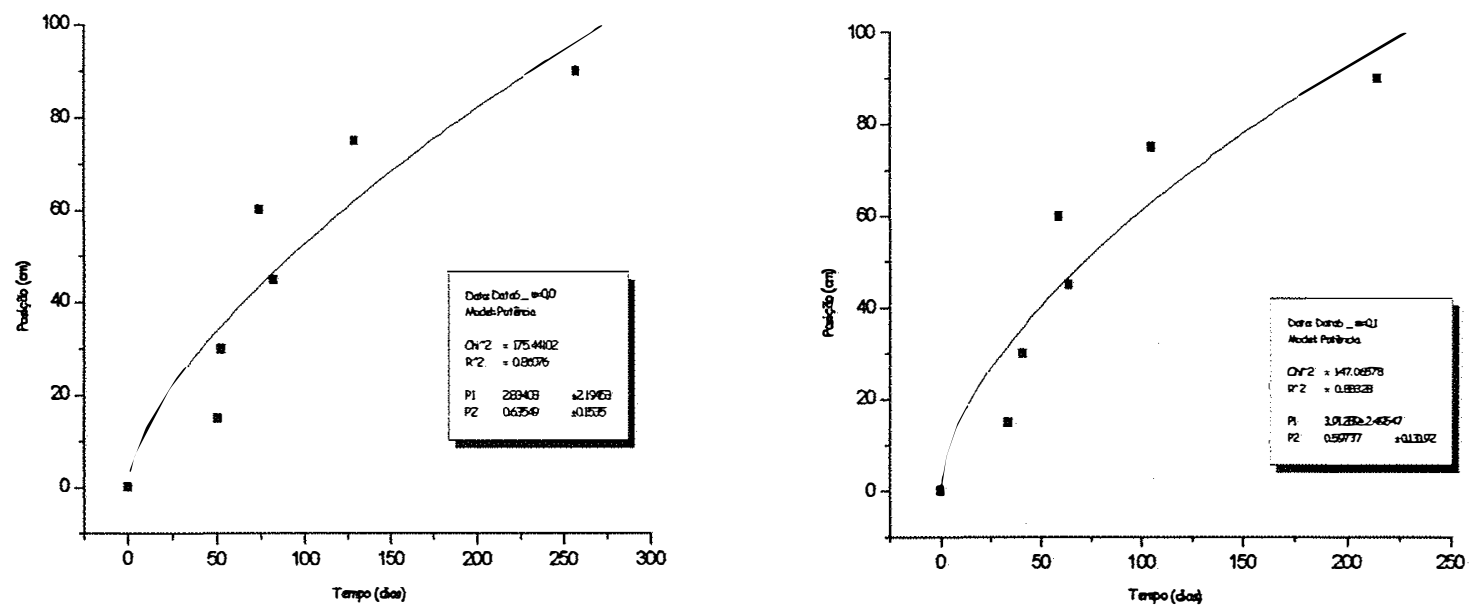

Figura 01 - Posição em cm de $x(\omega)$ em função do tempo (dias) para a obtenção da dimensão fractal, pelo modelo curva de potência, para umidades $\omega=0,0$ e $\omega=0,1$ (Caso 1). 

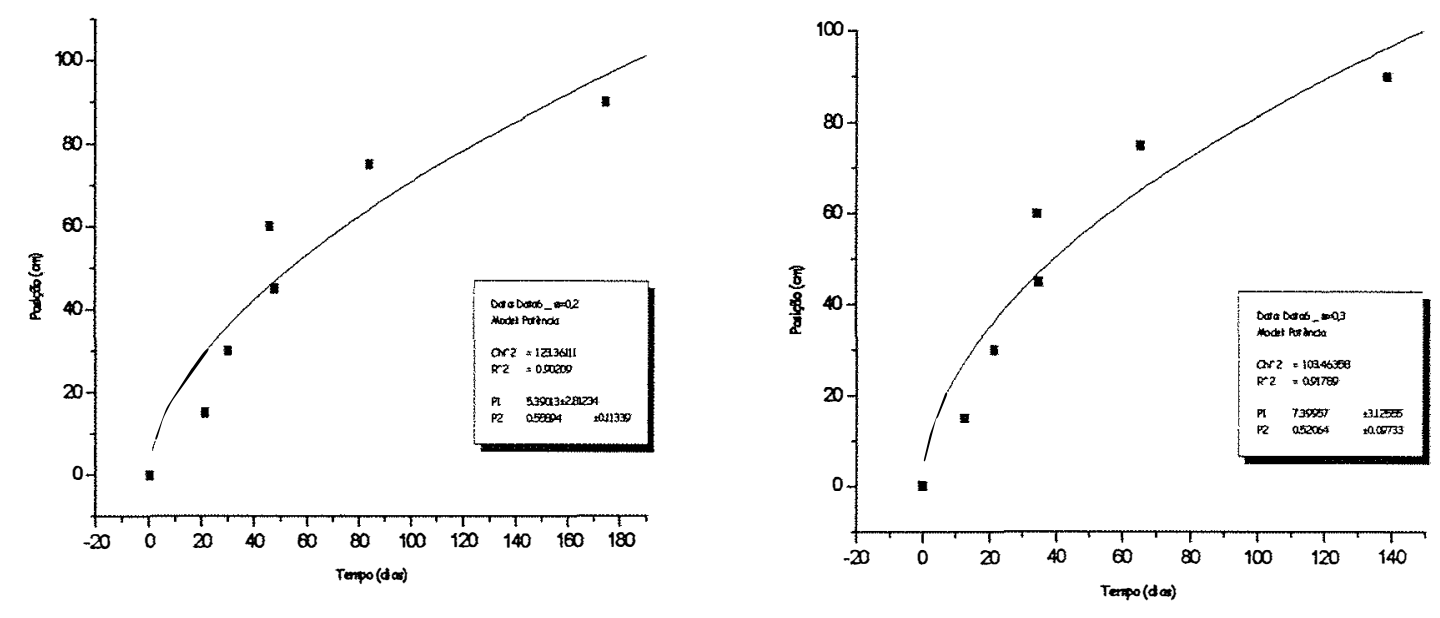

Figura 02 - Posição em $\mathrm{cm}$ de $x(\omega)$ em função do tempo (dias) para a obtenção da dimensão fractal, pelo modelo curva de potência, para umidades $\omega=0,2$ e $\omega=0,3$ (Caso 1).
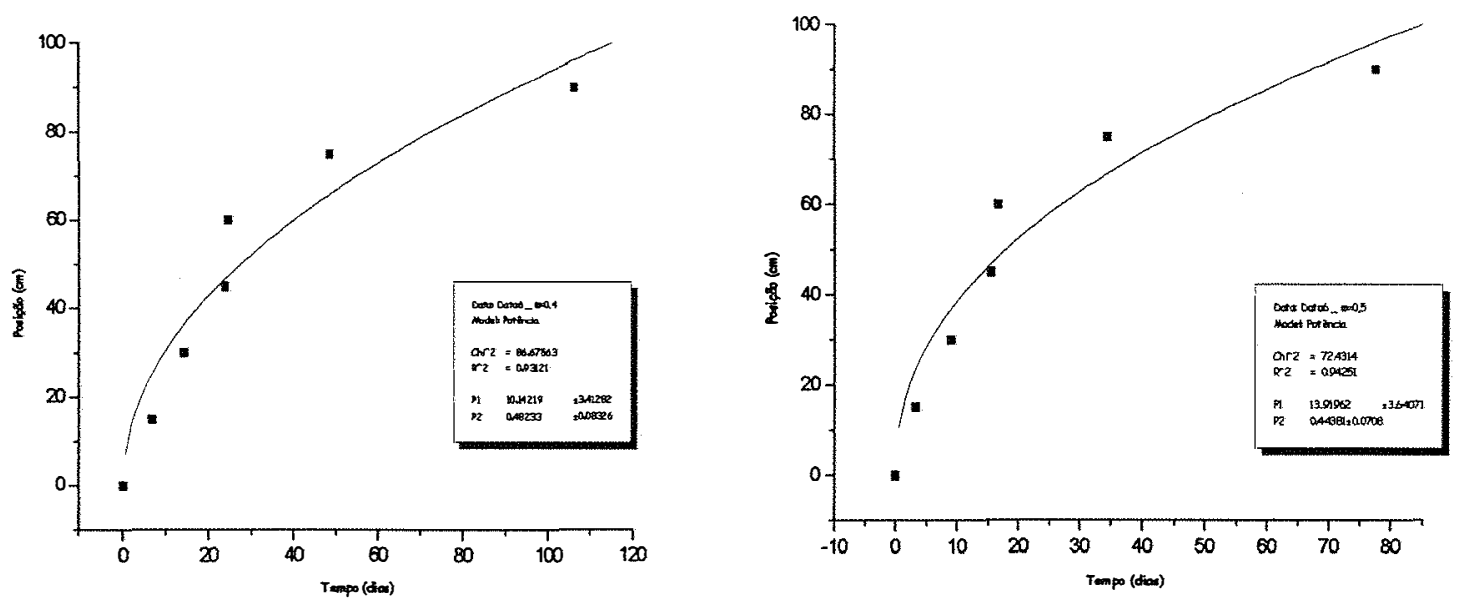

Figura 03 - Posição em cm de x ( $\omega)$ em função do tempo (dias) para a obtenção da dimensão fractal, pelo modelo curva de potência, para umidades $\omega=0,4$ e $\omega=0,5$ (Caso 1). 

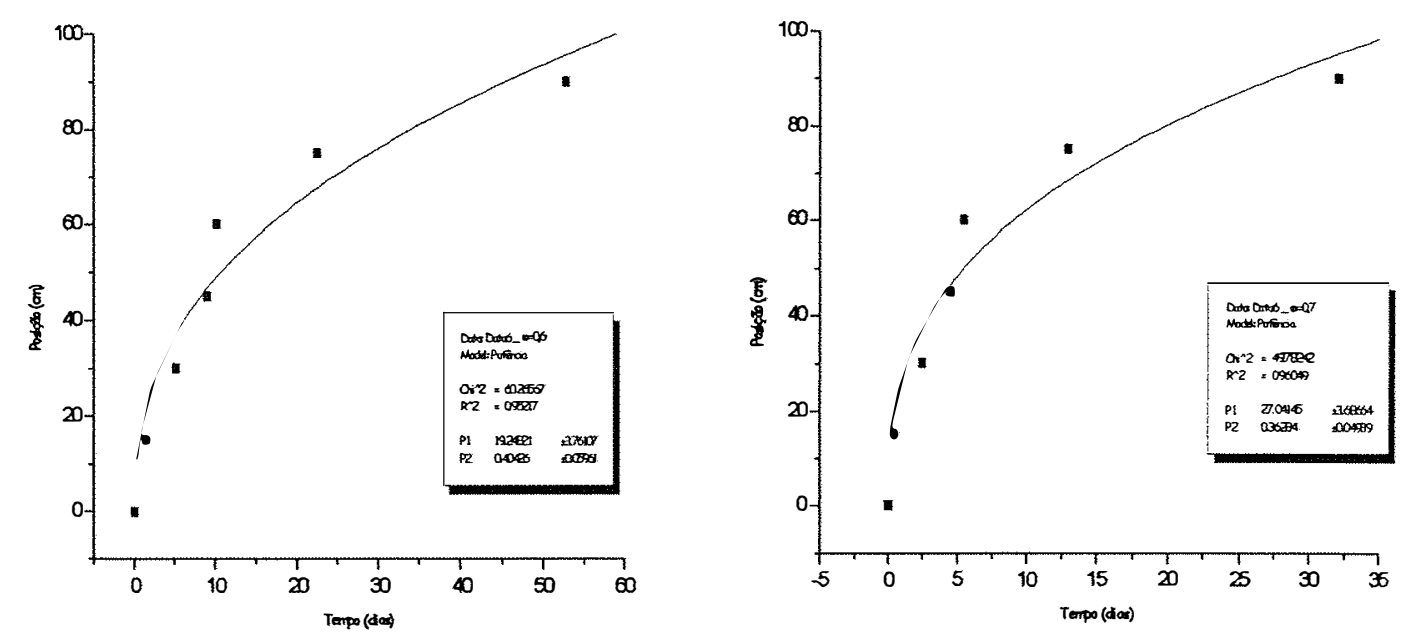

Figura 04 - Posição em cm de x ( $\omega)$ em função do tempo (dias) para a obtenção da dimensão fractal, pelo modelo curva de potência, para umidades $\omega=0,6$ e $\omega=0,7$ (Caso 1).
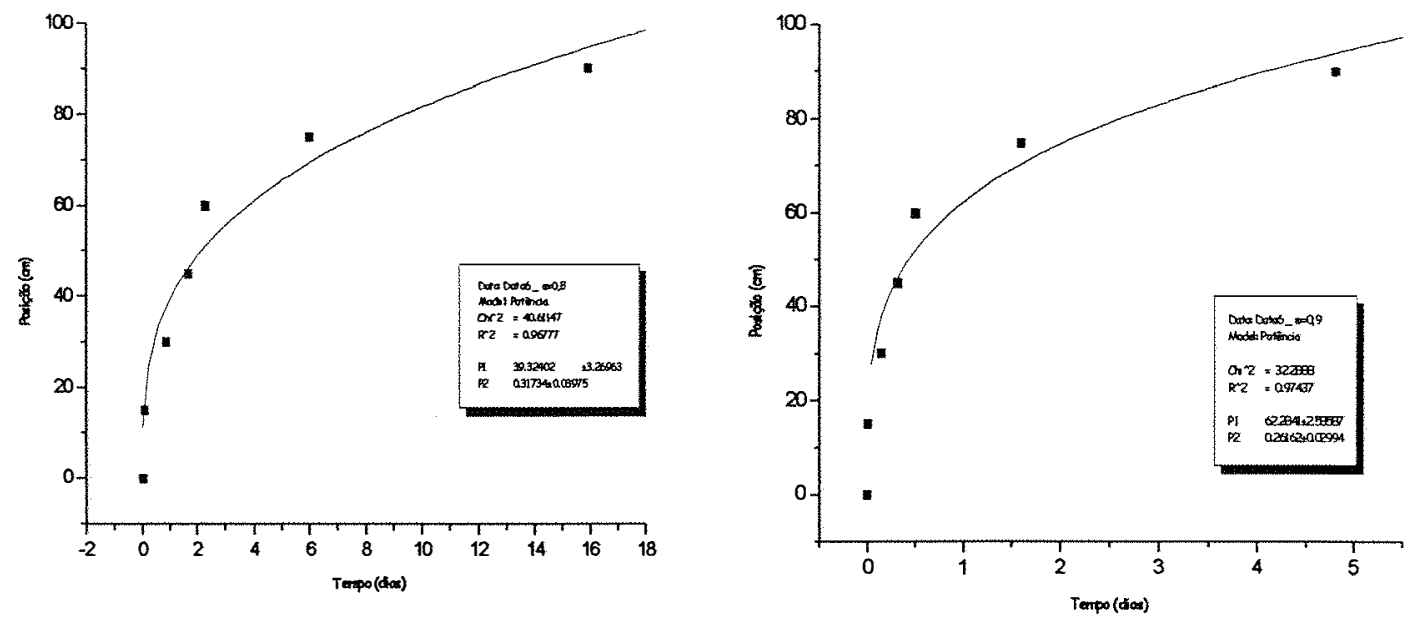

Figura 05 - Posição em cm de x ( $\omega)$ em função do tempo (dias) para a obtenção da dimensão fractal, pelo modelo curva de potência, para umidades $\omega=0,8$ e $\omega=0,9$ (Caso 1). 
Tabela 02 - Posição em cm de x ( $\omega)$ em função do tempo (dias) em cada nível de umidade (Caso 2)

\begin{tabular}{|c|c|c|c|c|c|c|c|c|c|c|}
\hline Posiçảo(Y) & TWOO(X1) & Tho 1(02) & ThO2(X) & ThO3(X4) & TW04(5) & TWO5( & TWO6(X) & TWO7(X8) & TWO $8(0)$ & $T W \infty(\times 10)$ \\
\hline 0 & 0 & 0 & 0 & 0 & 0 & 0 & 0 & 0 & 0 & 0 \\
\hline 15 & 50.68794 & 33,42077 & 20,97976 & 1237505 & 6,72812 & 327246 & 135447 & 0,43437 & 0,08745 & 0,00565 \\
\hline 30 & 52,38589 & 40,0505 & 29,6656 & 21,10007 & 1425164 & 8,95536 & 5,07133 & 2,43632 & 0,86004 & 0,1482 \\
\hline 45 & 8196174 & 63,55853 & 47,83166 & 3465372 & 2388754 & 15,38384 & 897778 & 4,48358 & 1,68500 & 0.31628 \\
\hline 60 & 740,02942 & 5892653 & 45,65974 & 34,19357 & 24,48853 & 1650006 & 10,17688 & 5,45813 & 226828 & 0,50557 \\
\hline$\overline{15}$ & 128,32781 & 105,00824 & 8391832 & 6508361 & 48,53347 & 34,3023 & 22,43155 & 12,9731 & 5,996 & 1,60274 \\
\hline 90 & 256,5478 & 21386236 & 174,49457 & 13855300 & 106,16549 & 77,4852 & 52,70264 & 32,06519 & 15,91779 & 4,80765 \\
\hline 105 & 129,41658 & 943,59224 & 77180884 & 61456235 & 472,43681 & 346,13659 & 23653918 & 144,7895 & 72,49006 & 2221722 \\
\hline
\end{tabular}
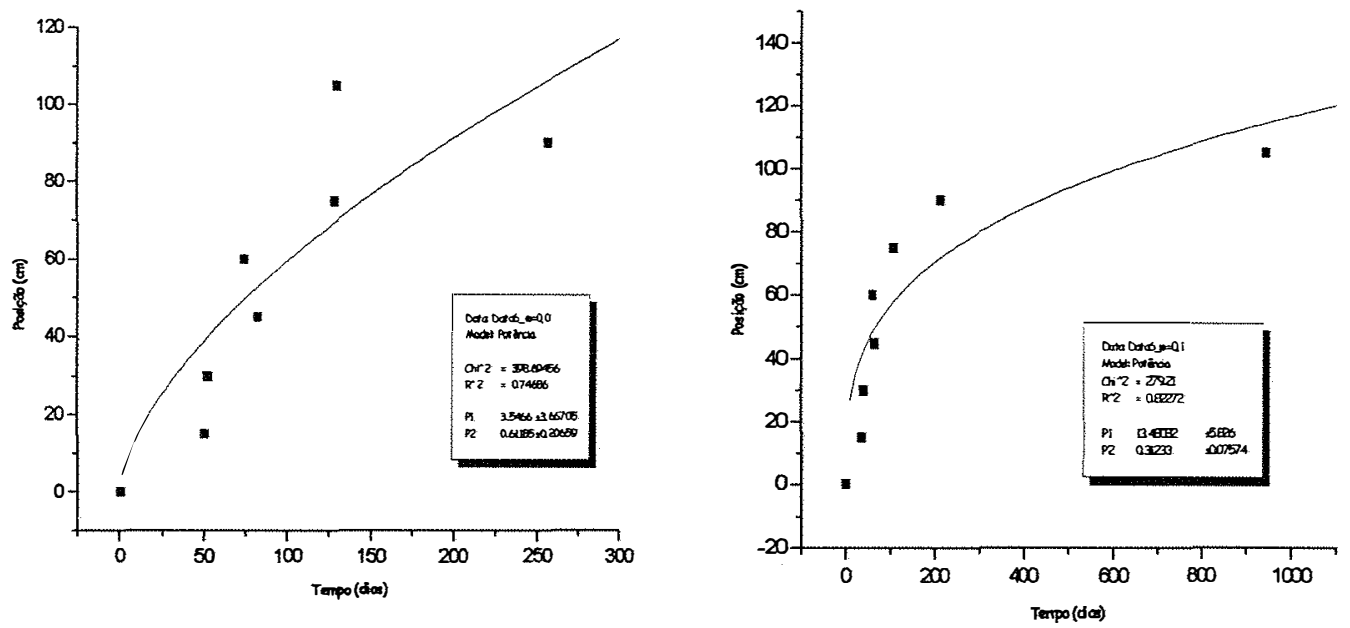

Figura 06 - Posição em $\mathrm{cm}$ de $\mathrm{x}(\omega)$ em função do tempo (dias) para a obtenção da dimensão fractal, pelo modelo curva de potência, para umidades $\omega=0,0$ e $\omega=0,1$ (Caso 2). 

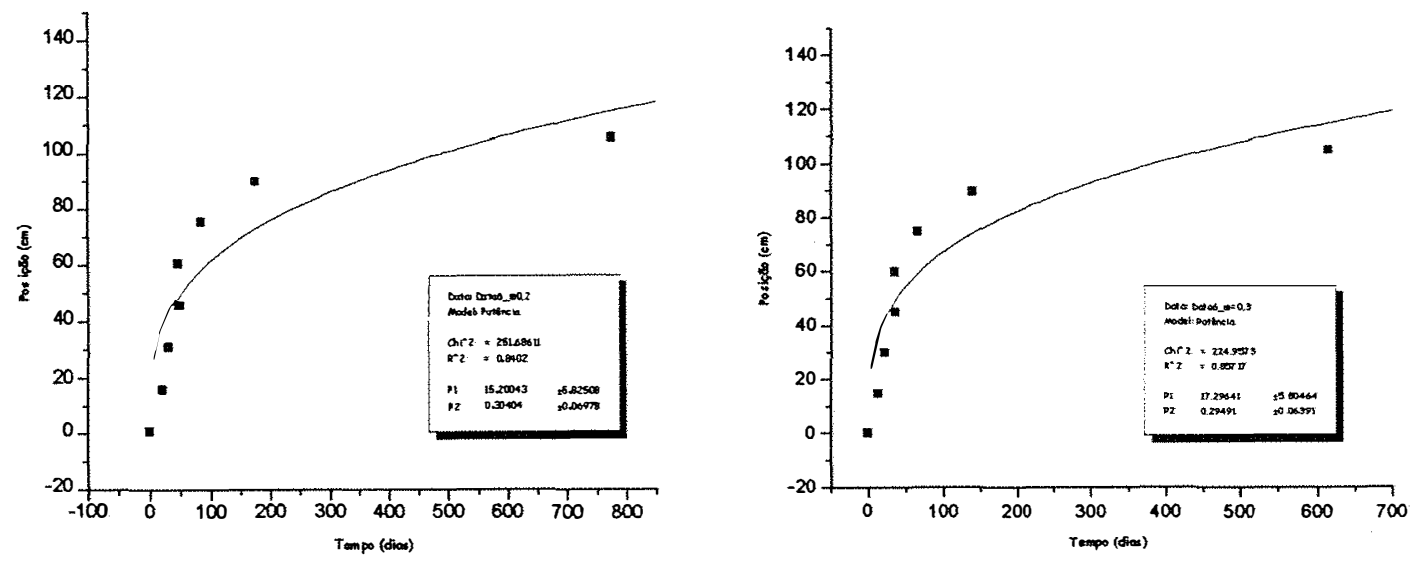

Figura 07 - Posição em cm de x ( $\omega)$ em função do tempo (dias) para a obtenção da dimensão fractal, pelo modelo curva de potência, para umidades $\omega=0,2$ e $\omega=0,3$ (Caso 2).
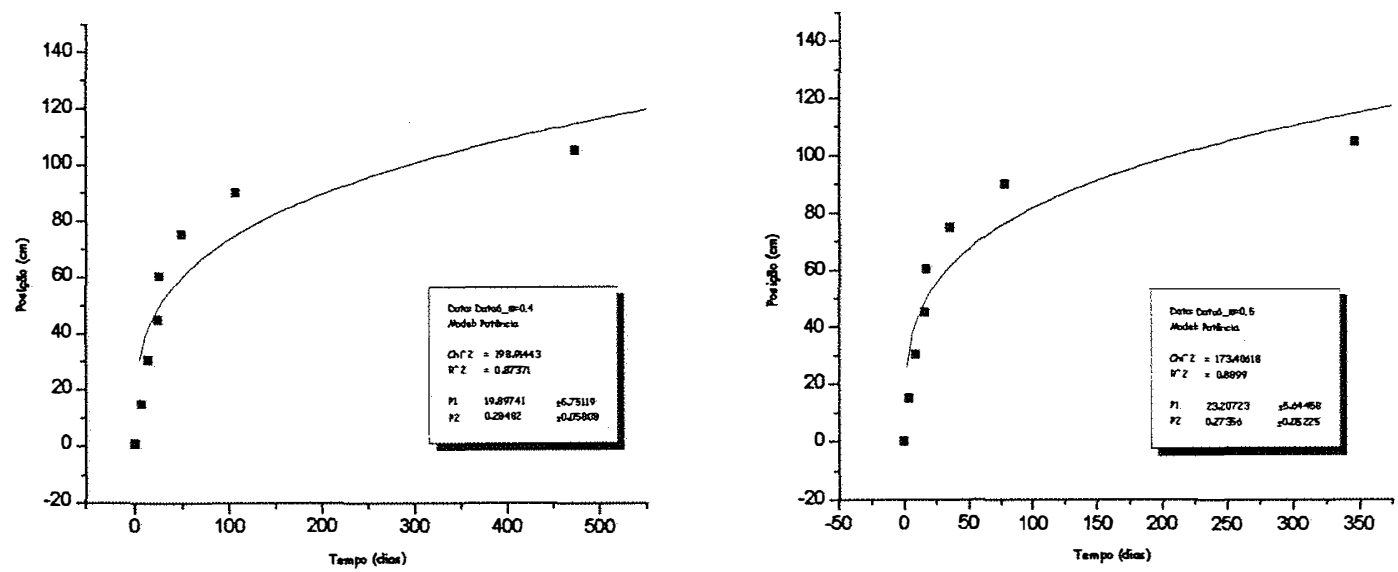

Figura 08 - Posição em cm de x $(\omega)$ em função do tempo (dias) para a obtenção da dimensão fractal, pelo modelo curva de potência, para umidades $\omega=0,4$ e $\omega=0,5$ (Caso 2). 

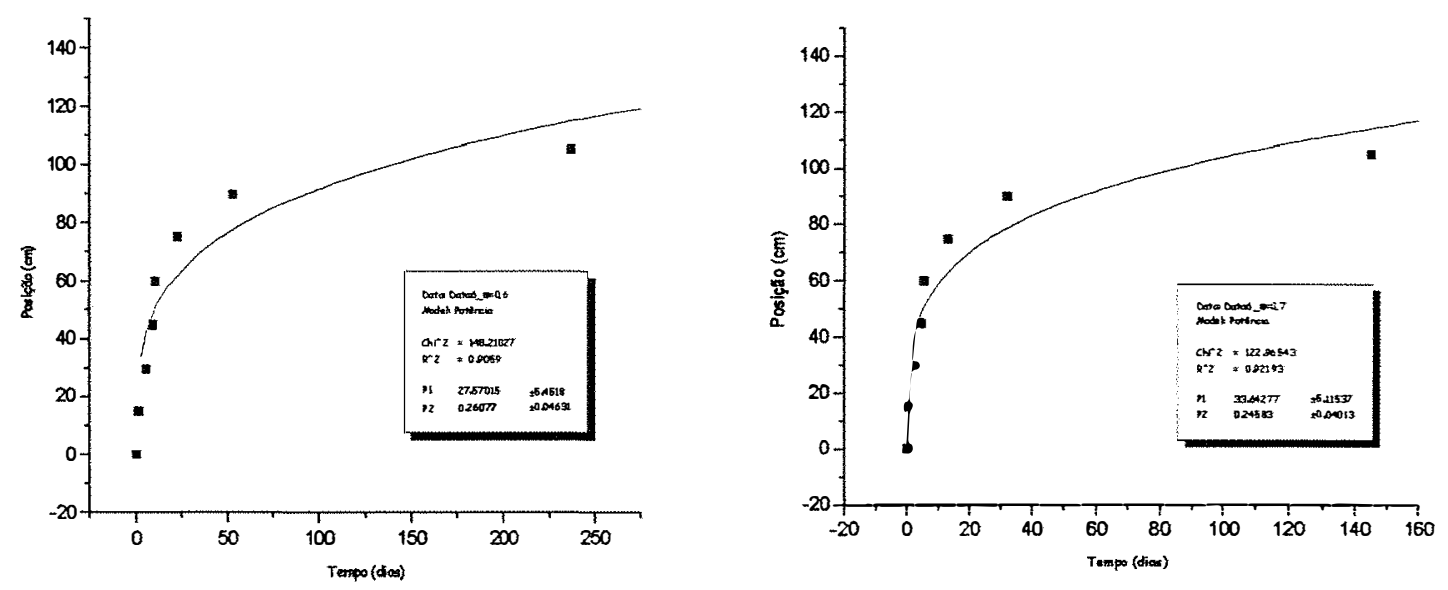

Figura 09 - Posição em $\mathrm{cm}$ de x $(\omega)$ em função do tempo (dias) para a obtenção da dimensão fractal, pelo modelo curva de potência, para umidades $\omega=0,6$ e $\omega=0,7$ (Caso 2).
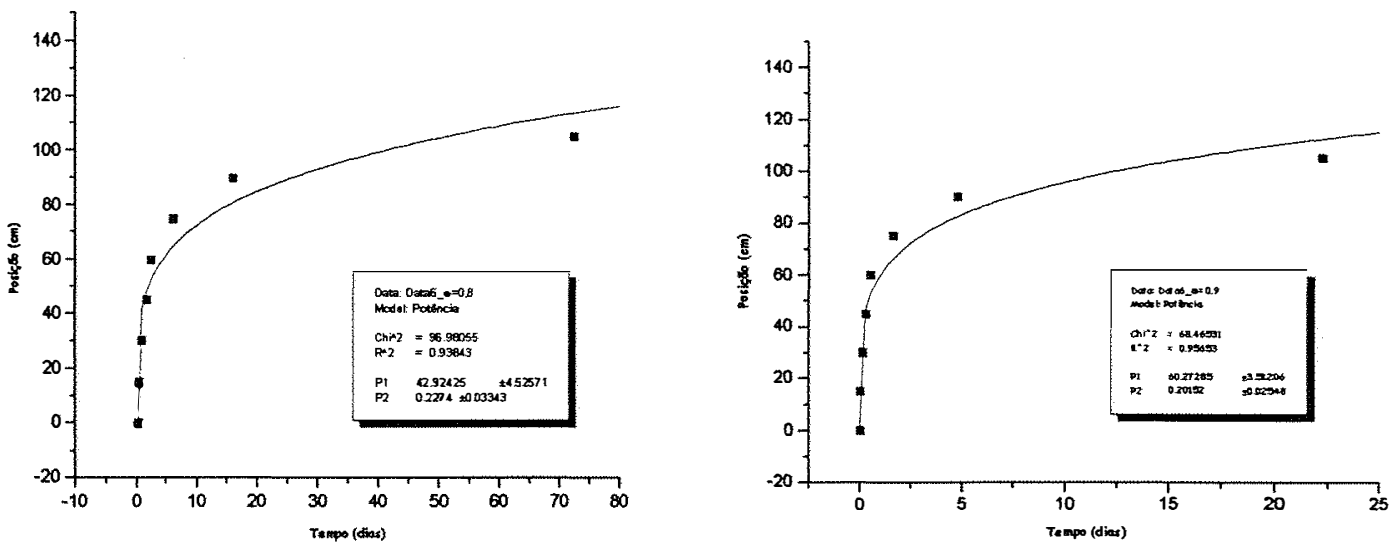

Figura 10 - Posição em cm de x ( $\omega)$ em função do tempo (dias) para a obtenção da dimensão fractal, pelo modelo curva de potência, para umidades $\omega=0,8$ e $\omega=0,9$ (Caso 2). 
Tabela 03 - Posição em cm de $\mathrm{x}(\omega)$ em função do tempo (dias) em cada nível de umidade (Caso 3)

\begin{tabular}{|c|c|c|c|c|c|c|c|c|c|c|}
\hline Posiçán & TWOO(X) & Tw01M & Tw02M & TWOBM & TW04(Y) & TW05(Y) & Tw06M & Tw07M & TW08M & Two9M \\
\hline 0 & 0 & 0 & 0 & 0 & 0 & 0 & 0 & 0 & 0 & 0 \\
\hline 15 & 50,68794 & 33,42077 & 20,97976 & 12,37505 & 6,72812 & 3,27246 & 1,35447 & 0,43437 & 0,08745 & 0,00565 \\
\hline 30 & 52,38589 & 40,0505 & 29,6656 & 21,10907 & 14,25164 & 8,95536 & 5,07133 & 2,43632 & 0,86694 & 0,1482 \\
\hline 45 & 81,96174 & 63,55853 & 47,83166 & 34,65372 & 23,88754 & 15,38384 & 8,97778 & 4,48358 & 09 & 0,31628 \\
\hline 60 & 74,02942 & 58,92653 & 45,65974 & 357 & 24,48853 & 16,50006 & 10,17688 & 5,45813 & 2,26828 & 0,50557 \\
\hline 75 & 128,32781 & 105,00824 & 83,91832 & 65,08361 & 48,53347 & 34,3023 & 22,43155 & 129731 & 5996 & 1,60274 \\
\hline 90 & 256,5478 & 213,86236 & 174,49457 & 138,55309 & 106,16549 & 77.4852 & 52,70264 & 32,06519 & 15,91779 & 4,80765 \\
\hline 105 & 129,41658 & 943,59224 & 771,80884 & 614,56235 & 472,43681 & 346,13659 & 236,53918 & 144,7895 & 72.49306 & 22,21722 \\
\hline 120 & 145,84402 & 122,69925 & 101,14555 & 81,25206 & 63,10084 & 46,79185 & 3245102 & 20,24495 & 10,41142 & 3,34035 \\
\hline
\end{tabular}
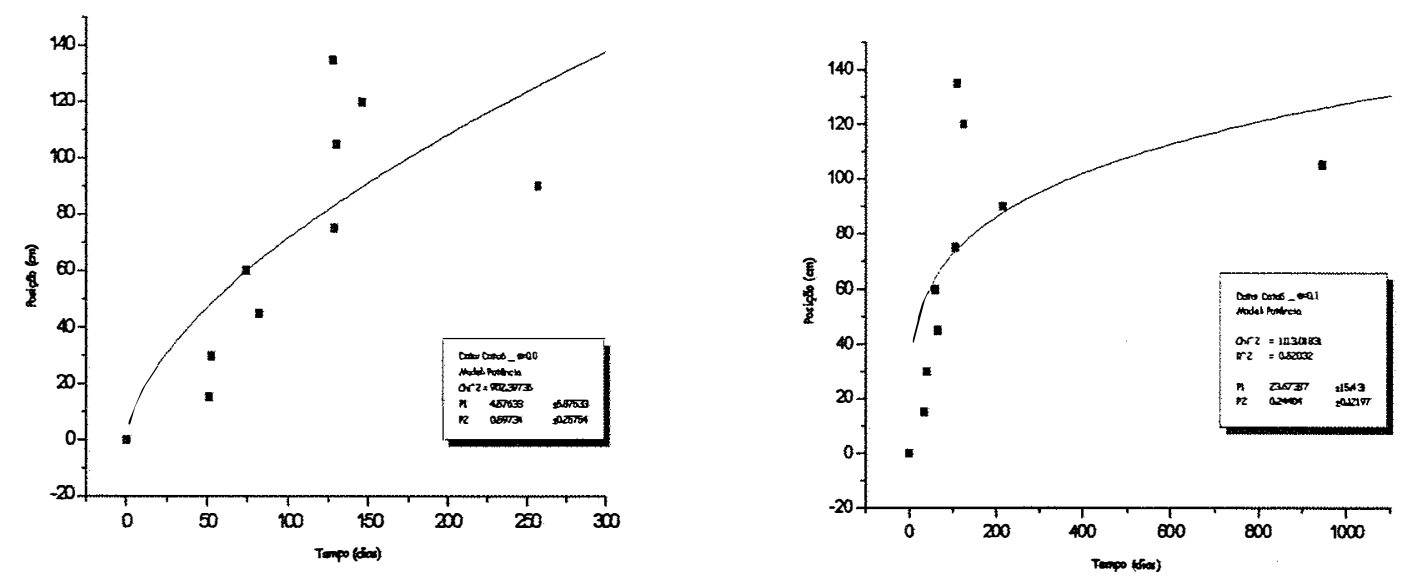

Figura 11 - Posição em $\mathrm{cm}$ de $\mathrm{x}(\omega)$ em função do tempo (dias) para a obtenção da dimensão fractal, pelo modelo curva de potência, para umidades $\omega=0,0$ e $\omega=0,1$ (Caso 3). 

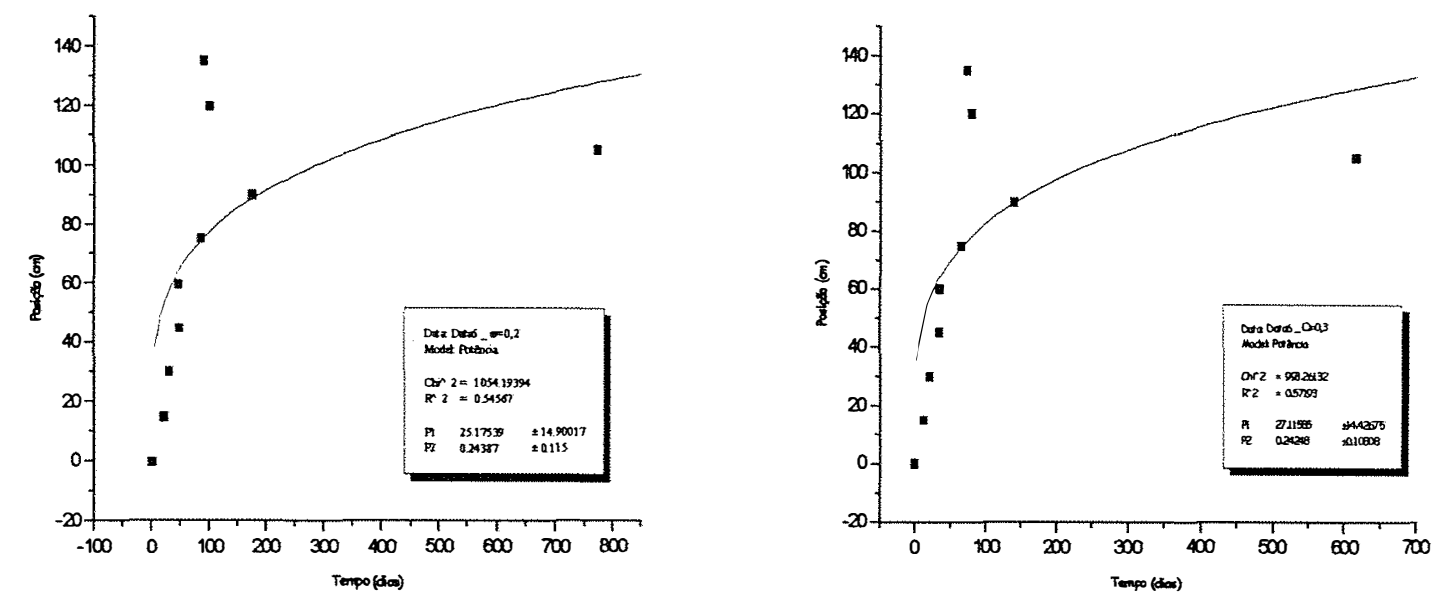

Figura 12 - Posição em cm de x ( $\omega)$ em função do tempo (dias) para a obtenção da dimensão fractal, pelo modelo curva de potência, para umidades $\omega=0,2$ e $\omega=0,3$ (Caso 3).
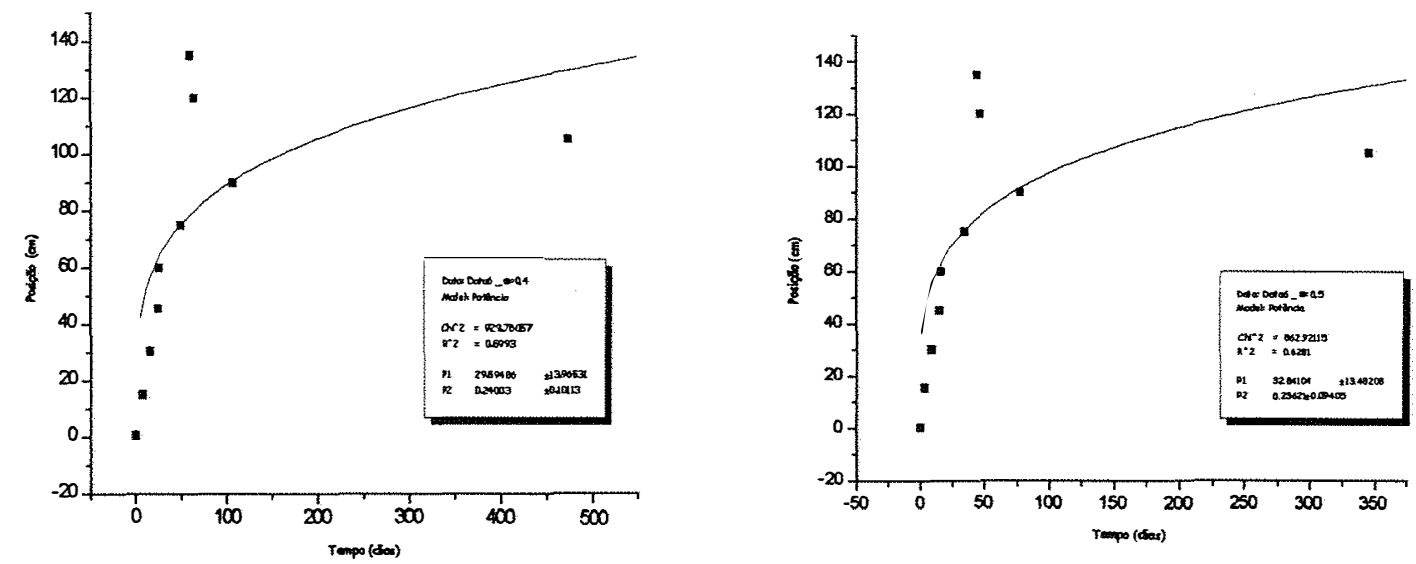

Figura 13 - Posição em cm de x ( $\omega)$ em função do tempo (dias) para a obtenção da dimensão fractal, pelo modelo curva de potência, para umidades $\omega=0,4$ e $\omega=0,5$ (Caso 3). 

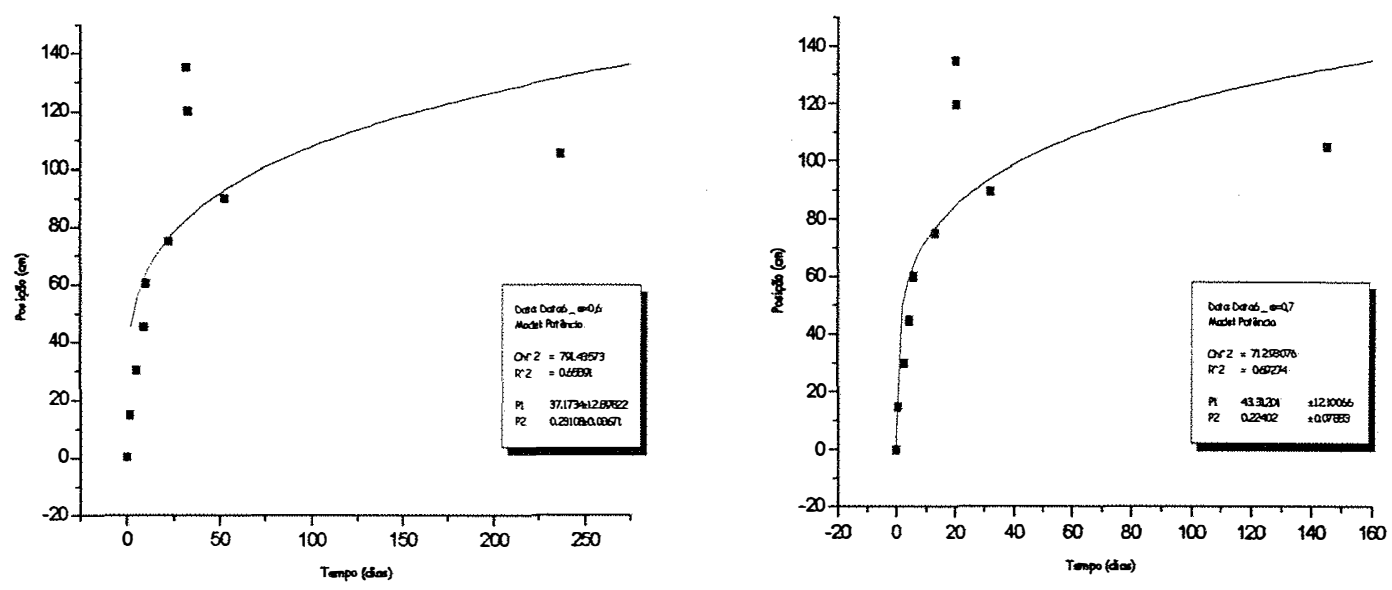

Figura 14 - Posição em $\mathrm{cm}$ de x $(\omega)$ em função do tempo (dias) para a obtenção da dimensão fractal, pelo modelo curva de potência, para umidades $\omega=0,6$ e $\omega=0,7$ (Caso 3).
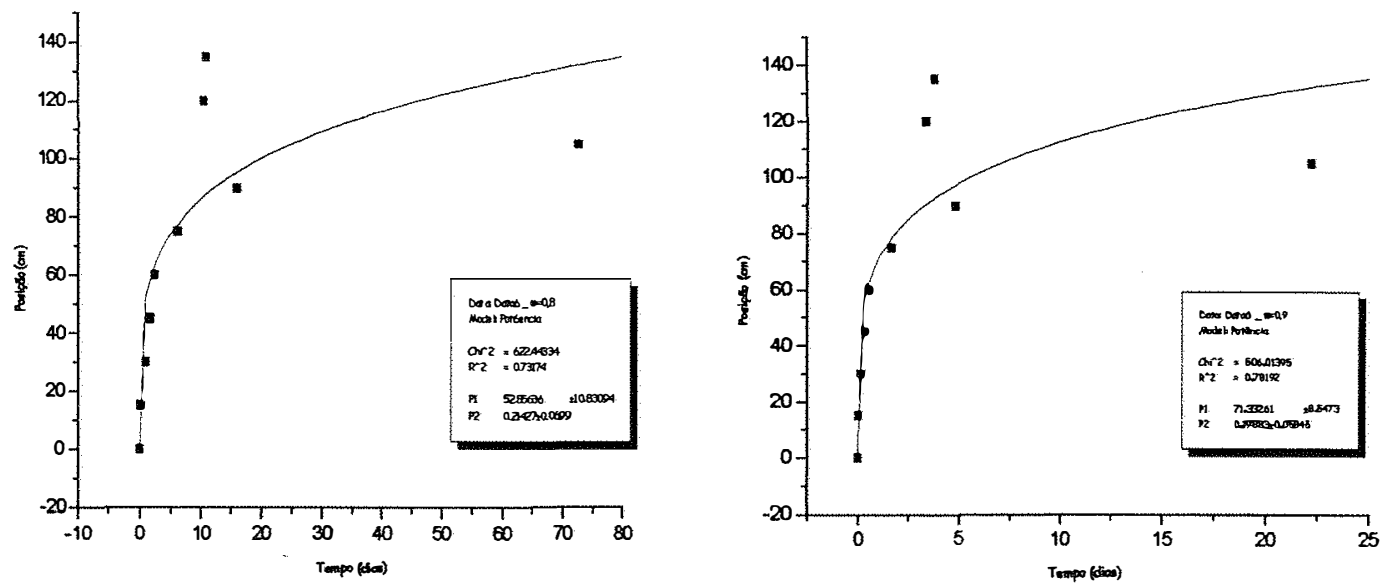

Figura 15 - Posição em cm de x ( $\omega)$ em função do tempo (dias) para a obtenção da dimensão fractal, pelo modelo curva de potência, para umidades $\omega=0,8$ e $\omega=0,9$ (Caso 3). 
Tabela 04 - Posição em $\mathrm{cm}$ de x ( $\omega)$ em função do tempo (dias) em cada nível de umidade (Caso 4)

\begin{tabular}{|c|c|c|c|c|c|c|c|c|c|c|}
\hline Posiçāo(Y) & TWOO $(X)$ & TW01 $(\gamma)$ & TW02 (Y) & TWO3 $(Y)$ & TW04 (Y) & TW05 (N) & TW06M & Tw07 (Y) & $T$ Tos $(Y)$ & TWOS(Y) \\
\hline 0 & 0 & 0 & 0 & 0 & 0 & 0 & 0 & 0 & 0 & 0 \\
\hline 15 & 50,68794 & 33,42077 & 20,97976 & 12,37505 & 6,72812 & 3,27246 & 1,35447 & 0,43437 & 0,08745 & 0,00565 \\
\hline 30 & 52,38589 & 40,0505 & 29,6656 & 21,10907 & 14,25164 & 8,95536 & 5,07133 & 2,43632 & 0,86694 & 0,1482 \\
\hline 45 & 81,96174 & 63,55853 & 47,83166 & 34,65372 & 23,88754 & 15,38384 & 8.97778 & 4,48358 & 1,68500 & 0,31628 \\
\hline 60 & 74,02942 & 58,92653 & 45,65974 & 34,19357 & 24,48853 & 16,50006 & 10,17688 & 5,45813 & 2,26828 & 0,50557 \\
\hline 75 & 128,32781 & 105,00824 & 83,91832 & 65,08361 & 48,53347 & 34,3023 & 22,43155 & 12,9731 & 5,996 & 1,60274 \\
\hline 90 & 2565478 & 213,86236 & 174,49457 & 138,55309 & 106,16549 & 77,4852 & 52,70264 & $32,065,19$ & 15,91779 & 4,80765 \\
\hline 120 & 145,84402 & 122,69025 & 101,14555 & 81,25206 & 63,10084 & 46,79185 & 32,45102 & 20,24495 & 10,41142 & 3,34035 \\
\hline 135 & 127,25689 & 108,32256 & 90,47064 & 73,76308 & 58,27451 & 44,09729 & 31,35005 & 20,19339 & 10,86348 & 3,76443 \\
\hline
\end{tabular}
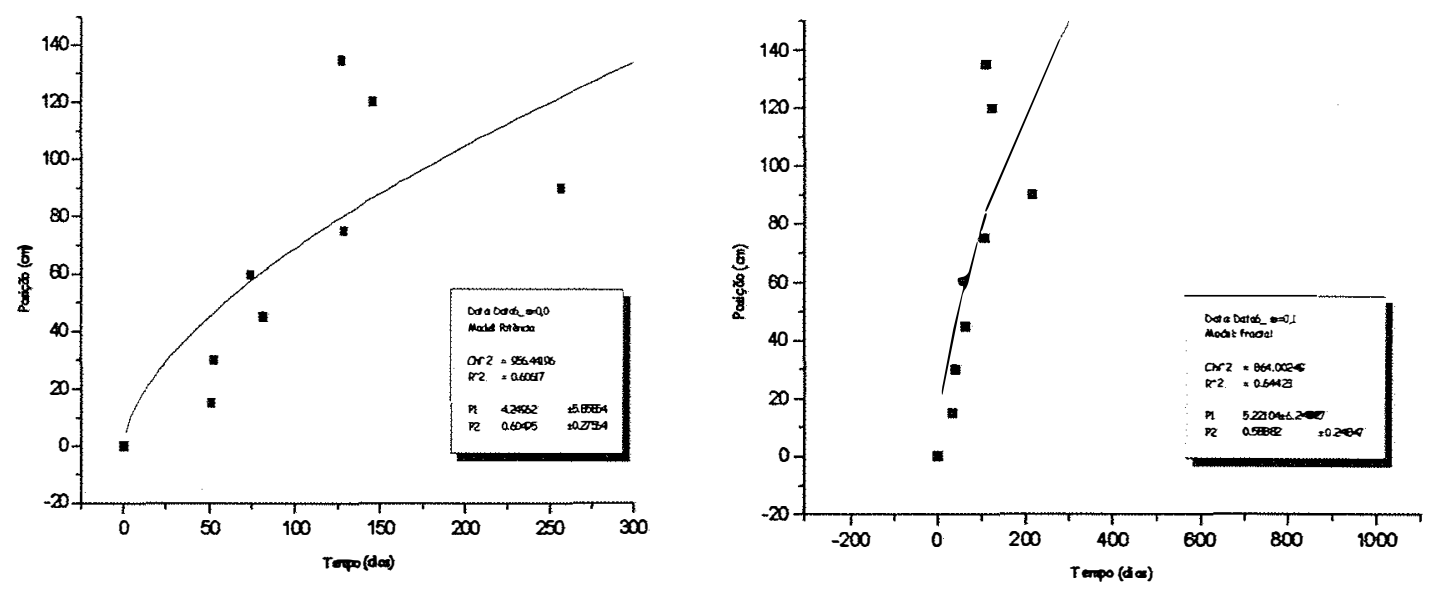

Figura 16 - Posição em $\mathrm{cm}$ de x ( $\omega)$ em função do tempo (dias) para a obtenção da dimensão fractal, pelo modelo curva de potência, para umidades $\omega=0,0$ e $\omega=0,1$ (Caso 4). 

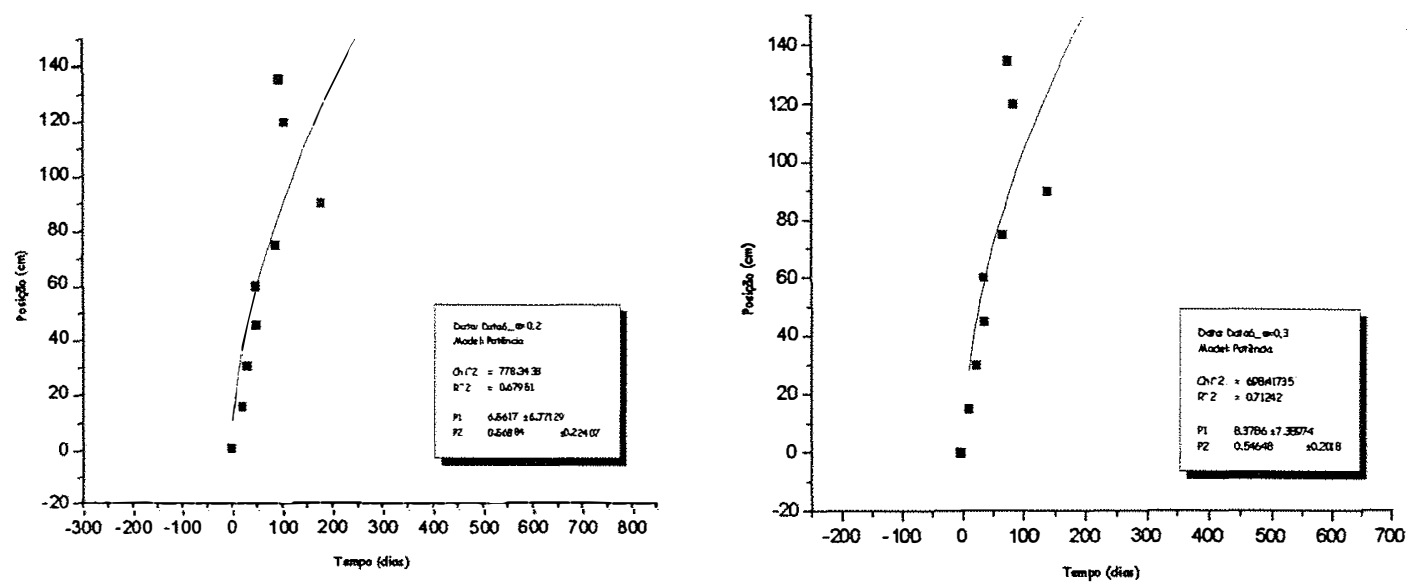

Figura 17 - Posição em cm de x ( $\omega)$ em função do tempo (dias) para a obtenção da dimensão fractal, pelo modelo curva de potência, para umidades $\omega=0,2$ e $\omega=0,3$ (Caso 4).
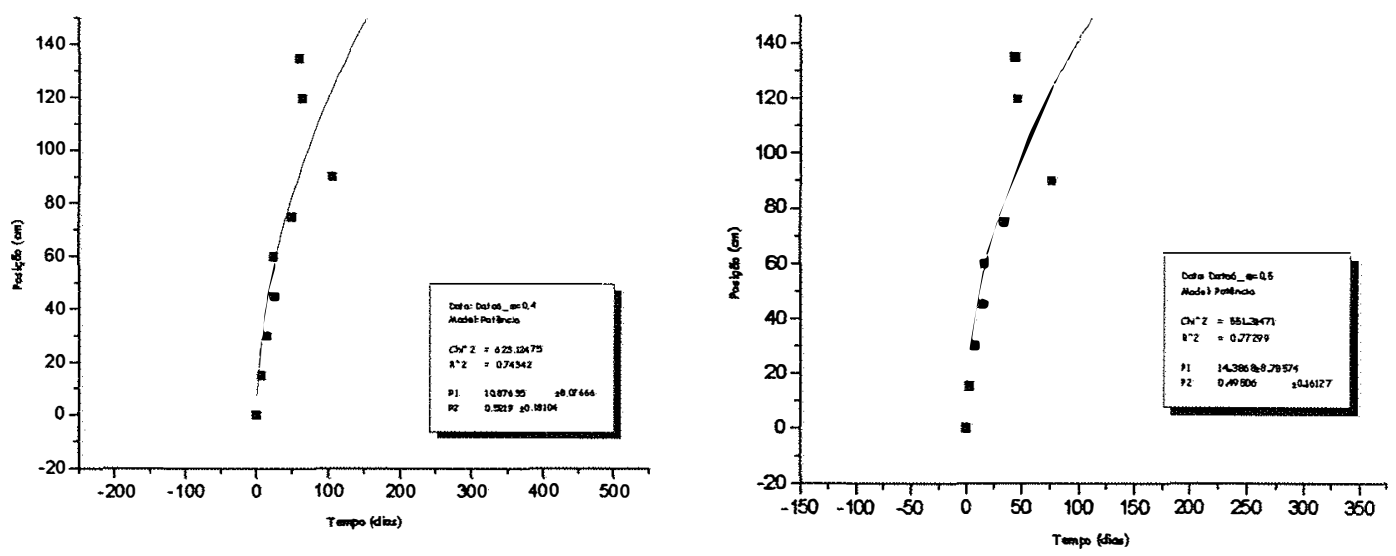

Figura 18 - Posição em cm de x ( $\omega)$ em função do tempo (dias) para a obtenção da dimensão fractal, pelo modelo curva de potência, para umidades $\omega=0,4$ e $\omega=0,5$ (Caso4). 

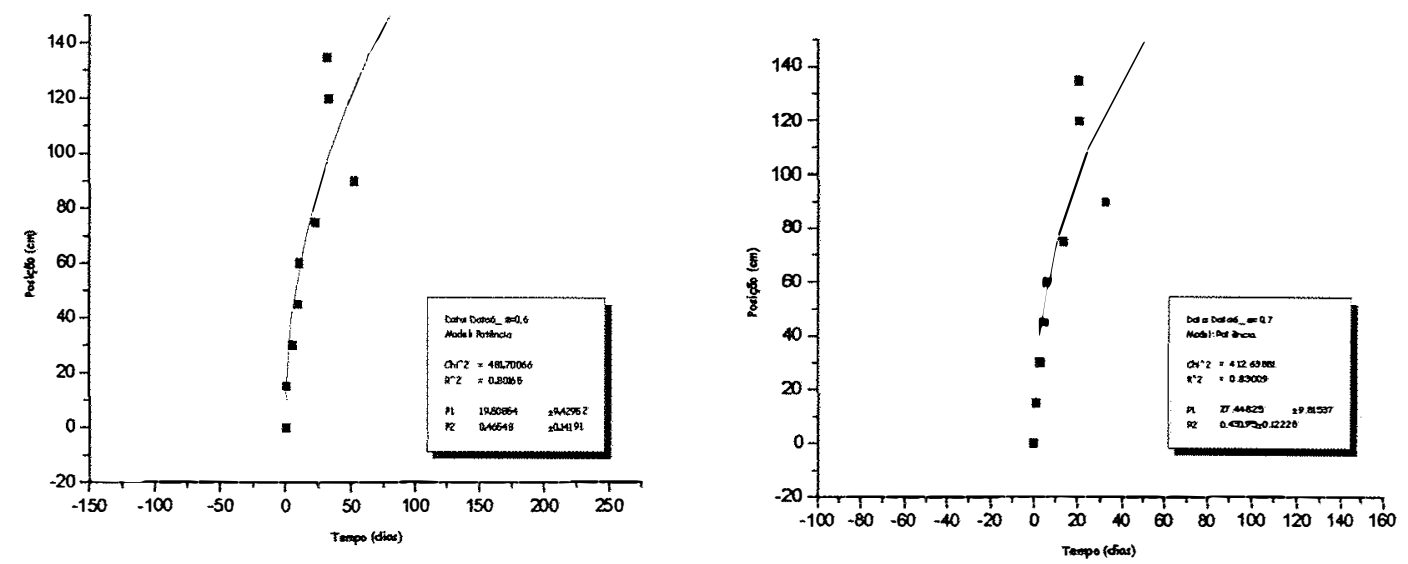

Figura 19 - Posição em cm de x ( $\omega)$ em função do tempo (dias) para a obtenção da dimensão fractal, pelo modelo curva de potência, para umidades $\omega=0,6$ e $\omega=0,7$ (Caso 4).
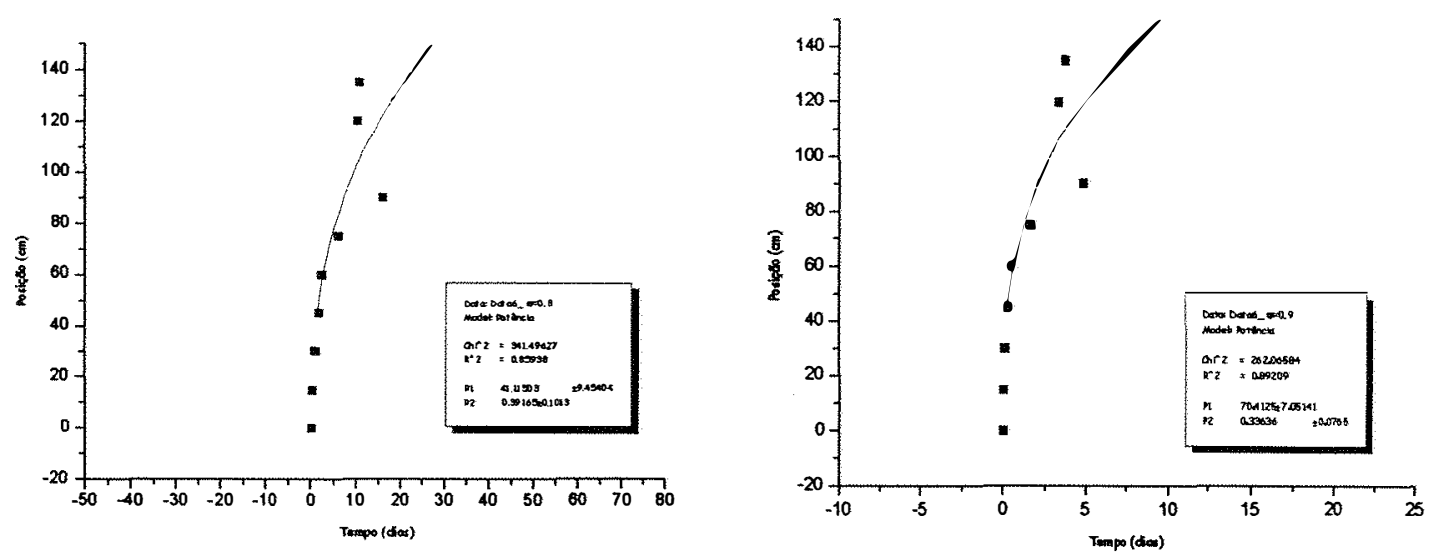

Figura 20 - Posição em cm de x ( $\omega)$ em função do tempo (dias) para a obtenção da dimensão fractal, pelo modelo curva de potência, para umidades $\omega=0,8$ e $\omega=0,9$ (Caso 4). 
Tabela 05 - Posição em cm de x ( $\omega$ ) em função do tempo (dias) em cada nível de umidade (Caso 5)

\begin{tabular}{|c|c|c|c|c|c|c|c|c|c|}
\hline$w(X)$ & $T 15(Y)$ & $\mathrm{T} 30(\mathrm{Y})$ & $T 45(Y)$ & $T 60(Y)$ & $T 75(Y)$ & TSO(Y) & $\mathrm{T1} 05(\mathrm{Y})$ & T120(Y) & $\mathrm{T} 135(\mathrm{Y})$ \\
\hline 0 & 50,68794 & 52,38589 & 81,96174 & 74,02942 & 128,3781 & 256,5478 & 1129,41658 & 145,84402 & 127,25089 \\
\hline 0,1 & 33,42077 & 40,0505 & 63,55853 & 58,9265 & 105,00824 & 213,86236 & 943,59224 & 122,69925 & 108,32256 \\
\hline 02 & 20,97976 & 29,6656 & 47,83166 & 45,65974 & 83,91832 & 174,49457 & 771,80884 & 10114555 & 90,47054 \\
\hline 0,3 & 12,37505 & 21,10907 & 34,65372 & 34,19357 & 65,08361 & 138,55009 & 614,56235 & 81,25206 & 73,76308 \\
\hline 0,4 & 6,72812 & 14,25164 & 23,88754 & 24,48853 & 48,53347 & 106,16549 & 472,43681 & 63,10084 & 58,27451 \\
\hline 0,5 & 3,27246 & 8,95536 & 15,38384 & 16,50006 & 34,3023 & 77,4852 & 346,13659 & 46,79185 & 44,09729 \\
\hline 0,6 & 1,35447 & 5,07133 & 8,97778 & 10,17688 & 22,43155 & 52,70264 & 236,53918 & 32,45102 & 31,35005 \\
\hline 0,7 & 0,43437 & 2,43632 & 4,48358 & 5,45813 & 12,9731 & 32,06519 & 144,7895 & 20,24495 & 20,19339 \\
\hline 0.8 & 0,08745 & 0,86694 & 1,58509 & 2,26828 & 5,996 & 15,91779 & 72,49306 & 10,41142 & 10,86348 \\
\hline 09 & 0,00565 & 0,1482 & 0,31628 & 0,50557 & 1,60274 & 4,80765 & 22,21722 & 3,34035 & 3,76443 \\
\hline 1 & 0 & 0 & 0 & 0 & 0 & 0 & 0 & 0 & 0 \\
\hline
\end{tabular}
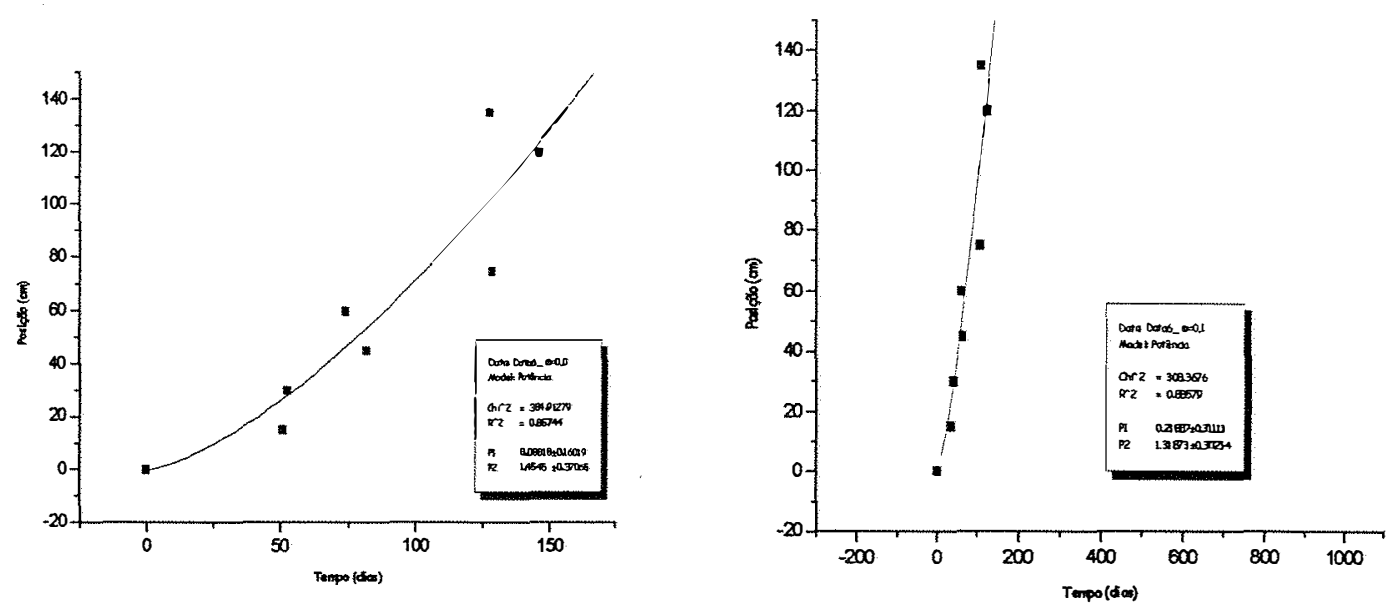

Figura 21 - Posição em $\mathrm{cm}$ de $\mathrm{x}(\omega)$ em função do tempo (dias) para a obtenção da dimensão fractal, pelo modelo curva de potência, para umidades $\omega=0,0$ e $\omega=0,1$ (Caso 5). 


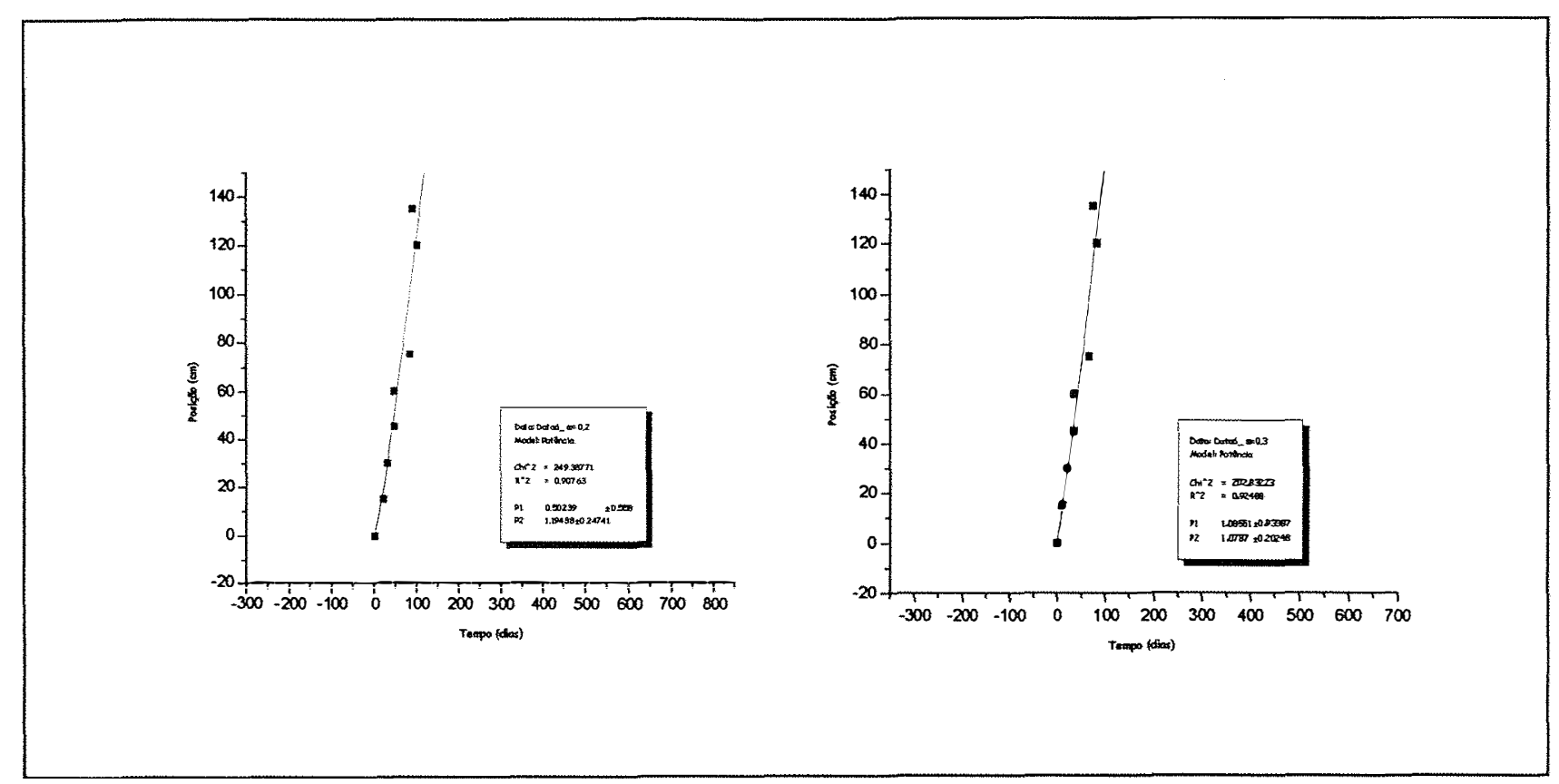

Figura 22 - Posição em cm de x ( $\omega)$ em função do tempo (dias) para a obtenção da dimensão fractal, pelo modelo curva de potência, para umidades $\omega=0,2$ e $\omega=0,3$ (Caso 5).
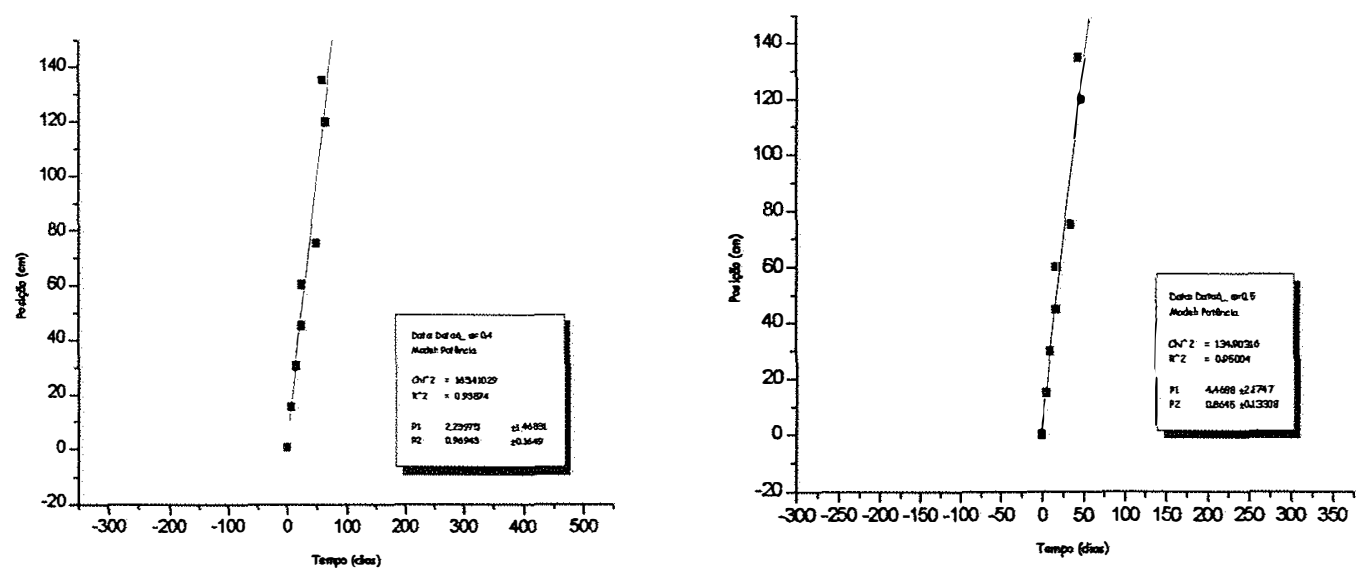

Figura 23 - Posição em $\mathrm{cm}$ de $\mathrm{x}(\omega)$ em função do tempo (dias) para a obtenção da dimensão fractal, pelo modelo curva de potência, para umidades $\omega=0,4$ e $\omega=0,5$ (Caso 5). 

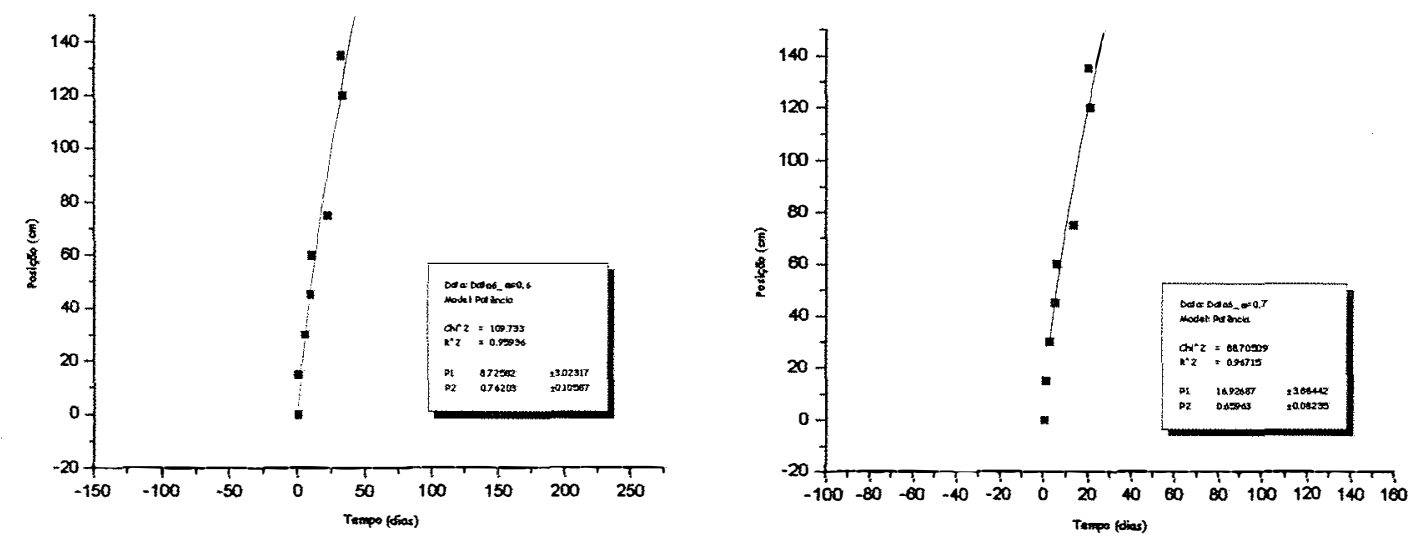

Figura 24 - Posição em $\mathrm{cm}$ de $\mathrm{x}(\omega)$ em função do tempo (dias) para a obtenção da dimensão fractal, pelo modelo curva de potência, para umidades $\omega=0,6$ e $\omega=0,7$ (Caso 5).
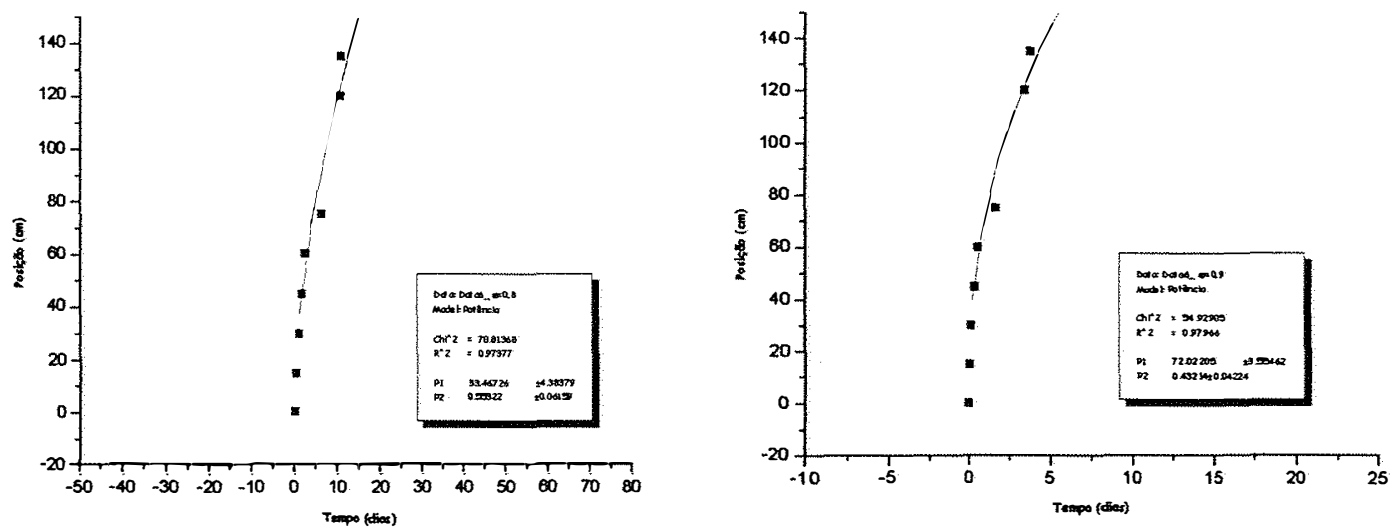

Figura 25 - Posição em $\mathrm{cm}$ de $\mathrm{x}(\omega)$ em função do tempo (dias) para a obtenção da dimensão fractal, pelo modelo curva de potência, para umidades $\omega=0,8$ e $\omega=0,9$ (Caso 5). 


\section{REFERÊNCIAS BIBLIOGRÁFICAS}

BACCHI,O.S. Teoria dos fatores de escala na análise comparativa de métodos de determinação da condutividade hidráulica de um solo. Piracicaba, 1988. 94 p. Tese (Doutorado) Escola Superior de Agricultura "Luiz de Queiroz", Universidade de São Paulo .

BARNSLEY, M.F. Fractals everywhere New York: Academic Press,1993. 531p.

BERGÉ, P. et al. Dos ritmos ao caos. Trad. de R. L. Ferreira. São Paulo: Ed. UNESP, 1996.

BIRD, K.S. Fractals in Chemistry, geochemistry and biophysics. New York: Plenum Press, 1993. 263p.

CHIEPPE Jr., J.B. Estudo da precisão e exatidão do método das pesagens, método gravimétrico padrão e método de atenuação dos raios gama para a determinação do teor de água no solo. Botucatu, 1993. 101 p. Dissertação (Mestrado) - Faculdade de Ciências Agrárias "Júlio de Mesquita Filho", Universidade Estadual Paulista.

COMEGNA, V.; DAMIANI, P.; SOMMELLA, A. Use of a fractal model for determining soil water retention curves. Geoderma, V. 85, n. 4, p. 307-323, 1998. 
DURANT, A.P.D.A.; CRESTANA, S. Aplicação da teoria fractal na caracterização do fenômeno "fingering" em solos não saturados. Revista Brasileira de Ciência do Solo, V. 17, n. 1, p. 1-8, 1993.

DURANT, A.P.D.A.; CRESTANA, S.; STEUDE, J. et al. Estudo do fluxo preferencial em solos por imagens tomográficas e teoria fractal. In: CONGRESSO BRASILEIRO DE CIÊNCIA DO SOLO, 23, Porto Alegre, SBCS, 1991. Resumos. Porto Alegre: 1991. p.178.

ELRICK, D.E. Unsaturatede flow properties of soil. Australian Journal Soil Research, V. 1, p. 1-8, 1963.

FEDER, J. Fractals. New York: Plenum Press, 1988. 283p.

FILGUEIRA, R.R. FOURNIER, L. L.; SARLI, G.O. et al. Sensitivity of fractal parameters of soil aggregates to different management practices in a Phaeozen in Central Argentina. Soil Tillage Research, V. 52, p. 217-222, 1999.

FILGUEIRA,R.R.; FOURNIER, L.L.; PIRO, A. et al. A teoria fractal aplicada à caracterização das propriedades fisicas de um solo. In: CONGRESSO BRASILEIRO DE ENGENHARIA AGRÍCOLA, 24, Viçosa, 1995. Resumos. Viçosa: SBEA, 1995. p. 302.

GIMENÉZ, D.; RAWLS, W.J.; LAUREN, J.G. Scaling properties of saturated hydraulic conductivity in soil. Geoderma, V. 88, p. 205-219, 1999.

GUERRINI, I. A. Emprego da equação de Weibull na obtenção da difusividade da água no solo na infiltração horizontal. Piracicaba, 1982. 95p. Tese (Doutorado) - Escola Superior de Agricultura "Luiz de Queiroz", Universidade de São Paulo. 
GUERRINI, I. A. Equação de Darcy-Buckingham para fluxos insaturados da água no solo. In: ESCUELA LATINOAMERICANA DE FISICA DE SUELOS. São Carlos, 1988. Resumos. São Carlos: 1988. P.36.

GUERRINI, I. A. Uma abordagem não-convencional para a infiltração da água no solo. Botucatu, 1992. 158p. Tese (Livre-Docência) instituto de Biociências, Universidade Estadual Paulista.

GUERRINI, I. A. Caos e fractais: apostila didática. 4. ed. Botucatu: UNESP. 2000. $86 \mathrm{P}$.

GUERRINI, I. A.; SWARTZENDRUBER, D. Soil water difusivity as explicit dependent on both time and water content. Soil Science Society of America Journal, V. 56, n. 2, p. 335-340, 1992.

GUERRINI, I. A.; SWARTZENDRUBER,D. Fractal characteristics of the horizontal movement of water in soil. Fractal, V. 2, n. 3, p. 465-468, 1994.

GUERRINI, I. A.; SWARTZENDRUBER,D. Fractals concepts in relation to soil-water difusivity. Soil Science, V. 162, n. 11, p. 778-784, 1997.

GUERRINI, I. A.; SWARTZENDRUBER, D. Three-parameter soil-water transient equations in water-transports analysis. Soil Science Society of America Journal, V. 62, n. 3 , p. $580-584,1998$.

GUERRINI, I. A.; FERRAZ, E.S.B. Uso do duplo feixe de radiação gama no estudo da variação da densidade com a umidade de um solo expansivo. Científica, V.21, n. 2 , p. 295-300. 1993. 
GUERRINI, I. A.; SPADOTTO, A.J.; CARREIRA, M.C. et al. Influência da densidade do solo na determinação da dimensão fractal da infiltração vertical. In: CONGRESSO BRASILEIRO DE CIÊNCIA DO SOLO,26, Rio de Janeiro, 1997. Resumos. Rio de Janeiro: SBCS, 1997.

GUERRINI, I. A.; NASSER, M.D.; HIRANO, A. H. et al Fractals aspects of the wetting front advance of horizontal soil water movement. In: CONGRESSO LATINO AMERICANO DE CIÊNCIA DO SOLO,13, 1996, Águas de Lindóia. Resumos. Äguas de Lindóia: SBCS, 1996.

GUERRINI, I. A. et al. Comparação entre as análises convencional e fractal no estudo da absorção horizontal da água em colunas de solo. In: CONGRESSO BRASILEIRO DE CIÊNCIA DO SOLO, 25, Viçosa ,1995, Resumos. Viçosa: SBCS, 1995.

HILL, D.E.; PARLANGE, J.Y. Wetting from instability in layered soil. Soil Science Society of America Proceeding, V. 36, p. 697-702, 1972.

HOFSTADLER, D.R. et al. U'n eterna ghirlanda brilhante. Milano: Adelphi, 1984.

KAO, C.S.; HUNT, R.J. Prediction of infiltration into soil. Water Research Resource, V. 32, n. 1, p. 55-64, 1996.

LIBARDI, P.L. Infiltração da água no solo: uma generalização. Piracicaba, 1973. 46p. Dissertação (Mestrado) - Centro de Energia Nuclear na Agricultura, Universidade de São Paulo.

MANDELBROT, B.B. The fractal geometry of nature. San Francisco: W.H. Freeman, 1983. $429 p$. 
MIYASAKI, T.; NIELSEN, D.R.; MACINTYRE, J. L. Early stage infiltration of water into horizontal and vertical soil columns. Hilgardia, V. 52, n. 6, 1984.

NIELSEN, D.R.; BIGGAR, J.M.; DAVIDSON, J.M. Experimental consideration of diffusion analysis in insatured flow problem. Soil Science Society of America Journal, V. 26, n. 2, p. 107-112, 1962.

PACHEPSKY Y.; TIMLIN, D. Water transport in soils as in fractal media. Journal of Hydrology, V. 204, n. 98-107, 1998.

PECK, A.J. The diffusivity of water in a porous material. Australian Journal Soil Resource, V. 2, p. 1-7, 1964.

PEITGEN, H.O.; JURGENS, H.; SAUPE, D. Fractals for the classrom. New York: Springer-Verlag, pt. 1, 450 p., 1992: Part one: Introduction to fractals and Chaos, in fractals for the classroom.

PERFECT, E.; KAY, B.D. Fractal theory applied to soil aggregation Soil Science Society of America Journal, V. 55, p. 1552-1558, 1991.

PERFECT, E.; KAY, B.D. Brittle fracture of fractal cubic aggregates. Soil Science Society of America Journal, V. 59, p. 969-974, 1995a.

PERFECT, E.; KAY, B.D. Aplications of fractals in soil and tillage research: a review. Soil \& Tillage Research, V. 36, p. 1-20, 1995 b.

PERFECT, E.; Mc LAUGHLIN, N.B.; KAY, B.D. et al. Un improved fractal equation for the soil water retention curve. Water Research Resource, V. 32, n. 2, p.281287, 1996. 
RAWLINS, S.L.; BRAKENSIEK, D.L. Utilizing fractal principles for predicting soil hidraulic properties. Journal Soil and Water Conservation, V. 50, n. 5, p. 463$465,1995$.

RAWLINS, S.L.; GARDNER, W.H. A test of the validity of the diffusion equation for insaturated flow in soil-water. Soil Science Society of America Proceeding, V. 27, p. 507-511, 1963.

RAWLS, W. J.; BRAKENSIEK, D. L.; LOGSDON, S. D. Predicting saturated hydraulic conductivity ytilizing fractal principles. Soil Science Society of America Journal, V. 57, p. 1193-1197, 1993.

RIEU, M.; SPOSITO, G. Fractal fragmentation, soil porosity, and soil properties: I. Theory. Soil Science Society of America Journal, V. 55, p. 1231-1238, 1991a.

RIEU, M.; SPOSITO, G. Fractal fragmentation, soil porosity, and soil properties: I. Applications. Soil Science Society of America Journal, V. 55, p. 1239-1244, $1991 b$.

RUELE, D. Acaso e caos. São Paulo: UNESP, 1993, 224 p.

SANTOS, E. dos Análise fractal da absorção horizontal de água no solo à diferentes pressões. Botucatu, 1997. 108p. Dissertação (Mestrado) - Faculdade de Ciências Agrárias "Júlio Mesquita Filho", Universidade Estadual Paulista.

SANTOS, E. dos; GUERRINI, IVAN A. Determinação experimental da dimensão fractal do movimento da água no solo em fluxos horizontais. Revista IRRIGA, V. 3, n. 2, p. 96-107, 1998. 
TYLER, S.W.; WHEATCRAFT, S.W. Aplications of fractal mathematics to soil water retention estimation. Soil Science Society of America Journal, V. 53, p. 987-996, 1989

TYLER, S.W.; WHEATCRAFT, S.W. Fractal processes in soil water retention. Water Resources Research, V. 26, n. 5, p. 1047-1054, 1990.

VILLAGRA, M. de las M. Variabilidade de medidas de tensiômetro em terra roxa estruturada. Piracicaba, 1988. 64 p. Dissertação (Mestrado) - Escola Superior de Agricultura "Luiz de Queiroz", Universidade de São Paulo.

VOSS, R.F. Fractal in nature. In: PEITGEN, H.O.; SAUPE, D.. The science of fractal images. New York: Springer-Verlag, 1988. p.1-70.

YOUNG, I.M.; CRAWFORD, J.W. The fractal struture of soil aggregates: its measurements and interpretation. Journal of Soil Science, V. 42, p. 187-192, 1991. 